\title{
ANÁLISE DE PROBLEMAS DE FRETTING USANDO O MÉTODO DOS ELEMENTOS DE CONTORNO
}

BRUNO RICARDO DE MELO CAVALCANTE

DISSERTAÇÃO DE MESTRADO EM CIÊNCIAS MECÂNICAS DEPARTAMENTO DE ENGENHARIA MECÂNICA

\section{FACULDADE DE TECNOLOGIA}

UNIVERSIDADE DE BRASÍLIA 
UNIVERSIDADE DE BRASÍLIA

FACULDADE DE TECNOLOGIA

DEPARTAMENTO DE ENGENHARIA MECÂNICA

\section{ANÁLISE DE PROBLEMAS DE FRETTING USANDO O MÉTODO DOS ELEMENTOS DE CONTORNO}

BRUNO RICARDO DE MELO CAVALCANTE

ORIENTADOR: PROF. DR. ÉDER LIMA DE ALBUQUERQUE, ENM/UNB COORIENTADOR: PROF. DR. THIAGO DE C. RODRIGUES DOCA, ENM/UNB

DISSERTAÇÃO DE MESTRADO EM CIÊNCIAS MECÂNICAS

PUBLICAÇÃO PCMEC.DM - 250/2016

BRASÍLIA-DF, 15 DE DEZEMBRO DE 2016. 


\section{UNIVERSIDADE DE BRASÍLIA \\ FACULDADE DE TECNOLOGIA \\ DEPARTAMENTO DE ENGENHARIA MECÂNICA}

ANÁLISE DE PROBLEMAS DE FRETTING
USANDO O MÉTODO DOS ELEMENTOS DE CONTORNO

BRUNO RICARDO DE MELO CAVALCANTE

DISSERTAÇÃO DE MESTRADO ACADÊMICO SUBMETIDA AO DEPARTAMENTO DE ENGENHARIA MECÂNICA DA FACULDADE DE TECNOLOGIA DA UNIVERSIDADE DE BRASÍLIA, COMO PARTE DOS REQUISITOS NECESSÁRIOS PARA A OBTENÇÃO DO GRAU DE MESTRE EM ENGENHARIA MECÂNICA.

APROVADA POR:

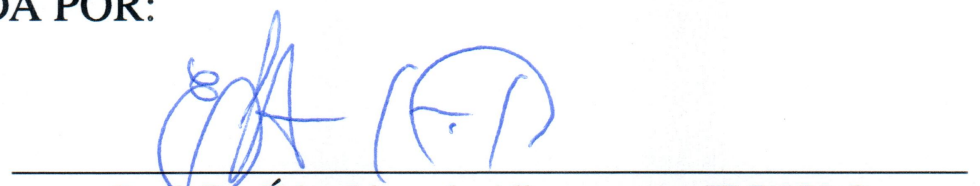

Prof. Dr. Éder Lima de Albuquerque, ENM/UnB

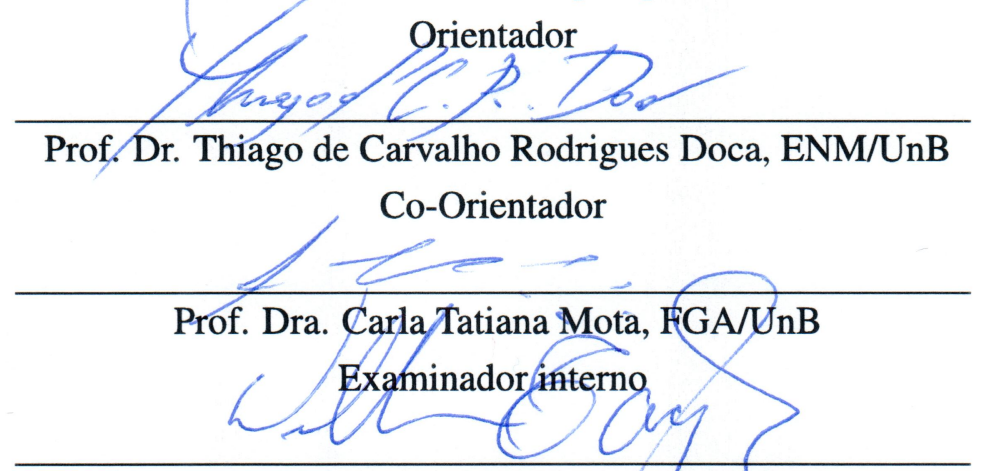

Prof. Dr. William Taylor Matias Silva, ENC/UnB

Examinador externo

BRASÍLIA, 15 DE DEZEMBRO DE 2016. 


\title{
UNIVERSIDADE DE BRASÍLIA \\ FACULDADE DE TECNOLOGIA \\ DEPARTAMENTO DE ENGENHARIA MECÂNICA
}

\author{
ANÁLISE DE PROBLEMAS DE FRETTING \\ USANDO O MÉTODO DOS ELEMENTOS DE CONTORNO
}

\section{BRUNO RICARDO DE MELO CAVALCANTE}

DISSERTAÇÃO DE MESTRADO ACADÊMICO SUBMETIDA AO DEPARTAMENTO DE ENGENHARIA MECÂNICA DA FACULDADE DE TECNOLOGIA DA UNIVERSIDADE DE BRASÍLIA, COMO PARTE DOS REQUISITOS NECESSÁRIOS PARA A OBTENÇÃO DO GRAU DE MESTRE EM CIÊNCIAS MECÂNICAS.

APROVADA POR:

Prof. Dr. Éder Lima de Albuquerque, ENM/UnB

Orientador

Prof. Dr. Thiago de C. Rodrigues Doca, ENM/UnB

Coorientador

Prof. Dra. Carla Tatiana Mota Anflor, FGA/UnB

Examinador interno

Prof. Dr. William Taylor Matias Silva, ENC/UnB

Examinador externo

BRASÍLIA, 15 DE DEZEMBRO DE 2016. 


\section{FICHA CATALOGRÁFICA}

BRUNO RICARDO DE MELO CAVALCANTE

ANÁLISE DE PROBLEMAS DE FRETTING USANDO O MÉTODO DOS ELEMENTOS DE CONTORNO

2016xv, 82p., 201x297 mm

(ENM/FT/UnB, Mestre, Ciências Mecânicas, 2016)

Dissertação de Mestrado - Universidade de Brasília

Faculdade de Tecnologia - Departamento de Engenharia Mecânica

\section{REFERÊNCIA BIBLIOGRÁFICA}

BRUNO RICARDO DE MELO CAVALCANTE (2016) ANÁLISE DE PROBLEMAS DE FRETTING USANDO O MÉTODO DOS ELEMENTOS DE CONTORNO. Dissertação de Mestrado em Ciências Mecânicas, Publicação 250/2016, Departamento de Engenharia Mecânica, Universidade de Brasília, Brasília, DF, 82p.

\section{CESSÃO DE DIREITOS}

AUTOR: BRUNO RICARDO DE MELO CAVALCANTE

TÍTULO: ANÁLISE DE PROBLEMAS DE FRETTING USANDO O MÉTODO DOS ELEMENTOS DE CONTORNO.

GRAU: Mestre ANO: 2016

É concedida à Universidade de Brasília permissão para reproduzir cópias desta dissertação de Mestrado e para emprestar ou vender tais cópias somente para propósitos acadêmicos e científicos. O autor se reserva a outros direitos de publicação e nenhuma parte desta dissertação de Mestrado pode ser reproduzida sem a autorização por escrito do autor.

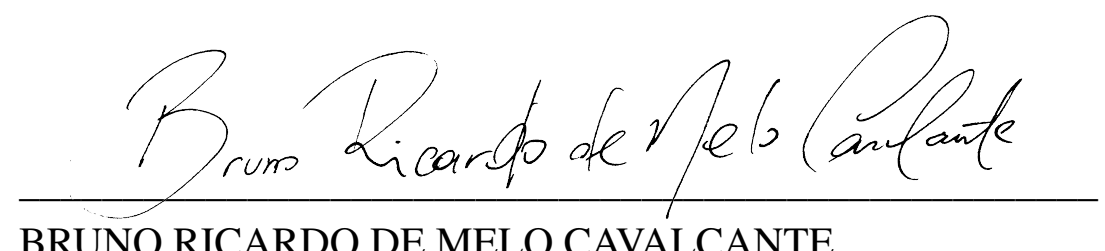

BRUNO RICARDO DE MELO CAVALCANTE

Correio Eletrônico: bruno.melocavalcante@gmail.com 


\section{Agradecimentos}

Agradeço primeiramente a todos os membros da minha família, pois sem eles nenhuma das minhas realizações seriam possíveis, em especial minha mãe, Débora, minha avó, Elza, e meu pai, François.

Aos meus orientadores Éder e Thiago, pelos ensinamentos e conselhos tanto acadêmicos quanto pessoais.

Agradeço à minha namorada Ariane, por estar ao meu lado, sempre me ouvindo e me aconselhando.

A meus amigos, Gustavo, Hosana, Lara, Mari e Thiago, que tornaram essa jornada memorável e divertida.

A todos do SG9 que tornaram o convívio longe de casa mais fácil, D. Raimunda, Marcão, Taise e Túlio.

Agradeço à Prof. Simone por ter acreditado em mim durante a graduação e pela indicação ao Prof. Éder.

Finalmente, agradeço à CAPES pelo apoio financeiro e ao programa de Pós-Graduação em Ciência Mecânicas da UnB pela oportunidade

Bruno Cavalcante 


\section{ABSTRACT}

The main objective of this work is the implementation of an algorithm that allows the evaluation of frictional contact problems by the Boundary Element Method, more specifically, in fretting conditions. In order to achieve this goal, a boundary element formulation for bidimensional elastic bodies was developed applying the direct constraint technique that describes the mechanical influence of a body in contact with another, a nonlinear problem due to fact of the contact area being initially unknown and its evolution during loading. Thereafter, the formulation was computationally implemented having the ability discern between slip and stick regions and to measure the contact area and ultimately the nonlinear system could be solved by Newton's Method. Problems with previously known analytical solutions were simulated as an indentation process with a rigid flat-ended punch, Cattaneo-Mindlin with oscillatory tangential loading and contact between a cylinder and a flat specimen with bulk stress. The numerical results were compared with the analytical solution showing good agreement.

Keywords: Boundary Element Method, Computational Contact Mechanics, Fretting, Newton's Method

\section{RESUMO}

O principal objetivo deste trabalho é a implementação de um algoritmo que permita a avaliação de problemas de contato com atrito pelo método dos elementos de contorno, mais especificamente, em condições de fretting. Para isso, desenvolveu-se a formulação de elementos de contorno para corpos elásticos bidimensionais e se aplicou o método das restrições diretas para descrever a influência de um corpo em contato com outro, um problema não-linear devido ao desconhecimento da área de contato e como ela evolui durante o carregamento. Consequentemente, a formulação foi implementada computacionalmente, com capacidade de discernir modos de contatos diferentes e medir o comprimento da área de contato e por fim, o sistema pôde ser resolvido com sucesso pelo Método de Newton. Foram resolvidos problemas com solução analítica previamente conhecida como o de indentação por cilindro plano, Cattaneo-Mindlin com a carga tangencial oscilatória e contato entre um cilindro e um plano com carga de fadiga. Os resultados numéricos foram então comparados com as soluções analíticas de seus respectivos problemas, apresentando boa concordância.

Palavras-chave: Método dos elementos de contorno, Mecânica do contato computacional, Fretting, Método de Newton. 


\section{SUMÁRIO}

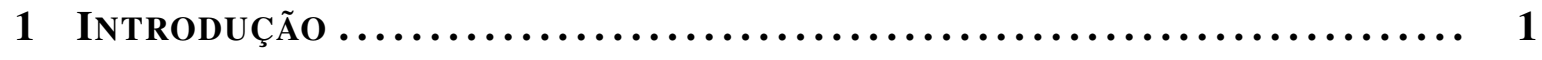

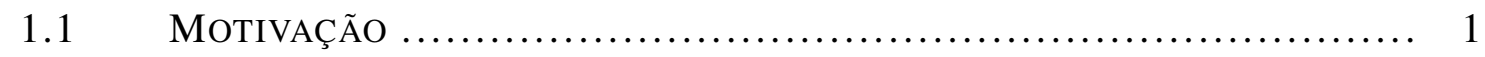

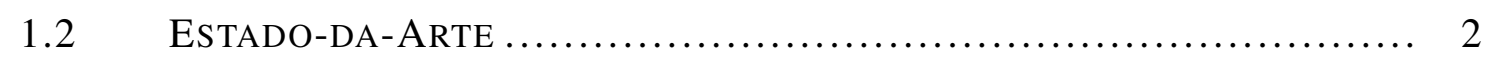

1.3 MÉTODO DOS ELEMENTOS DE CONTORNO ........................... 3

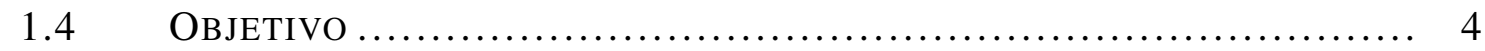

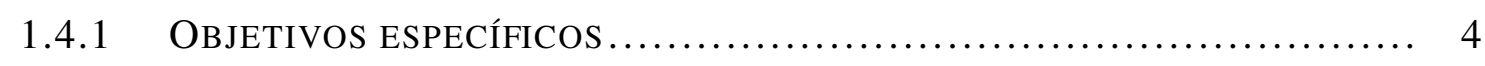

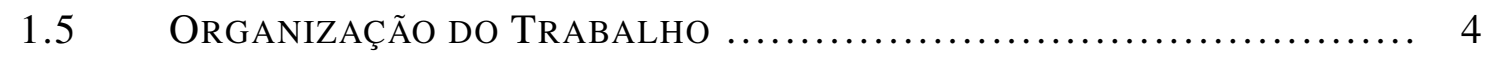

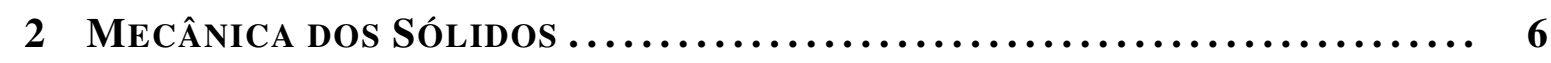

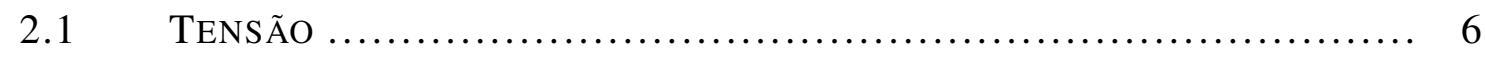

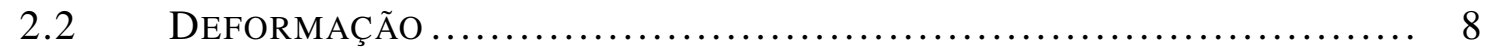

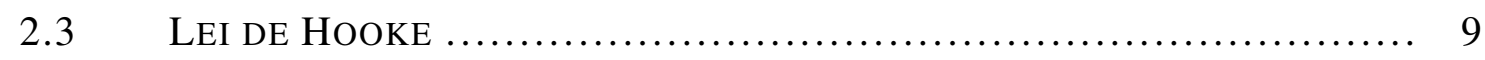

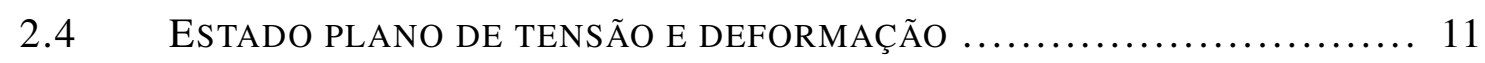

2.5 TEORIA DA DENSIDADE DE ENERGIA DE DISTORÇÃO MÁXIMA, .......... 12

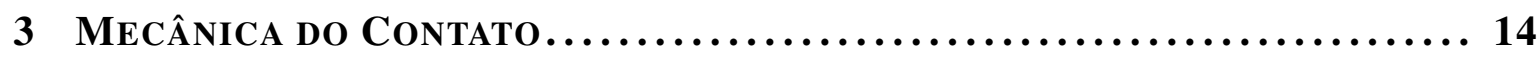

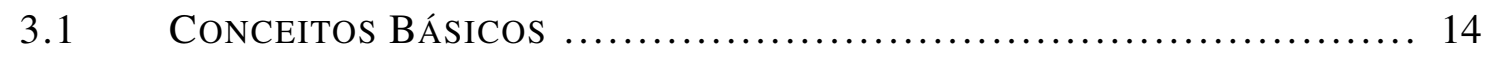

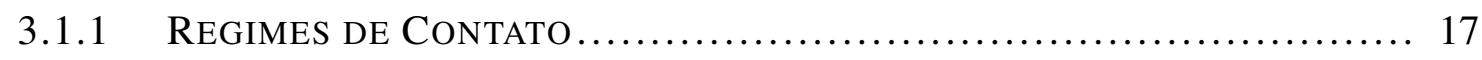

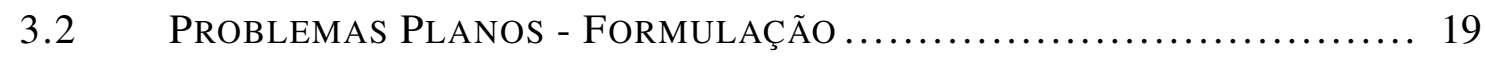

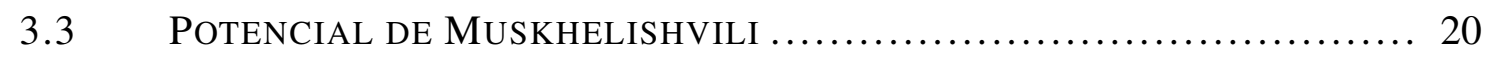

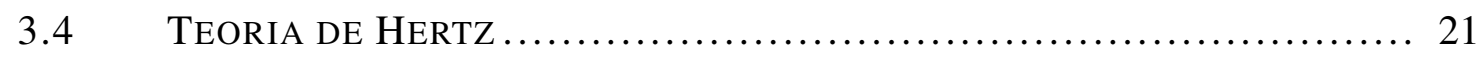

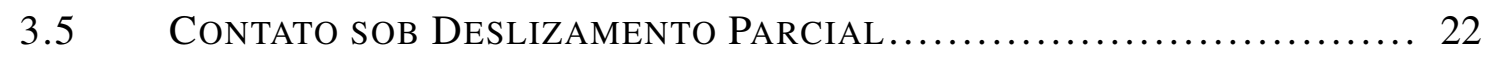

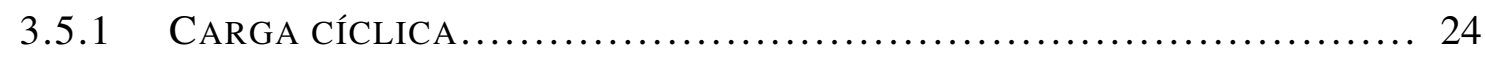

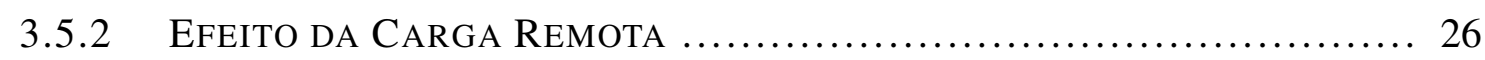

4 O MÉTODO DOS ELEMENTOS DE CONTORNO $\ldots \ldots \ldots \ldots \ldots \ldots \ldots \ldots \ldots, 28$

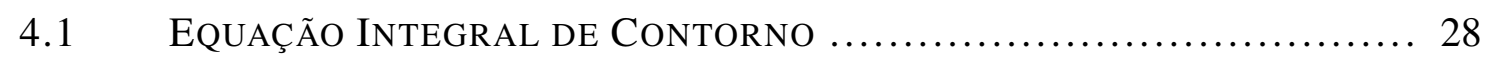

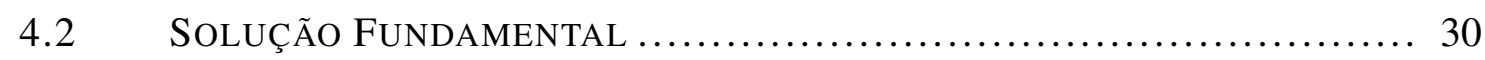

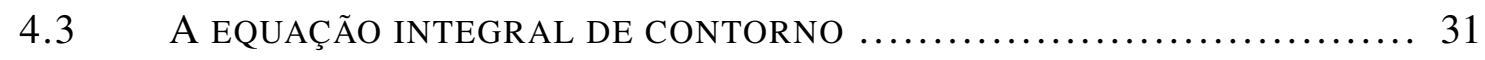

4.4 ELEMENTOS DE CONTORNO QUADRÁTICOS CONTÍNUOS ................. 33

4.4 .1 INTEGRAÇÃO DAS MATRIZES H E G QUANDO O PONTO FONTE NÃO

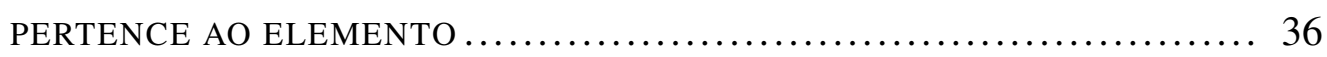

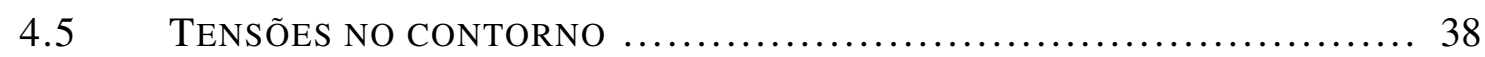


5 MODELAGEM NUMÉRICA $. . \ldots \ldots \ldots \ldots \ldots \ldots \ldots \ldots \ldots \ldots \ldots \ldots \ldots \ldots, 41$

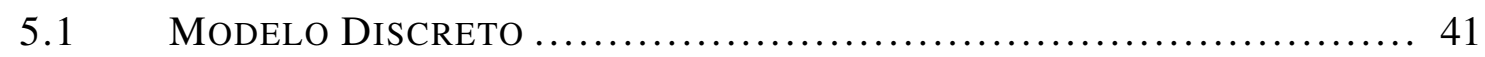

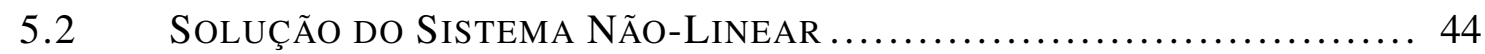

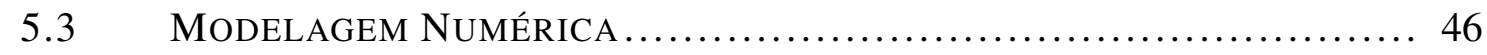

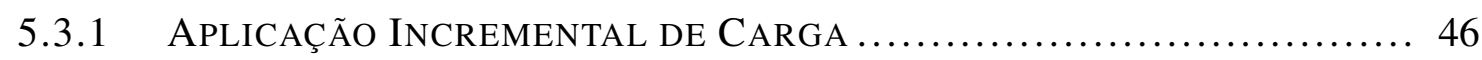

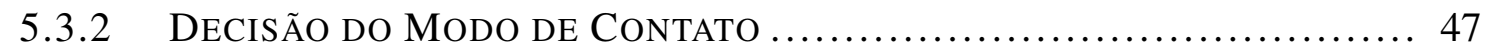

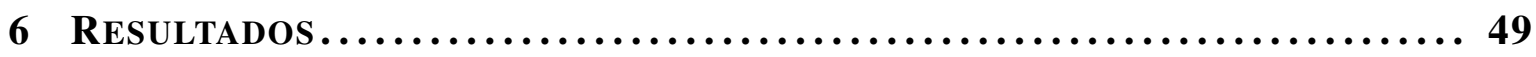

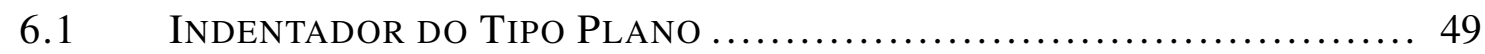

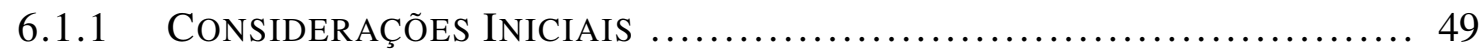

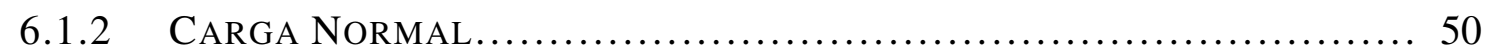

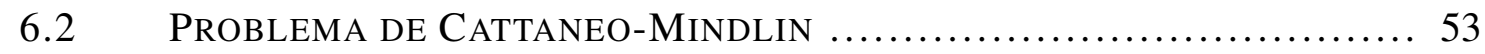

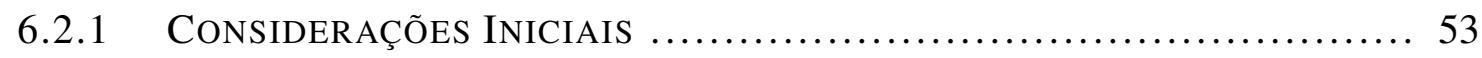

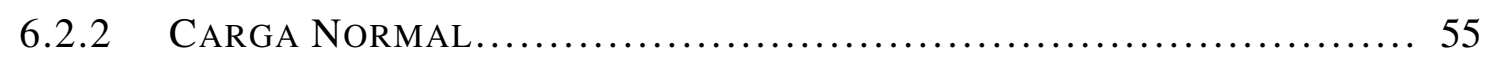

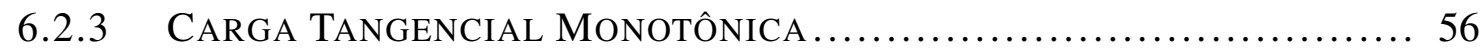

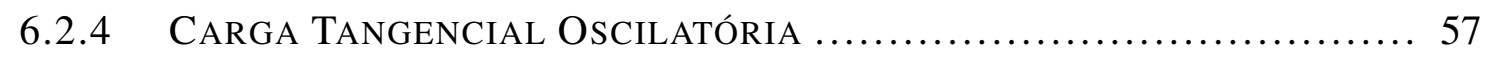

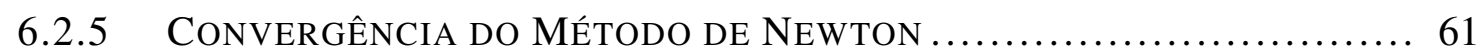

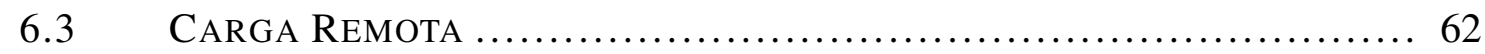

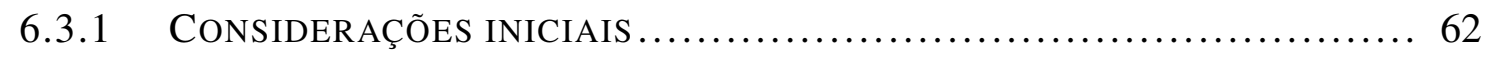

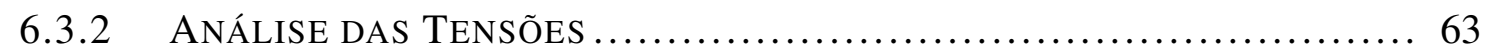

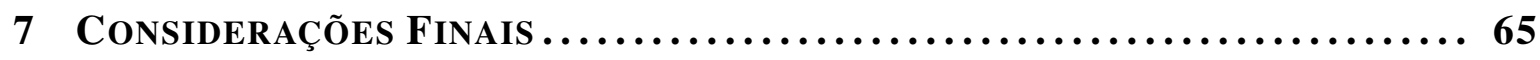

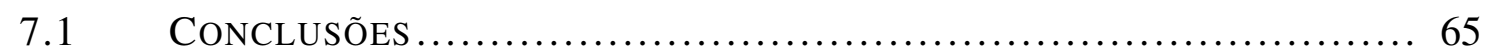

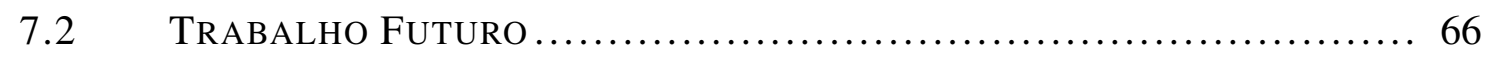

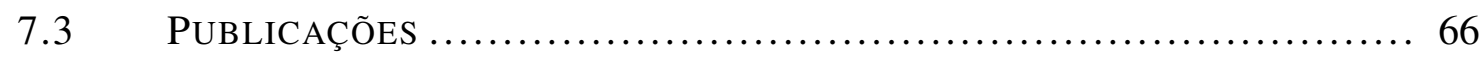

REFERÊNCIAS BIBLIOGRÁFICAS $, \ldots \ldots \ldots \ldots \ldots \ldots \ldots \ldots \ldots \ldots \ldots \ldots \ldots, \ldots, \ldots \ldots$ 


\section{LISTA DE FIGURAS}

1.1 Anotações dos estudos feitos por Leonardo da Vinci (HUTCHINGS, 2016). ... 2

2.1 Corpo em equilíbrio sob as forças externas. ................................. 7

2.2 Vetores de tensão sobre as faces do elemento infinitesimal de volume........... 8

2.3 Placa fina sujeita a um carregamento uniforme distribuído na espessura. ........ 11

2.4 Cilindro longo sujeito a um carregamento uniforme ao longo do comprimento. 11

2.5 Teoria da energia de distorção máxima (von Mises). .......................... 13

3.1 Caracterização de contatos: (a) Incompleto e não-conforme; (b) Completo; (c) Incompleto com singularidade; (d) Incompleto e conforme. ................ 15

3.2 Contato normal entre corpos elasticamente similares ............................ 16

3.3 Zonas dentro da área de contato ............................................ 17

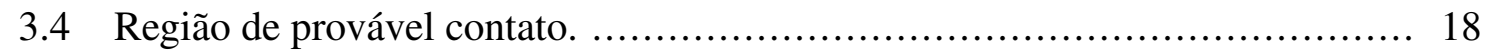

3.5 Contato entre corpos elasticamente similares.................................. 19

3.6 Semi-plano submetido a uma distribuição de tensão arbitrária.................... 20

3.7 Perfil de distribuição de tensões normais e cisalhantes para diferentes coefi-

cientes de atrito ............................................................. 23

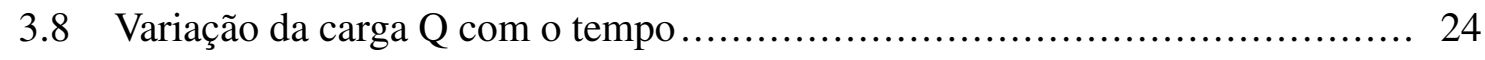

$\begin{array}{lll}3.9 & \text { Tensões cisalhantes durante o ciclo de carregamento mostrado na Figura } 3.8 & \text {.. } 24\end{array}$

3.10 Tensões cisalhantes superficiais durante um carregamento cíclico, com

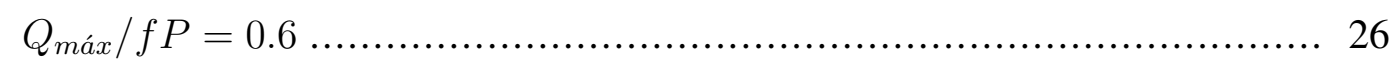

3.11 Configuração típica de aplicações de carga em fadiga por fretting ................ 26

3.12 Carregamento cíclico com carga de fadiga em fase com a carga tangencial,

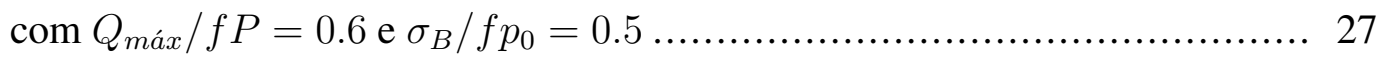

$4.1 \quad$ O ponto fonte $x^{\prime}$ pertence ao contorno. ................................... 31

4.2 Ângulo interno no contorno do componente................................... 32

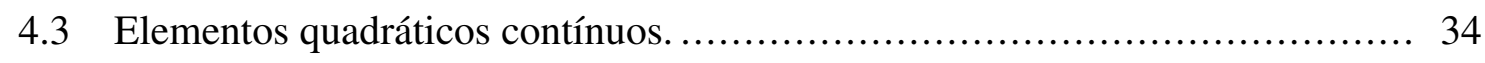

4.4 Coordenada local $\xi$ para elementos quadráticos contínuos. ...................... 35

4.5 Funções de forma de elementos quadráticos contínuos. ......................... 35

4.6 Tensões no contorno. ....................................................... 38

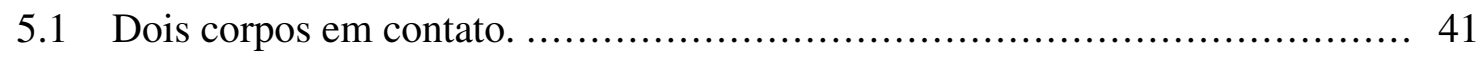

6.1 Malha do problema com 20 elementos de contato (240 Graus de liberdade).... 50 
6.2 Comparação do resultado numérico com o resultado analítico da pressão de contato (10 elementos). ..................................................... 50

6.3 Pressão de Contato para diferentes malhas. .................................. 51

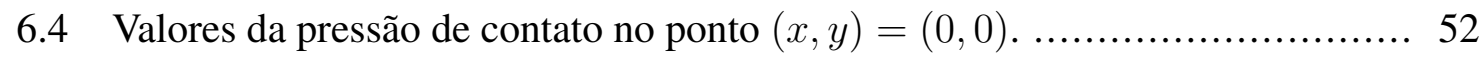

6.5 Distribuição das tensões de von Mises. .................................... 52

6.6 Esquema de carregamento incremental para o problema de Cattaneo-Mindlin. 53

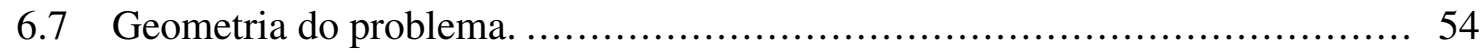

6.8 Malha com 60 elementos de contato e 584 pontos internos em cada corpo..... 55

6.9 Erro percentual da semi-largura de contato em função do número de elementos de contato. .................................................................... 56

6.10 Erro percentual da zona de adesão em função do número de elementos de contato. ........................................................................ 57

6.11 Erro percentual da zona de adesão $\left(c^{\prime}\right)$ em função do número de elementos de contato.

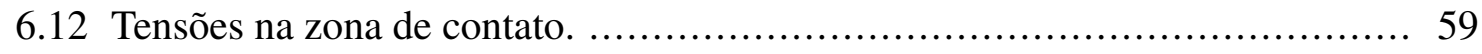

6.13 Tensões na zona de contato. .................................................... 60

6.14 Número de iterações para cada passo de aplicação de carga. ..................... 61

6.15 Resíduo em cada iteração para diferentes passos. .............................. 62

6.16 Condições de contorno do problema........................................... 63

6.17 Tensões na zona de contato. ..................................................... 64 


\section{LISTA DE TABELAS}

$3.1 \quad$ Regimes de Contato........................................................... 18

3.2 Tensões superficiais cisalhantes para cada região durante a variação do carregamento tangencial com o tempo.

$6.1 \quad$ Propriedades materiais e geométricas. ........................................ 54 


\section{Capítulo 1}

\section{Introdução}

\subsection{Motivação}

Fretting é o fenômeno que ocorre na interface de contato de um componente estrutural restringido submetido a uma excitação vibratória ou uma força oscilatória tangencial (SZOLWINSKI; FARRIS, 1996). O micro-deslizamento leva à dano superficial e abertura de trincas precoces no componente (ARAÚJO; NOWELL, 1999). Foi primeiramente detectado no início do Séc. XX, na região das garras de máquinas de fadiga que sofriam falha prematura (EDEN; ROSE; CUNNINGHAM, 1911). Tomlison (1927) propôs que o deslocamento tangencial entre as superfícies de contato era o parâmetro principal do fenômeno. A amplitude de deslizamento relativo é muitas vezes na ordem de mícron a milímetros, mas pode ser tão baixa quanto 3 a 4 nanômetros (METALS, 1961).

Em aplicações de engenharia, fretting aparece em juntas parafusadas e rebitadas (HARISH; FARRIS, 1998; JUOKSUKANGAS; LEHTOVAARA; MÄNTYLÄ, 2016), acoplamentos de eixos com engrenagens e rolamentos, na interface da montagem das palhetas com o disco de turbinas ou compressores (RUIZ; BODDINGTON; CHEN, 1984; RUIZ; CHEN, 1986; RUIZ; NOWELL, 2000; GOLDEN, 2009), cabos de alta tensão (AZEVEDO et al., 2009; FADEL et al., 2012), válvulas de exaustão (KESAVAN et al., 2016), implantes ortopédicos (ROYHMAN et al., 2016) e muitos outros.

Esses componentes devem ser projetados, principalmente, de maneira a evitar falhas causadas por fadiga por fretting, que impactam indústrias de grande importância econômica. Dentro da indústria aeronáutica fadiga por fretting causa cerca de $17 \%$ das falhas ou contratempos nos sistemas de propulsão (GOLDEN, 2009). De forma geral esses elementos submetidos à deslizamentos parciais e cargas cíclicas, tem sua resistência a fadiga severamente reduzidos (WARLOW-DAVIES, 1941; MCDOWELL, 1952).

Um passo fundamental para a avaliação da resistência a fadiga é determinar a evolução do campo de tensão durante o ciclo de fretting. De forma geral, os corpos são submetidos à carregamentos normais e cisalhantes com a presença de atrito, condições que aumentam 
a complexidade do problema. Além disso, cargas remotas de fadiga causam variações nas tensões resultantes gerando um problema alto grau de complexidade.

Neste ponto a modelagem analítica se prova ineficaz, e são utilizadas técnicas numéricas para simular os campos de tensão e aumentar a quantidade de problemas de contato que podem ser resolvidos. O Método dos Elementos Finitos (MEF) é o método numérico mais usado para avaliação de sistemas mecânicos em contato (HOJJATI-TALEMI et al., 2013, KONYUKHOV; IZI, 2015), sendo que o intuito do presente trabalho é apresentar um método alternativo que consiga ser tão preciso quanto o MEF e mais barato computacionalmente para fins de avaliação das tensões e deformações de corpos em contato.

\subsection{Estado-da-Arte}

O estudo formal do contato entre dois corpos pode ser encontrado a partir do século XV em experimentos feitos por Da Vinci sobre o deslizamento de blocos (HUTCHINGS, 2016). Ele discutiu a influência da área de contato e do peso dos blocos na força de atrito. A Figura 1.1 apresenta anotações do polímata italiano.

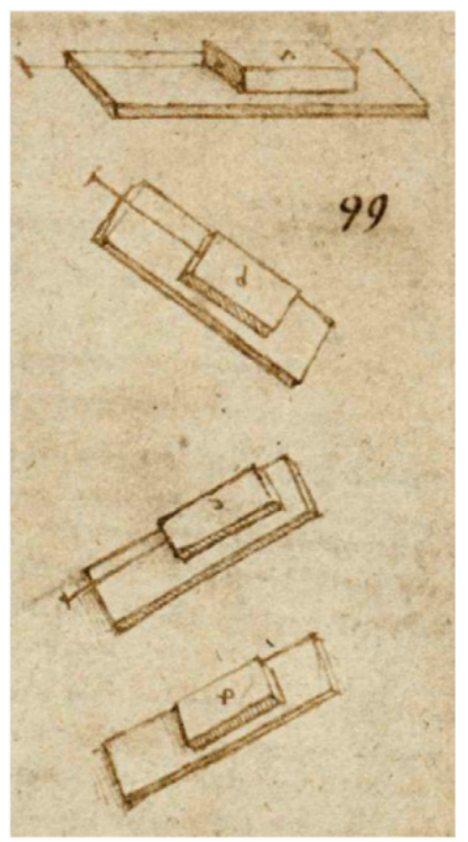

(a) Esboço dos desenhos dos blocos.

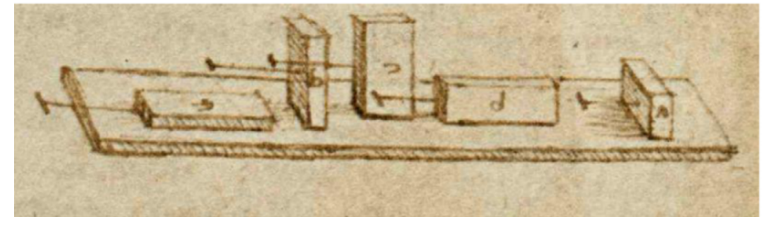

(b) Esboço do experimento com blocos.

Figura 1.1: Anotações dos estudos feitos por Leonardo da Vinci (HUTCHINGS, 2016).

Mais tarde, Amontons (1699) e Coulomb (1779) postularam as leis de atrito, onde era determinado que a força de atrito era diretamente proporcional à carga normal aplicada e independe da área de contato aparente, e que o atrito cinético independia da velocidade de deslizamento.

Foi então que Hertz (1881) combinou a teoria de elasticidade clássica, as leis de atrito e a mecânica do contínuo para obter o primeiro conjunto de soluções analíticas de corpos elásti- 
cos em contato. Apesar de resolver um número limitado de problemas, o trabalho despertou curiosidade pela área e formulações mais sofisticadas foram propostas por Signorini (1933).

Cattaneo (1938) propôs que os problemas com fricção eram extensões da solução de Hertz e considerou o deslizamento tangencial entre os corpos. Já Mindlin (1949) considerou que a zona de contato entre os corpos estavam em adesão.

Os modelos analíticos foram se tornando mais complicados pela número de considerações feitas em cada caso, os corpos tinham que ser modelados como inelásticos, incluir o desgaste superficial, corrosão e a influência da temperaturas precisavam ser medidas.

Foi o momento em que as primeiras formulações do Método dos Elementos Finitos surgiu para corpos em contato elástico (PANAGIOTOPOULOS, 1975). Elas evoluíram para resolver uma quantidade maior de problemas de contato, incluindo atrito e novos tipos de acoplamentos de malha (ALART; CURNIER, 1991; CHRISTENSEN; KLARBRING, 1998, STRÖMBERG, 1999; MCDEVITT; LAURSEN, 2000).

Essas formulações são disseminadas pelos softwares comerciais mas, o método de forma geral se baseia em dividir os corpos em subdomínios, o que aumenta seu custo computacional, principalmente para problemas tridimensionais, onde são usados elementos volumétri$\cos$.

\subsection{Método dos Elementos de Contorno}

O Método dos Elementos de Contorno (MEC) surgiu na década de 70 como uma alternativa para as técnicas baseadas em divisão de domínio (BREBBIA; DOMINGUEZ, 1996, BANERJEE, 1994). Sua grande vantagem é a redução da dimensão do problema, baseandose nas equações integrais de contorno e nas soluções fundamentais das equações diferencias que regem o fenômeno a ser estudado (KANE, 1994). A redução de malha é benéfica para problemas que possuem domínios infinitos ou semi-infinitos presentes na acústica, mecânica dos solos e mecânica dos fluidos (WROBEL, 2002)

A abordagem com as variáveis no contorno, traz uma maior resolução das tensões e deslocamentos internos, pois diferente de elementos finitos, o MEC calcula deslocamentos e trações com a mesma precisão no contorno e modela o interior dos corpos continuamente. Isso é especialmente adequado para problemas de alto gradiente como propagação de ondas, propagação de trincas e mecânica do contato (ALIABADI, 2002; POPOV, 2010).

Dentro da mecânica do contato as primeiras modelagens com elementos de contorno se inciaram na década de 80 por Anderson (1981) e Paris (1995). Eles inciaram o uso de técnicas de restrições diretas para resolver exemplos bidimensionais de contato que foram melhorados posteriormente (KARAMI, 1987; PARIS; GARRIDO, 1989) até que Man (1994) optimizou a metodologia com cargas incrementais e a presença de múltiplos modos de contato no problema. No entanto, os métodos de aplicação das restrições e de 
- Capítulo 3: Mecânica do Contato. Introduz os conhecimentos de mecânica do contato entre corpos elásticos e as soluções analíticas dos problemas que serão resolvidos numericamente.

- Capítulo 4: Método dos Elementos de Contorno. Apresenta o desenvolvimento da formulação elástica bidimensional do MEC, deduzindo as equações integrais de contorno e o equacionamento discretizado do método.

- Capítulo 5: Método dos Elementos de Contorno na Mecânica do Contato. Expõe conceitos de mecânica do contato computacional, o método de restrições unilaterais e como elas são combinadas com o MEC para solução de problemas de contato. Também apresenta conceitos de modelagem computacional e de solução de sistemas nãolineares.

- Capítulo 6: Resultados. Resultados numéricos do problema de endentação com cilindro plano, problema de Cattaneo-Mindlin e da aplicação da carga de fadiga;

- Capítulo 7: Considerações finais. Principais conclusões e contribuições do trabalho. 


\section{Capítulo 2}

\section{Mecânica dos Sólidos}

Este capítulo apresenta os conceitos básicos para o entendimento do comportamento de meios sólidos e como os mesmos reagem a aplicações de cargas. Esses princípios são base para todas as formulações apresentadas posteriormente de Mecânica do Contato e para o Método dos Elementos de Contorno.

\subsection{Tensão}

Tensão é uma medida das forças internas que atuam em pontos dentro de um corpo. Quantitativamente, é uma medida da força média por unidade de área de uma superfície no interior do corpo sobre a qual atuam as forças internas. Estas forças internas surgem como reação às forças externas aplicadas ao corpo. Uma vez que o corpo deformável carregado é assumido como contínuo, estas forças internas são distribuídas de forma contínua dentro do volume do corpo e o corpo tem uma deformação contínua.

A Figura 2.1 representa um corpo em equilíbrio sob as forças $P_{1}, \ldots, P_{7}$. Imagine o corpo dividido em duas partes $A$ e $B$ através de um corte na seção $\mathrm{mm}$ '. Será assumido que estas forças estão distribuídas sobre a área $m m^{\prime}$ continuamente, da mesma forma que a pressão é continuamente distribuída sobre a superfície sob a qual atua.

A área $\Delta S$ é uma área infinitesimal com normal unitária $n_{i}$ e $\Delta F$ é uma força interna exercida sobre essa área. Define-se o vetor tensão como:

$$
t_{i}^{(n)}=\lim _{\Delta S \rightarrow 0} \frac{\Delta F_{i}}{\Delta S}=\frac{d F_{i}}{d S}
$$

O vetor de tensão $\mathbf{t}_{i}$ depende da sua localização no corpo e da orientação do plano sobre o qual atua. Dependendo da orientação do plano considerado, o vetor de tensão pode não ser necessariamente perpendicular a esse plano e pode ser decomposto em dois componentes: 


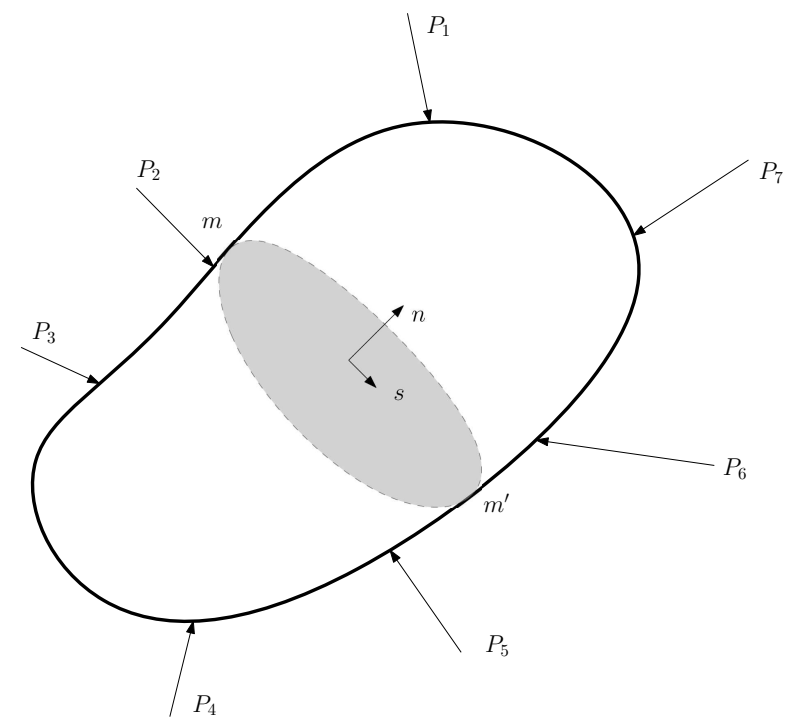

Figura 2.1: Corpo em equilíbrio sob as forças externas.

- Normal ao plano, chamado de tensão normal:

$$
\sigma_{n}=\lim _{\Delta S \rightarrow 0} \frac{\Delta F_{n}}{\Delta S}
$$

onde $\Delta F_{n}$ é o componente normal da força $\Delta F$ que atua sobre a área $\Delta S$.

- Paralelo a este plano, chamado tensão de cisalhamento:

$$
\tau=\lim _{\Delta S \rightarrow 0} \frac{\Delta F_{s}}{\Delta S}
$$

onde $\Delta F_{s}$ é a componente tangencial da força $\Delta F$ que atua sobre a área $\Delta S$. A tensão de cisalhamento pode ser ainda decomposta em dois vetores mutuamente perpendiculares.

Em um elemento infinitesimal de volume do corpo elástico, o vetor de tensão pode decomposto em três vetores de tensão em cada face nas direções de coordenadas cartesianas $(x, y, z)$. Um vetor normal à superfície e outros dois tangentes à superfície e perpendiculares entre si. Portanto, observam-se 9 vetores de tensão em um volume de corpo.

As tensões sobre um volume infinitesimal de um corpo podem ser organizadas em uma matriz simétrica pois há equilíbrio de momentos. Utilizando-se notação indicial, pode-se escrever cada componente de tensão como $\sigma_{i j}$, onde $i$ representa a coordenada normal ao plano em que a tensão se encontra e $j$ é a direção do componente do vetor tensão. Essa matriz é denominada de tensor de tensões de Cauchy e é representada pelo símbolo $\sigma$, como abaixo:

$$
\sigma_{i j}=\left[\begin{array}{ccc}
\sigma_{x x} & \sigma_{x y} & \sigma_{x z} \\
\sigma_{y x} & \sigma_{y y} & \sigma_{y z} \\
\sigma_{z x} & \sigma_{z y} & \sigma_{z z}
\end{array}\right]=\left[\begin{array}{ccc}
\sigma_{x} & \tau_{x y} & \tau_{x z} \\
\tau_{y x} & \sigma_{y} & \tau_{y z} \\
\tau_{z x} & \tau_{z y} & \sigma_{z}
\end{array}\right]
$$



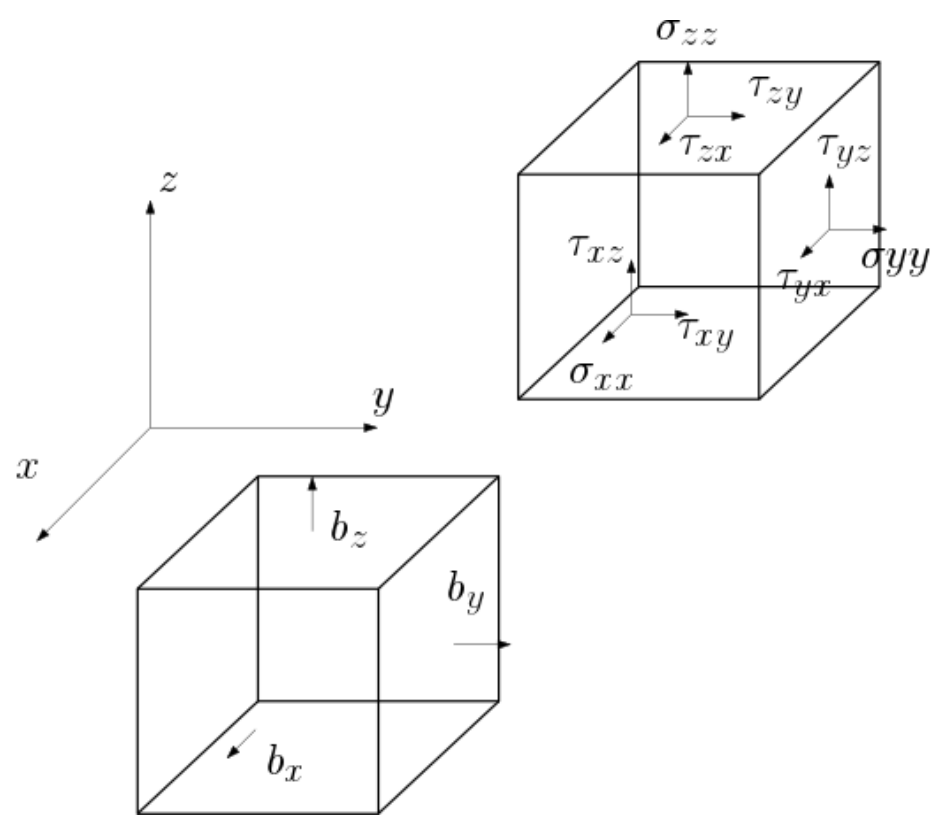

Figura 2.2: Vetores de tensão sobre as faces do elemento infinitesimal de volume.

O teorema de Cauchy afirma que existe um campo tensorial $\sigma$, chamado de tensor de Cauchy, independente da direção normal $n$, tal que té uma função linear de $n$ :

$$
t(n)=\sigma_{i j} n
$$

Definindo $b_{i}$ como uma força por unidade de volume, tem-se:

$$
b_{i}=\left[\begin{array}{l}
b_{x} \\
b_{y} \\
b_{z}
\end{array}\right]
$$

Portanto o equilíbrio estático pode ser escrito como:

$$
\sigma_{i j, j}+b_{i}=0
$$

\subsection{Deformação}

A deformação de um corpo elástico é definida como a variação de comprimento e forma em certa direção. A deformação linear média, $\varepsilon_{i j}$, é definida pela razão entre a variação de comprimento, $\partial u_{i}$, pelo comprimento inicial , $\partial x_{i}$. Em um elemento infinitesimal, a deformação é definida como a variação de comprimento por unidade de comprimento, e 
pode ser escrita como:

$$
\varepsilon_{x x}=\frac{\partial u_{x}}{\partial x}, \varepsilon_{y y}=\frac{\partial u_{y}}{\partial y}, \varepsilon_{z z}=\frac{\partial u_{z}}{\partial z}
$$

As Equações (2.8) representam as deformações normais ou lineares. As componentes cisalhantes de deformação também fazem parte da deformação. Estas componentes são chamadas deformações angulares e podem ser escritas como:

$$
\varepsilon_{x y}=\frac{1}{2}\left(\frac{\partial u_{x}}{\partial y}+\frac{\partial u_{y}}{\partial x}\right), \quad \varepsilon_{y z}=\frac{1}{2}\left(\frac{\partial u_{y}}{\partial z}+\frac{\partial u_{z}}{\partial y}\right) \quad \text { e } \varepsilon_{z x}=\frac{1}{2}\left(\frac{\partial u_{z}}{\partial x}+\frac{\partial u_{x}}{\partial z}\right)
$$

Todos os componentes de deformação podem ser escritos na forma de uma matriz denominada tensor de deformações representado por $\varepsilon$ que envolve todos os componentes normais e de cisalhamento do tensor de deformação.

$$
\varepsilon_{i j}=\left[\begin{array}{lll}
\varepsilon_{x x} & \varepsilon_{x y} & \varepsilon_{x z} \\
\varepsilon_{y x} & \varepsilon_{y y} & \varepsilon_{y z} \\
\varepsilon_{z x} & \varepsilon_{z y} & \varepsilon_{z z}
\end{array}\right]
$$

Na matriz 2.10), devido ao equilíbrio de momentos, os componentes de cisalhamento da deformação são iguais em dupla, por simetria, ou seja $\varepsilon_{i j}=\varepsilon_{j i}$.

As Equações 2.8) e (2.9) podem ser reescritas como:

$$
\varepsilon(\mathbf{u})=\nabla_{s} \mathbf{u}=\frac{1}{2}\left(\nabla \mathbf{u}+\nabla \mathbf{u}^{T}\right)
$$

\subsection{Lei de Hooke}

Como já foi explicado anteriormente, qualquer material, sobre o qual atua uma força, sofrerá uma deformação. Em materiais com comportamento elástico linear, a deformação do corpo se relaciona diretamente com as tensões atuantes no corpo (TIMOSHENKO; GERE, 2012). Esta relação é dada pela lei de Hooke que relaciona o tensor de tensões de Cauchy e o tensor de deformações.

No caso de material homogêneo e isotrópico, a lei de Hooke pode ser escrita de forma generalizada como:

$$
\sigma_{i j}=\lambda \delta_{i j} u_{k, k}+G\left(u_{i, j}+u_{j, i}\right)
$$

onde $\lambda$ e $G$ são constantes de Lamé, expressas em termos do módulo Young $E$ e do coefici- 
ente de Poisson $\nu$ e são definidos assim:

$$
\begin{gathered}
\lambda=\frac{\nu E}{(1+\nu)(1-2 \nu)} \\
G=\frac{E}{2(1+\nu)}
\end{gathered}
$$

$G$ é chamado de módulo de cisalhamento e $\delta_{i j}$ é o delta de Kronecker cujas propriedades são:

$$
\delta_{i j}=\left\{\begin{array}{l}
0 i \neq j \\
1 i=j
\end{array}\right.
$$

e $u_{k, k}$ é o traço do tensor de deformação em notação indicial, ou seja:

$$
u_{k, k}=\varepsilon_{k k}=u_{x, x}+u_{y, y}+u_{z, z}
$$

A inversa da Equação (2.12) pode ser escrita como:

$$
\varepsilon_{i j}=\frac{1}{2 G}\left[\sigma_{i j}-\frac{\nu}{(1+\nu)} \sigma_{k k} \delta_{i j}\right]
$$

As Equações (2.12) e 2.17) também podem ser reescritas em termos de $E$ e $\nu$ como a seguir:

$$
\sigma_{i j}=\frac{E}{(1+\nu)}\left[\varepsilon_{i j}+\frac{\nu}{(1-2 \nu)} \varepsilon_{k k} \delta_{i j}\right]
$$

$\mathrm{e}$

$$
\varepsilon_{i j}=\frac{(1+\nu)}{E}\left[\sigma_{i j}+\frac{\nu}{(1+\nu)} \sigma_{k k} \delta_{i j}\right]
$$

Derivando a Eq. (2.12), substituindo na equação de equilíbrio 2.7) e substituindo os componentes de deformação com as derivadas de deslocamentos obtidos a partir da Eq. (2.9), obtém-se a equação de Navier para equilíbrio estático, dada por:

$$
u_{j, i i}+\frac{1}{(1-2 \nu)} u_{i, i j}+\frac{1}{G} b_{i}=0
$$

Esta equação é particularmente conveniente se as condições de contorno de deslocamento são especificadas. Da mesma forma, as condições de contorno de forças de superfície podem ser dadas pelo vetor de tensões definido como:

$$
t_{i}=\sigma_{i j} n_{j}=\left(\lambda \delta_{i j} u_{k, k}\right) n_{j}+2 G \varepsilon_{i j} \cdot n_{j}
$$

onde $n_{j}$ indica o cosseno diretor do vetor normal apontando para o exterior do domínio do corpo. 


\subsection{Estado plano de tensão e deformação}

- Estado plano de tensão: Este modo é considerado quando a espessura do componente é relativamente fina comparando com outras dimensões, e a força é uniformemente distribuída ao longo da espessura, como mostrado na Fig. 2.3 .
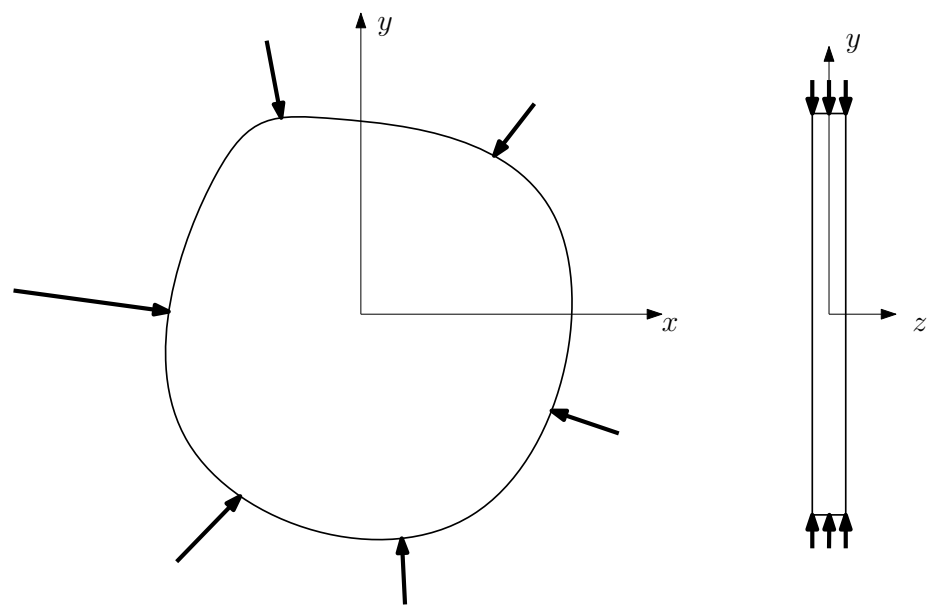

Figura 2.3: Placa fina sujeita a um carregamento uniforme distribuído na espessura.

No estado plano de tensão as componentes $\sigma_{z}, \tau_{z z}$ e $\tau_{z y}$ são zero em ambos os lados do corpo e também ao longo das faces. Portanto, é suficiente calcular as tensões $\sigma_{x}$, $\sigma_{y}$ e $\tau_{x y}$ do componente.

- Estado plano de deformação: Outra simplificação possível é quando a dimensão do componente na direção $z$ é muito grande e tem seção uniforme. Nesse caso, o carregamento aplicado está distribuído de forma uniforme ao longo do eixo $z$ do corpo. Assim sendo, será assumido que a seção inteira tem a mesma condição. Portanto, nos casos como por exemplo de um cilindro longo (Fig. 2.4), considera-se deformação ao longo do eixo $z$ igual zero.
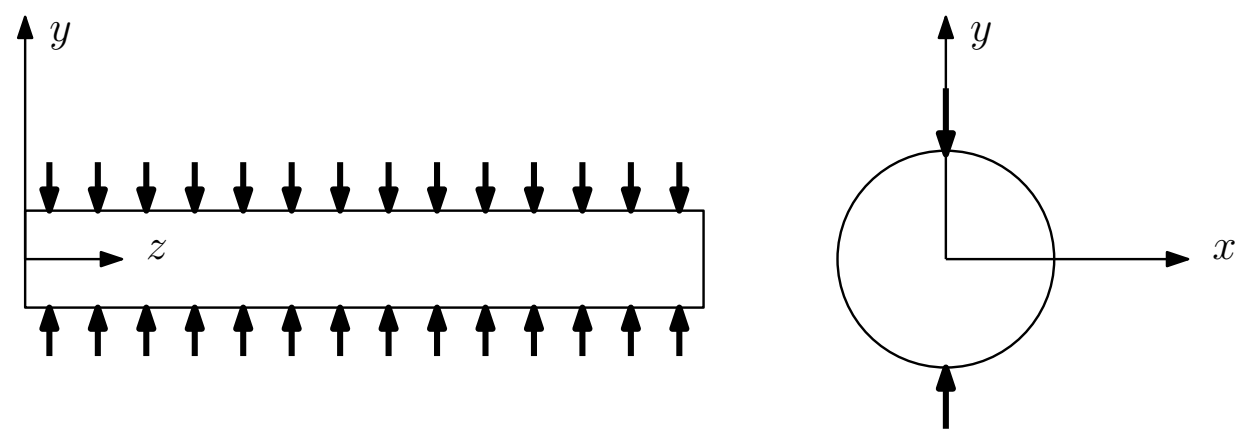

Figura 2.4: Cilindro longo sujeito a um carregamento uniforme ao longo do comprimento.

Desta forma, basta analisar uma fatia do corpo ao longo do eixo $z$. Os componentes $u$ e $v$ de deslocamento são funções de $x$ e $y$, sendo independentes da coordenada $z$. Uma vez que o deslocamento $w$ é zero, obtém-se: 


$$
\begin{aligned}
\gamma_{y z} & =\frac{\partial v}{\partial z}+\frac{\partial w}{\partial z}=0 \\
\gamma_{z z} & =\frac{\partial u}{\partial z}+\frac{\partial w}{\partial z}=0 \\
\epsilon_{x} & =\frac{\partial w}{\partial z}=0
\end{aligned}
$$

A Equação 2.22 define que no estado plano de deformação as componentes $\tau_{x z}$ e $\tau_{y z}$ da tensão são zero. Considerando $\epsilon_{z}=0$ por meio da lei de Hooke, a tensão $\sigma_{z}$ pode ser escrita em termos de $\sigma_{x}$ e $\sigma_{y}$ da seguinte forma:

$$
\sigma_{z}-\nu\left(\sigma_{x}+\sigma_{y}\right)=0 \Rightarrow \sigma_{z}=\nu\left(\sigma_{x}+\sigma_{y}\right)
$$

Logo, conclui-se que no estado plano de deformação, basta calcular as tensões $\sigma_{x}, \sigma_{y}$ e $\tau_{x y}$, que são funções de $x$ e $y$ e dessa forma a tensão $\sigma_{z}$ vai ser uma função de $\sigma_{x}$ e $\sigma_{y}$.

\subsection{Teoria da densidade de energia de distorção má- xima}

Os componentes mecânicos e os elementos estruturais são projetados e fabricados para resistir às condições de carregamento que é definido como tensão de escoamento para materiais dúctil. A tensão de escoamento pode ser obtida num ensaio de tração do corpo de prova sob carregamento uniaxial. Contudo, quando o componente estiver sujeito a tensão multiaxial, a avaliação da resistência do componente será mais difícil. Existem várias teorias para prever a falha de um componente sujeito a tensão multiaxial, como teoria de tensão de cisalhamento máxima e a teoria da densidade de energia de distorção máxima. Para usar essas teorias, as tensões principais no ponto desejado devem ser encontradas. Nessa seção, somente a teoria da densidade de energia de distorção máxima, também conhecida como critério de von Mises, será abordada pois somente esta teoria foi utilizada no trabalho.

Matemático von Mises (1913) propôs que o escoamento dos matérias começa quando o segundo invariante de tensão $J_{2}$ atinge um valor crítico conhecido como tensão de escoamento. $\mathrm{O}$ segundo invariante de tensão, $J_{2}$, também conhecido como $J_{2}$ plasticidade ou teoria de escoamento $J_{2}$ é definido da seguinte forma:

$$
J_{2}=\frac{1}{2} s_{i j} s_{j i}=-\left(s_{1} s_{2}+s_{2} s_{3}+s_{3} s_{1}\right)=\frac{1}{6}\left[\left(\sigma_{1}-\sigma_{2}\right)^{2}+\left(\sigma_{2}-\sigma_{3}\right)^{2}+\left(\sigma_{3}-\sigma_{1}\right)^{2}\right]
$$


Matematicamente a função de von Mises é definido como:

$$
f\left(J_{2}\right)=J_{2}-k^{2}=0
$$

onde $k$ é limite de escoamento do material sob tensão de cisalhamento puro. O valor de $k$ é $\sqrt{3}$ vezes menor que limite de escoamento do material, ou seja:

$$
k=\frac{\sigma_{e}}{\sqrt{3}}
$$

Substituindo as Eq. 2.25 e 2.26 em 2.24, tem-se:

$$
\sigma_{e}^{2}=\frac{1}{2}\left[\left(\sigma_{1}-\sigma_{2}\right)^{2}+\left(\sigma_{2}-\sigma_{3}\right)^{2}+\left(\sigma_{3}-\sigma_{1}\right)^{2}+6\left(\sigma_{23}^{2}+\sigma_{31}^{2}+\sigma_{12}^{2}\right)\right]
$$

No caso biaxial (tensão plana), considerando $\sigma_{3}=0$, tem-se:

$$
\left(\sigma_{1}^{2}-\sigma_{1} \sigma_{2}+\sigma_{2}^{2}\right)=\sigma_{e}^{2}
$$

A Equação 2.28 do critério von Mises é a equação de uma curva elíptica, como é mostrada na Fig. 2.5. Essa curva define a fronteira entre pontos seguros (pontos dentro da elipse) e pontos que causam escoamento no elemento (pontos fora da elipse).

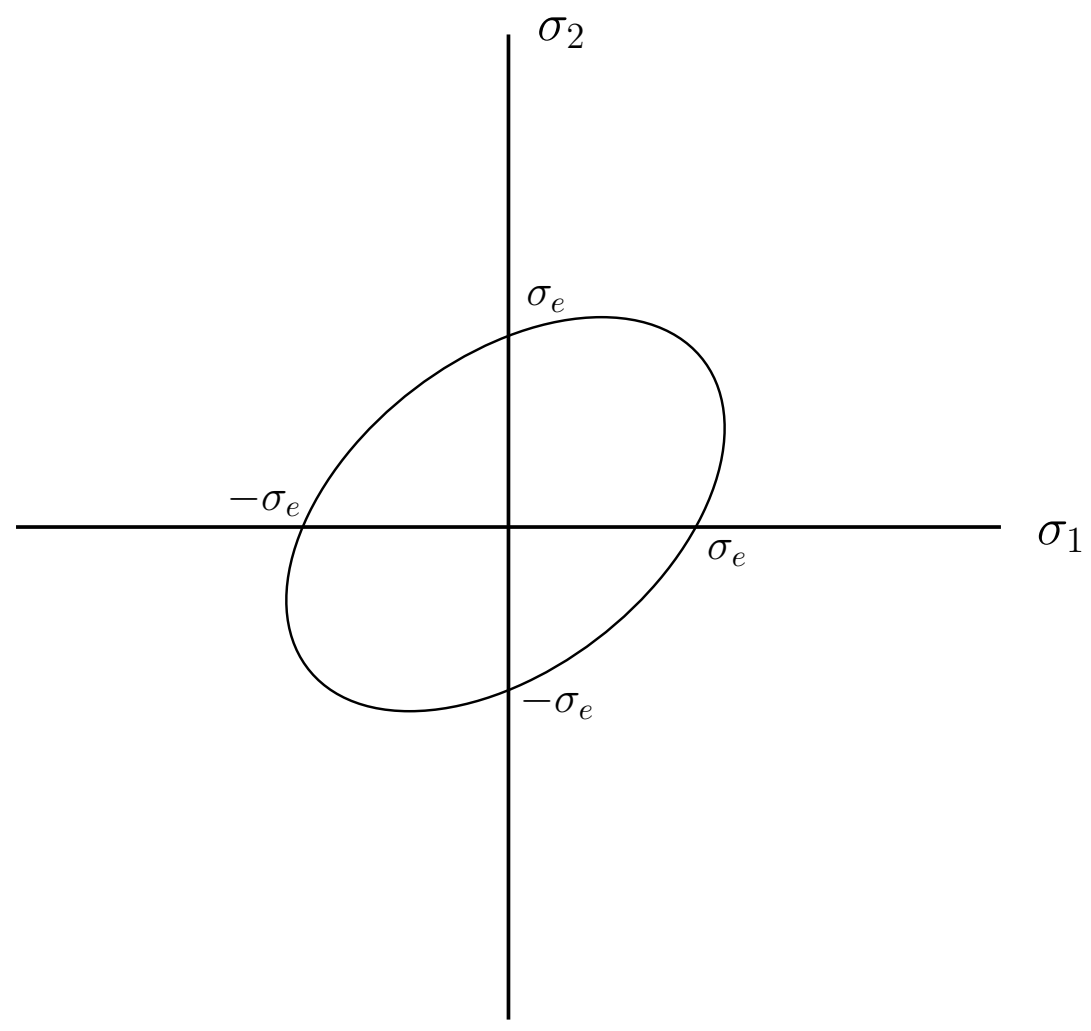

Figura 2.5: Teoria da energia de distorção máxima (von Mises). 


\section{Capítulo 3}

\section{Mecânica do Contato}

\subsection{Conceitos Básicos}

Na prática, problemas de fretting envolvem contato entre componentes com geometrias e históricos de carregamentos complexos (NOWELL; HILLS, 1987). Nestes casos é preferível o uso de métodos numéricos para a complicada modelagem do problema, sendo o utilizado neste trabalho o método dos elementos de contorno. Os resultados apresentados pelo método serão comparados com os resultados analíticos de problemas que abordam as principais variáveis de mecânica do contato: área de contato, zona de adesão, variação de carga tangencial e campo de tensão na região de contato.

Tendo isso em mente, este capítulo tem por objetivo descrever o desenvolvimento das principais equações de mecânica do contato e apresentar os princípios fundamentais da área. A análise de um problema de contato se inicia pela sua classificação. A Figura 3.1 apresenta a classificação do contato segundo sua natureza.

A primeira configuração 3.1(a) apresenta um cilindro rígido de raio $R$ pressionado contra um semi-plano. À medida que os corpos se encontram, o contato é feito ao longo de uma linha, e com o aumento da carga, a semi-largura de contato, $a$, aumenta. Esse tipo de contato é chamado de incompleto pois não é geometricamente fixo mas depende da carga. Além disso, a pressão de contato é nula nas extremidades do contato. Já na Fig. 3.1.b), o tamanho do contato não é afetado pela carga aplicada no penetrador plano rígido e a pressão de contato apresenta singularidades pois os dois corpos não têm uma tangente comum na borda do contato. De fato, a derivada da superfície do semi-plano elástico não é contínua nos limites do contato. O caso da Fig. 3.1. (c) é uma mistura das configurações apresentadas anteriormente onde uma borda possui pressão singular que se distribui através da linha de contato e cai continuamente até zero na outra.

No caso da conformidade, na Fig. 3.1(a), a área de contato é menor que as dimensões dos corpos, $a<<R$, e uma simplificação de semi-plano elástico pode ser feita ao problema, enquanto na Fig. 3.1 (d), à medida que a carga é aplicada ao cilindro, ele se deforma ao longo 


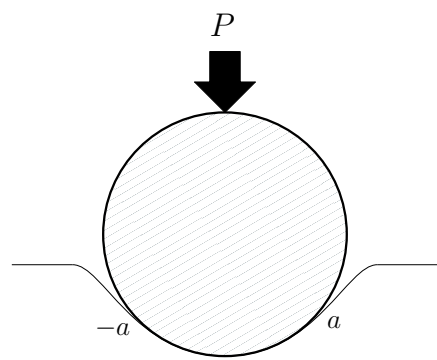

(a)

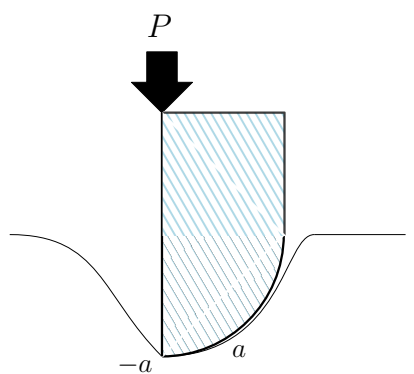

(c)

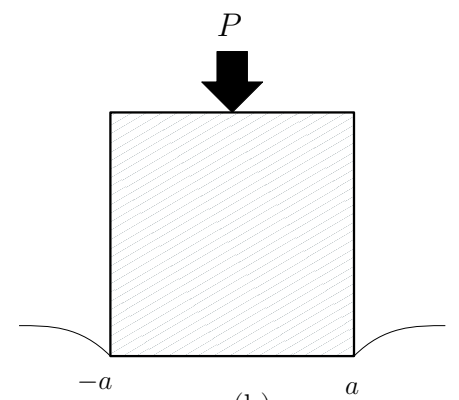

(b)

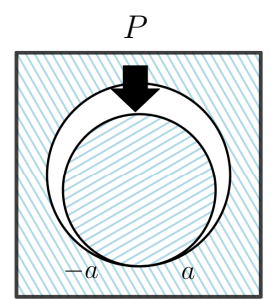

(d)

Figura 3.1: Caracterização de contatos: (a) Incompleto e não-conforme; (b) Completo; (c) Incompleto com singularidade; (d) Incompleto e conforme.

do furo, e $a$ se torna uma boa parte da geometria da situação. Sendo assim, nenhum dos corpos podem ser simplificados.

A formulação trata o contato como um problema de restrições unilateral é geralmente usada quando é de suma importância aplicar as restrições geométricas de forma correta (WRIGGERS, 2006).

O comportamento presente na zona de contato segue certas condições que valem por todo cálculo das variáveis de contato e é importante que elas sejam apresentadas como em trabalhos clássicos de mecânica do contato computacional (ALART; CURNIER, 1991; KIKUCHI; ODEN, 1988). As condições relacionam a pressão de contato $p_{N}$ e a distância normal relativa entre os corpos, também chamada de gap, $v_{N}$ :

$$
\begin{aligned}
v_{N} & \geq 0, \\
p_{N} & \leq 0, \\
p_{N} g_{N} & =0 .
\end{aligned}
$$

Essas são conhecidas como as condições de Kuhn-Karush-Tucker (KKT). A primeira afirmação da Eq. 3.1 é a condição de não-penetração, segundo a qual ou o gap é maior que zero e os corpos estão separados ou ele é zero e os corpos estão em contato. A segunda inequação afirma que os corpos em contato sofrem compressão, quando estão em contato, ou a pressão normal de contato é nula. Por último, o produto da pressão de contato com 
a distância relativa entre os nós deve ser zero, pois há momento de encontro dos corpos $\left(g_{N}=0, p_{N}<0\right)$ e momentos que eles não se influenciam elasticamente $\left(g_{N}>0, p_{N}=0\right)$.

Avançando para a distribuição de tensões na superfície de contato, supõe-se dois corpos elasticamente similares colocados em contato normal conforme a Fig. 3.2. Quando a carga de contato é aplicada, a pressão de contato comprime ambos os corpos e ocorre um deslocamento paralelo à zona de contato. No entanto, como os corpos tem as mesmas propriedades elásticas, as partículas correspondentes dos corpos sofrerão o mesmo deslocamento relativo em $x$, ou seja, mesmo que haja um coeficiente de atrito $(f)$ diferente de zero entre as superfícies, não haverá tensões cisalhantes.

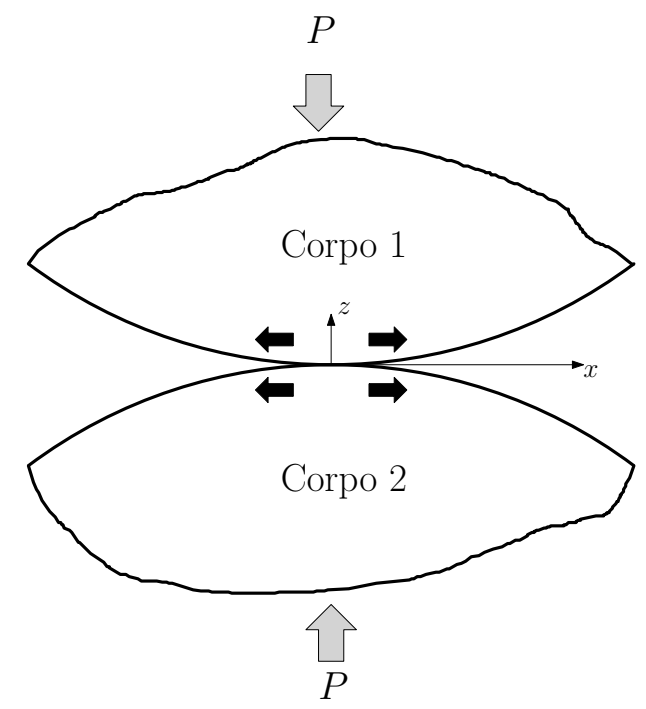

Figura 3.2: Contato normal entre corpos elasticamente similares

Se uma carga tangencial for aplicada o suficiente para causar deslizamento entre os dois corpos, tensões cisalhantes irão surgir e as mesmas serão limitadas em toda extensão do contato pelo coeficiente de fricção, ou seja:

$$
|q(x, y)|=-f p(x, y)
$$

onde $p(x, y)$ é a pressão normal de contato e $q(x, y)$ é a distribuição de tensão cisalhante. A presença dessas tensões cisalhantes causará um deslocamento normal das superfícies dos corpos, e porque ambos são elasticamente similares, os deslocamentos normais terão o mesmo valor, fazendo com que a pressão de contato permaneça inalterada. Em problemas de fretting a carga cisalhante, $Q$, é geralmente é muito pequena para causar deslizamento total de um corpo com o outro:

$$
|Q|<-f P
$$

onde $P$ é a carga normal. Neste caso a área de contato consiste de uma mistura de regiões em que as partículas não conseguem se mover em relação à outra, chamada de zona de adesão, e regiões onde as partículas deslizam entre elas mesmas e as forças de superfície 
são limitadas pelo atrito, chamada de zona de escorregamento. Essas zonas são ilustradas na Fig. 3.3. Dentro da zona de escorregamento, a distribuição de tensões cisalhantes é dada pela Eq. (3.2) e a pressão normal tende à zero a medida que se afasta do centro do contato. Já para a zona de adesão:

$$
|q(x, y)|<-f p(x, y)
$$

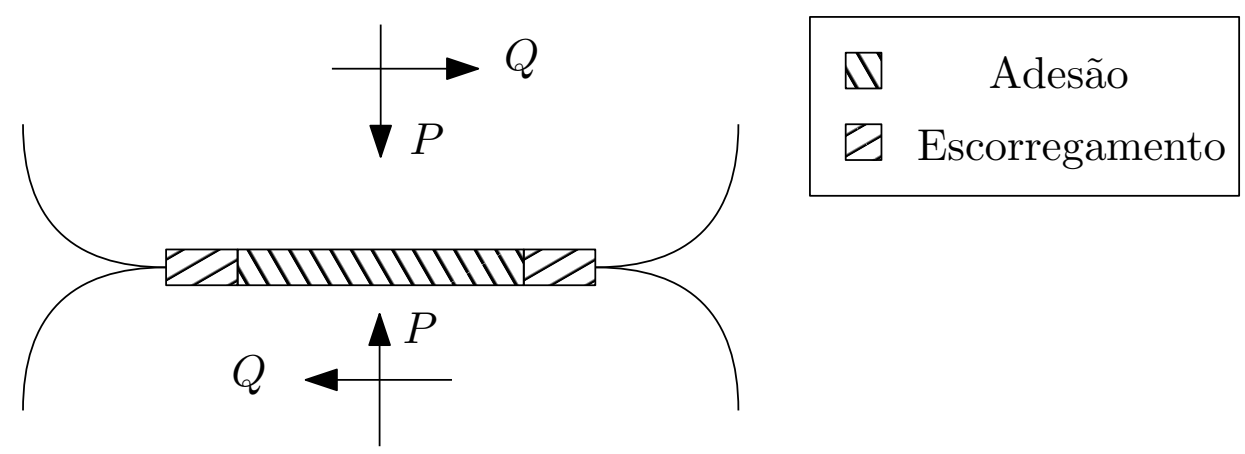

Figura 3.3: Zonas dentro da área de contato

Vale ressaltar novamente que as tensões cisalhantes dos corpos tem a mesma magnitude mas com direções opostas. Nos problemas de contato, a aplicação de carga deve ser de forma iterativa, uma vez que as zonas de adesão e escorregamento são funções da carga aplicada. As zonas devem ser recalculadas em cada iteração. Em outras palavras, tanto as zonas de adesão e escorregamento como a região efetiva de contato podem mudar de uma iteração para outra.

\subsubsection{Regimes de Contato}

Em simulações de contato, é usual escolher uma região de provável contato por causa da constante evolução da área de contato resultante do carregamento. Os nós no interior dessa região formam os chamados pares de contato ( $a$ e $b$ ) como ilustrado na Fig. 3.4, e podem apresentar três modos de contato. Existem diferentes relações para as forças de superfície normais e tangenciais, $t_{t}$ e $t_{n}$, e para os deslocamentos normais e tangenciais, $u_{t}$ e $u_{n}$. Os valores das forças de superfície e deslocamentos locais são mostrados na Tab. 3.1 e os modos de contato podem ser resumidos da forma:

- Separação: Os nós possuem uma distância positiva e diferente de zero entre eles;

- Deslizamento: O par de contato não está restrito na direção tangencial, mas livre para deslizar um sobre o outro;

- Adesão: Os pares de nós estão restritos nas direções tangencial e normal. 


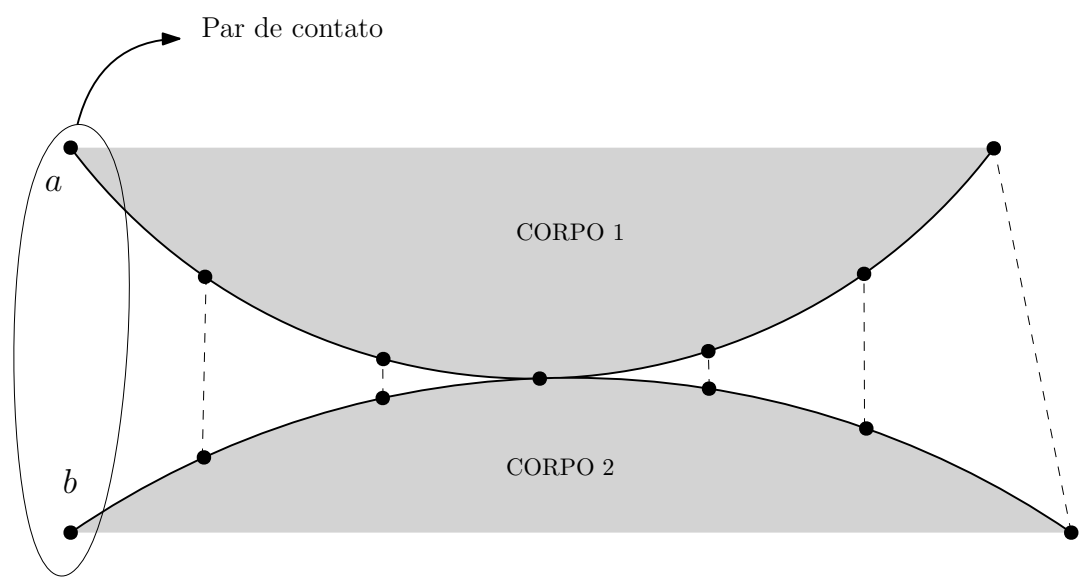

Figura 3.4: Região de provável contato.

Tabela 3.1: Regimes de Contato

\section{Separação Deslizamento Adesão}

$$
\begin{array}{ccc}
t_{t}^{a}-t_{t}^{b}=0 & t_{t}^{a}-t_{t}^{b}=0 & t_{t}^{a}-t_{t}^{b}=0 \\
t_{n}^{a}-t_{n}^{b}=0 & t_{n}^{a}-t_{n}^{b}=0 & t_{n}^{a}-t_{n}^{b}=0 \\
t_{t}^{a}=0 & t_{t}^{a} \pm f t_{n}^{a}=0 & u_{t}^{a}-u_{t}^{b}=0 \\
t_{n}^{a}=0 & u_{n}^{a}-u_{n}^{b}=g^{a p^{a b}} & u_{n}^{a}-u_{n}^{b}=\text { gap }^{a b}
\end{array}
$$




\subsection{Problemas Planos - Formulação}

Para se obter o campo de tensão sub-superficial, é preciso determinar o campo de tensões cisalhantes e a distribuição de pressão ao longo do contato. Para isso é preciso resolver as equações integrais que relacionam a distribuição de pressão $p(x)$ com o deslocamento normal $h(x)$ conforme ilustrado na Fig. 3.5, e a distribuição das tensões cisalhantes com o deslocamento tangencial relativo $g(x)$. Detalhes referentes ao desenvolvimento dessas equações podem ser encontrados na literatura (HILLS; NOWELL, 1994).

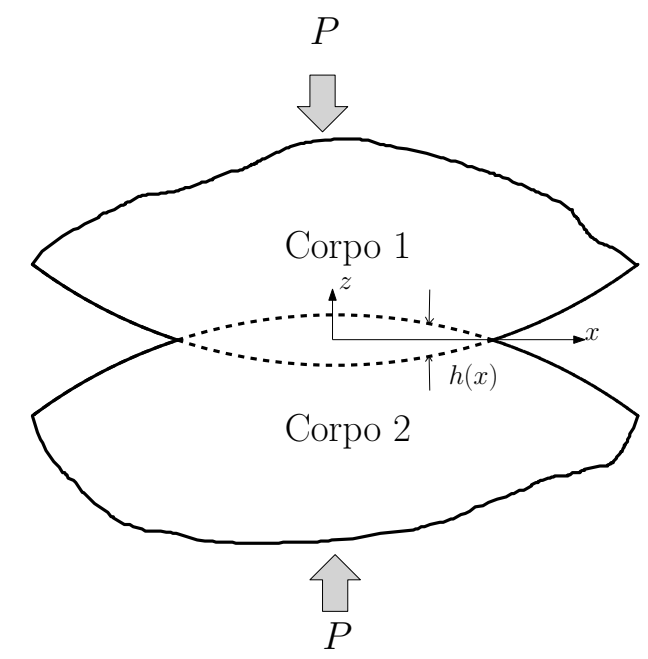

Figura 3.5: Contato entre corpos elasticamente similares

A equação que descreve a distribuição do carregamento normal ao longo da extensão da zona de contato é dado por:

$$
\frac{1}{A} \frac{\partial h}{\partial x}=\frac{1}{\pi} \int_{-a}^{a} \frac{p(\xi)}{x-\xi} d \xi
$$

De maneira análoga para o carregamento tangencial,

$$
\frac{1}{A} \frac{\partial g}{\partial x}=\frac{1}{\pi} \int_{-a}^{a} \frac{q(\xi)}{x-\xi} d \xi
$$

$\xi$ é a variável de integração do carregamento ao longo da zona de contato e $A$ é a complacência composta que é definida como:

$$
A=2\left(\frac{k+1}{4 \mu}\right)
$$

sendo $k=3-4 \nu$ em estado plano de deformação, $\nu$ o coeficiente de Poisson e $\mu$ é o módulo de rigidez. 


\subsection{Potencial de Muskhelishvili}

Uma forma eficiente de calcular o campo de tensão na superfície de contato é utilizando a formulação potencial de Muskhelishvili (MUSKHELISHVILI, 1953; HILLS; NOWELL; SACKFIELD, 1993). Na Figura 3.6, um semi-plano elástico é submetido a forças de superfícies normais e cisalhantes e deve ser achado o valor das tensões em um ponto qualquer dentro do domínio.

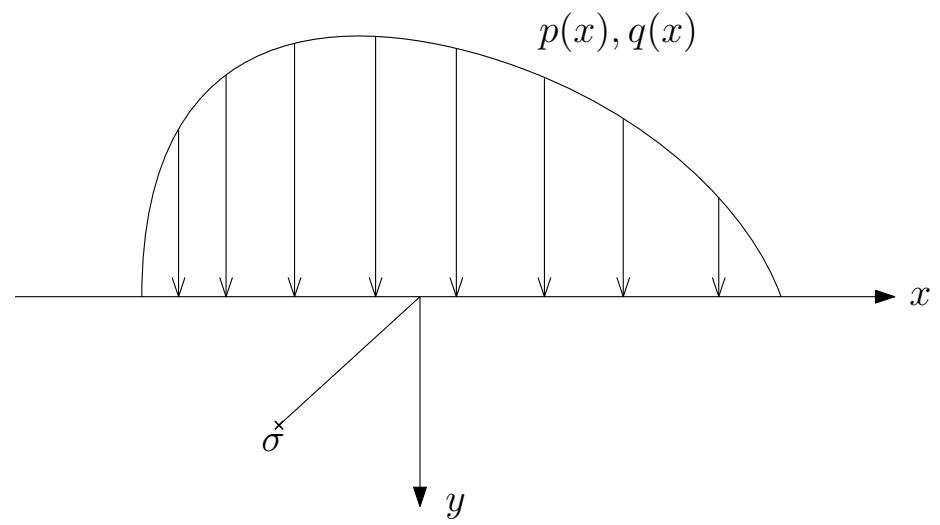

Figura 3.6: Semi-plano submetido a uma distribuição de tensão arbitrária

A coordenada das posições é dada de forma complexa $(z=x+y i)$ e o potencial pode ser descrito como:

$$
\Phi(z)=\frac{1}{2 \pi i} \int \frac{p(t)-i q(t)}{t-z} d t
$$

onde na Eq. (3.8), $p(t)$ e $q(t)$ são distribuições normais e cisalhantes arbitrárias. Em condições de escorregamento, essas distribuições são relacionadas pela Eq. (3.2). Assim, a Eq. (3.8) é escrita na forma:

$$
\Phi(z)=\frac{1-i f}{2 \pi i} \int \frac{p(t)}{t-z} d t
$$

Após a determinação do potencial, as componentes de tensão podem ser relacionadas através das equações:

$$
\begin{gathered}
\sigma_{x x}+\sigma_{y y}=2(\Phi(z)+\bar{\Phi}(\bar{z})) \\
\sigma_{y y}-\sigma_{x x}+2 i \tau_{x y}=2\left((\bar{z}-z) \Phi^{\prime}(z)+\bar{\Phi}(z)-\Phi(z)\right)
\end{gathered}
$$

onde $\Phi^{\prime}(z)$ é a derivada da função potencial em relação a $z, \bar{\Phi}(z)$ o conjugado da função potencial e $\bar{\Phi}(\bar{z})$ é o conjugado da função potencial aplicado ao conjugado de z. 


\subsection{Teoria de Hertz}

Em 1881, Hertz deduziu a solução analítica de uma série de problemas básicos para a mecânica do contato. Considerando o raio de curvatura do corpo como $R$ e a região de contato como $a$, as suposições necessárias para a aplicação da teoria de Hertz são as seguintes:

- As superfícies são contínuas e não conformes $(a<<R)$;

- A deformação é pequena (não é aplicável para materiais com módulo de elasticidade baixo);

- Cada componente pode ser modelado como um semi-espaço elástico $(a<<R)$;

- As superfícies são sem atrito $(f=0)$.

Para chegar às equações de distribuição de pressão normal e da área de contato, deve ser feita a inversão da integral da Eq. (3.5) com o objetivo de isolar $p(x)$. Sendo feita a inversão:

$$
p(x)=-\frac{w(x)}{A \pi} \int_{-a}^{a} \frac{h^{\prime}(\xi)}{w(\xi)(\xi-x)} d \xi+c w(x)
$$

a função $w(x)$ é chamada de função de forma e depende o comportamento do carregamento nas extremidades dos pontos de contato. Como o problema é para superfícies contínuas e não-conformes, $w(x)=\sqrt{a^{2}-x^{2}}$. A interpenetração $h(x)$ é aproximada por uma parábola. A Equação (3.12) vira:

$$
p(x)=-\frac{\sqrt{a^{2}-x^{2}}}{A \pi} \int_{-a}^{a} \frac{k \xi}{\sqrt{a^{2}-x^{2}}(\xi)(x-\xi)} d \xi
$$

onde $k$ é a curvatura da parábola. Normalizando a Eq. (3.13) $\operatorname{com} \zeta=\xi / a$ e $d \xi=a d \zeta$, tem-se:

$$
p(x)=-\frac{\sqrt{a^{2}-x^{2}}}{A \pi} k \int_{-1}^{1} \frac{\zeta}{\sqrt{1-\zeta^{2}}\left(\frac{x}{a}-\zeta\right)} d \zeta
$$

Utilizando as soluções da Integral Singular de Cauchy de Primeira Ordem, que é:

$$
\int_{-1}^{1} \frac{-u}{\sqrt{1-u^{2}}(s-u)} d u=\pi
$$

a Eq. 3.14 é resolvida para $p(x)$ :

$$
p(x)=\frac{k}{A \pi} \sqrt{a^{2}-x^{2}} \pi=\frac{k}{A} a \sqrt{1-\left(\frac{x}{a}\right)^{2}}
$$


A simplificação dos corpos para um semi-espaço elástico (JOHNSON, 1987) resulta em uma distribuição de normal da forma:

$$
p(x)=-p_{0} \sqrt{1-\left(\frac{x}{a}\right)^{2}}
$$

onde $p_{0}$ é o valor máximo da pressão de contato, obtido a partir de:

$$
p_{0}=\frac{2 P}{\pi a}
$$

e $a$ é a semi-largura de contato, dada por:

$$
a^{2}=\frac{4 P R^{*}}{\pi E^{*}}
$$

sendo $R^{*}$, o raio efetivo e $E^{*}$ o módulo de elasticidade combinado dados pelas Eq. (3.20) e (3.21):

$$
\begin{gathered}
R^{*}=\left(\frac{1}{R_{1}}+\frac{1}{R_{2}}\right)^{-1} \\
E^{*}=\left(\frac{1-\nu_{1}^{2}}{E_{1}}+\frac{1-\nu_{2}^{2}}{E_{2}}\right)^{-1}
\end{gathered}
$$

tendo em mente que as propriedades com subscrito são específicas de cada corpo.

\subsection{Contato sob Deslizamento Parcial}

Em seções anteriores, foi discutida a existência de regiões de adesão e deslizamento como resultado de uma carga cisalhante que não consegue promover o deslocamento total de um corpo sobre o outro. Neste caso, a região de adesão se estende do centro do contato até uma distância $c$ e a região de deslizamento vai do fim da zona de adesão até a semi-largura de contato $a$. É importante ressaltar que esse comportamento é simétrico em relação ao centro do contato.

Combinando a Eq. (3.2) com o valor da pressão normal de contato achado na Eq. (3.17) e modelando as tensões cisalhantes superficiais como uma pertubação da solução de escorregamento total, tem-se:

$$
q(x)=f p_{0} \sqrt{1-\left(\frac{x}{a}\right)^{2}}-q^{\prime}(x)
$$

Dentro da zona de adesão, obtém-se o valor do termo $q^{\prime}(x)$. Levando em consideração que não há movimento relativo na direção $x$ entre os pontos correspondentes na região de 
adesão $\left(g^{\prime}(x)=0,|x| \leq c\right)$. Dessa forma a Eq. (3.6) resulta em:

$$
q^{\prime}(x)=f p_{0} \frac{c}{a} \sqrt{1-\left(\frac{x}{c}\right)^{2}} \quad|x| \leq c
$$

Na zona de escorregamento $(c<|x| \leq a)$ não há pertubação da solução de escorregamento total, resultando:

$$
q^{\prime}(x)=0 \quad c<|x| \leq a
$$

Considerando o equilíbrio tangencial, pode-se achar o tamanho da zona de adesão, $c$ :

$$
\frac{c}{a}=\sqrt{1-\left(\frac{Q}{f P}\right)}
$$

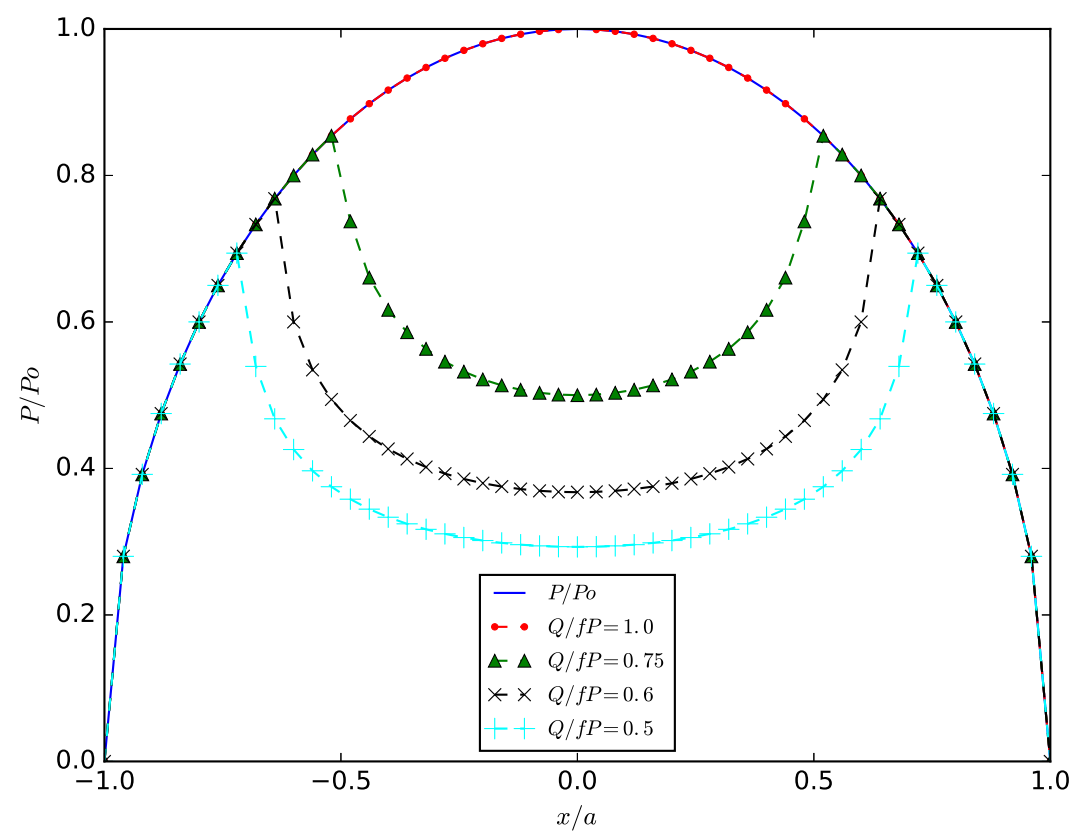

Figura 3.7: Perfil de distribuição de tensões normais e cisalhantes para diferentes coeficientes de atrito

A Figura 3.7 apresenta o perfil de distribuições cisalhantes para um carregamento monotônico para uma série de perfis de coeficiente de atrito. Eles são ilustrados juntamente com a distribuição de pressão normal mostrar que os valores da tensão cisalhante dividida pelo coeficiente de atrito na região de deslizamento são os mesmos que das tensões normais como deduzido anteriormente. Para o valor de $Q / f P=0,75$ é clara a variação da tensão cisalhante da zona de adesão para a zona de deslizamento, variação que ocorre nos limites da zona de adesão $(-0,5$ até 0,5$)$. É nítido também, o aumento da zona de adesão para coe- 
ficientes de fricção maiores, pois ele aumenta diretamente o valor da pertubação nas tensões cisalhantes.

\subsubsection{Carga cíclica}

Um dos objetivos desse trabalho é avaliar as tensões cisalhantes quando a carga tangencial aplicada é oscilatória como descrito na Fig. 3.8. As expressões desenvolvidas anteriormente são válidas para quando a força tangencial está em seu valor máximo, $Q_{\text {máx }}$, ilustrado pelo ponto $A$ da Fig. 3.8. Neste ponto as tensões de cisalhamento apontam na direção oposta ao movimento do corpo, comportamento que foi descrito nas Eq. (3.2) e Eq. (3.4). Esse fenômeno se repete por todo o ciclo, portanto:

$$
\operatorname{sgn}(q(x))=-\operatorname{sgn}\left(\frac{\partial g}{\partial t}\right)
$$

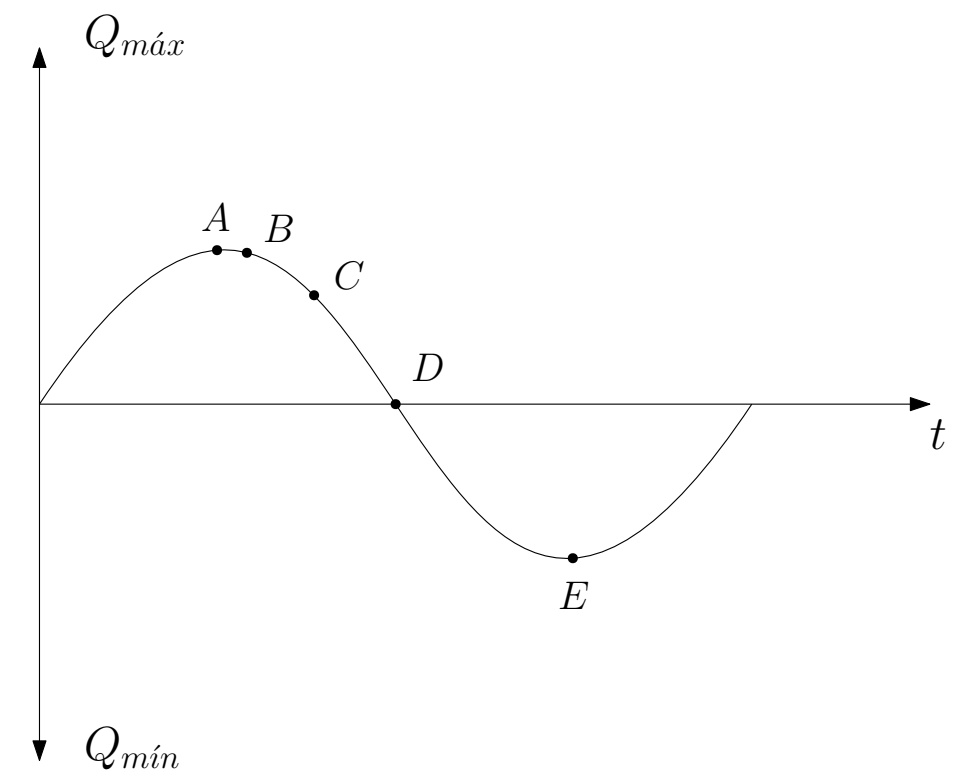

Figura 3.8: Variação da carga Q com o tempo

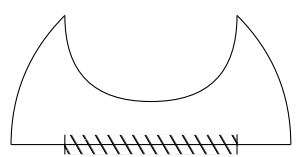

$A$

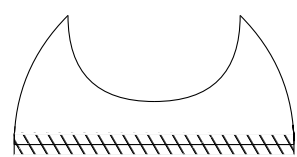

$B$

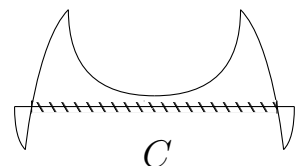

$C$

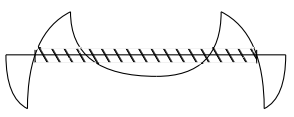

D

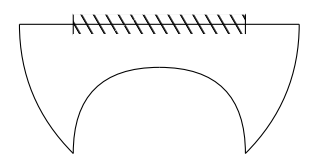

E

Figura 3.9: Tensões cisalhantes durante o ciclo de carregamento mostrado na Figura 3.8 
Posteriormente, é feita a suposição de que a carga tangencial foi reduzida infinitesimalmente do valor máximo, situação ilustrada pelo ponto $B$ (Fig. 3.8). As tensões cisalhantes também tem uma redução infinitesimal e o deslocamento tangencial cai. Neste, ponto a direção do movimento e as tensões cisalhantes existentes criam um estado de total adesão em todo o contato. A medida que a carga diminui (Ponto $C$ ), deslizamentos reversos surgem nos limites da largura de contato. O comportamento das tensões cisalhantes nesses fenômenos pode ser visto na Fig. 3.9 .

Dentro das novas zonas de adesão as tensões cisalhantes terão mudado de direção, de $f p(x) \sqrt{1-\left(\frac{x}{a}\right)^{2}}$ para $-f p(x) \sqrt{1-\left(\frac{x}{a}\right)^{2}}$. De forma análoga, pode-se deduzir que a pertubação necessária para evitar escorregamento na nova zona de adesão, $c^{\prime}$, é dada por:

$$
q^{\prime \prime}(x)=2 f p_{0} \frac{c^{\prime}}{a} \sqrt{1-\left(\frac{x}{c^{\prime}}\right)^{2}}
$$

O fator apresentado na Eq. (3.27) deve cancelar o deslocamento relativo quando as tensões da zona de deslizamento variam $2 f p_{0} \sqrt{1-\left(\frac{x}{a}\right)^{2}}$ ao invés de $f p_{0} \sqrt{1-\left(\frac{x}{a}\right)^{2}}$ como no carregamento monotônico. A tabela apresenta as distribuição de tensões cisalhantes para cada região na fase de descarregamento.

Tabela 3.2: Tensões superficiais cisalhantes para cada região durante a variação do carregamento tangencial com o tempo.

\begin{tabular}{cc}
\hline$q(x) / f p_{0}$ & Zona de Aplicação \\
$-\sqrt{1-\left(\frac{x}{a}\right)^{2}}$ & $c^{\prime}<|x| \leq a$ \\
$-\sqrt{1-\left(\frac{x}{a}\right)^{2}}+2 \frac{c^{\prime}}{a} \sqrt{1-\left(\frac{x}{c^{\prime}}\right)^{2}}$ & $c<|x| \leq c^{\prime}$ \\
$-\sqrt{1-\left(\frac{x}{a}\right)^{2}}+2 \frac{c^{\prime}}{a} \sqrt{1-\left(\frac{x}{c^{\prime}}\right)^{2}}-\frac{c}{a} \sqrt{1-\left(\frac{x}{c}\right)^{2}}$ & $|x| \leq c$ \\
\hline
\end{tabular}

O tamanho da nova zona de adesão é calculado a partir da condição de equilíbrio, resultando em:

$$
\frac{c^{\prime}}{a}=\sqrt{1-\left|\frac{Q_{\max }-Q(t)}{2 f P}\right|}
$$

A Figura 3.10 dá uma visão mais clara da variação das tensões cisalhantes no carregamento cíclico. A medida que $Q$ diminui com o tempo do seu valor máximo para o valor mínimo, é perceptível o aparecimento dos deslizamentos reversos e que as distribuições de tensão para $Q_{\text {máx }}$ e $Q_{\text {min }}$ são iguais em módulo. É notável que tanto na Fig. 3.9 quanto 
na Fig. 3.10, a remoção total da carga, ponto $D$ (Fig. 3.8), não resulta em tensões cisalhantes nulas, mas sim, em equilíbrio. Isso significa que a distribuição de tensões ao longo do tempo não é linear e, por consequência, tanto as tensões de cisalhamento quanto as tensões e deformações dos corpos em contato dependem do histórico de carregamento.

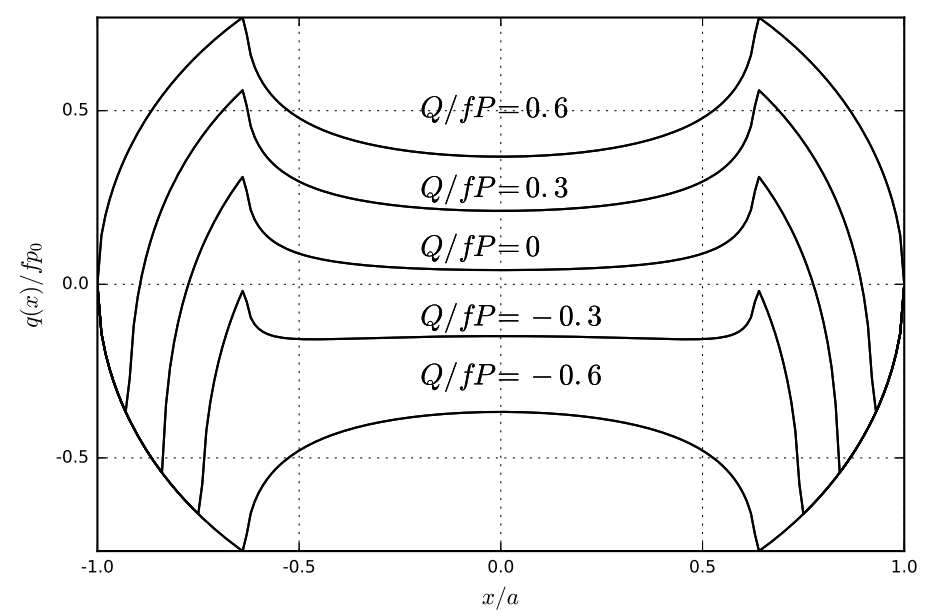

Figura 3.10: Tensões cisalhantes superficiais durante um carregamento cíclico, com $Q_{\text {máx }} / f P=0.6$

\subsubsection{Efeito da Carga Remota}

Habitualmente, componentes mecânicos submetidos às condições de fretting sofrem também ação de uma carga remota de fadiga ou bulk stress, como na Fig. 3.11 .

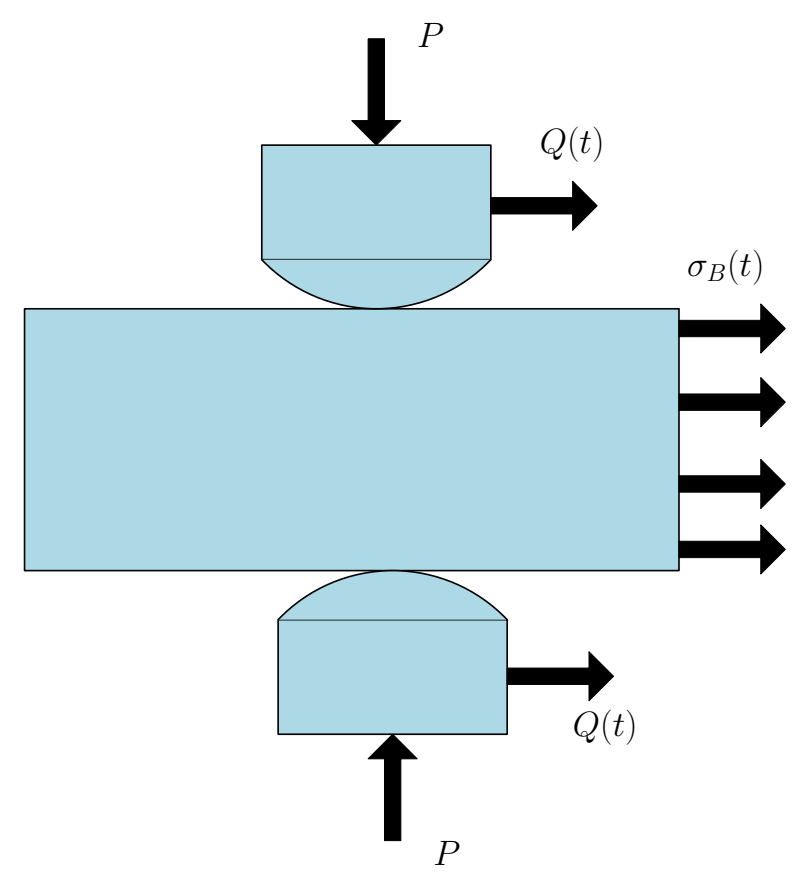

Figura 3.11: Configuração típica de aplicações de carga em fadiga por fretting

A aplicação da tensão remota de fadiga $\sigma_{B}$ se dá, geralmente, em fase com a carga tangencial. Consequência disso é o deslocamento da zona de adesão, nas fases de carregamento 
e descarregamento da força tangencial. Um fator de deslocamento da zona de adesão, e, é feito de maneira semelhante à $c$, onde:

$$
\begin{gathered}
\frac{e}{a}=\frac{\sigma_{B}}{4 f p_{0}} \\
\frac{e^{\prime}(t)}{a}=\frac{\sigma_{B}-\sigma_{B}(t)}{8 f p_{0}}
\end{gathered}
$$

A Equação (3.29) é válida para os momentos em que a carga tangencial tem seu módulo máximo, e a zona de adesão passa a ser $|x-e| \leq c$. Já a Eq. (3.30) é válida para os momento de carregamento e descarregamento e a aderência do contato é presente na região $\left|x-e^{\prime}\right| \leq c$. Esta solução analítica é valida apenas para valores limitados de $\sigma_{B}$, pois não deve haver escorregamento reverso na zona de contato, ou seja, $e+c^{\prime} \leq a$. Assim:

$$
\sigma_{B} \leq 4 f p_{0}\left(1-\sqrt{1-\frac{Q}{f P}}\right)
$$

A Figura 3.12 ilustra as tensões cisalhantes com a presença de carga de fadiga e a variação da zona de adesão. Para cargas remotas superiores, existe a necessidade de técnicas numéricas para obter a distribuição de tensões cisalhantes.

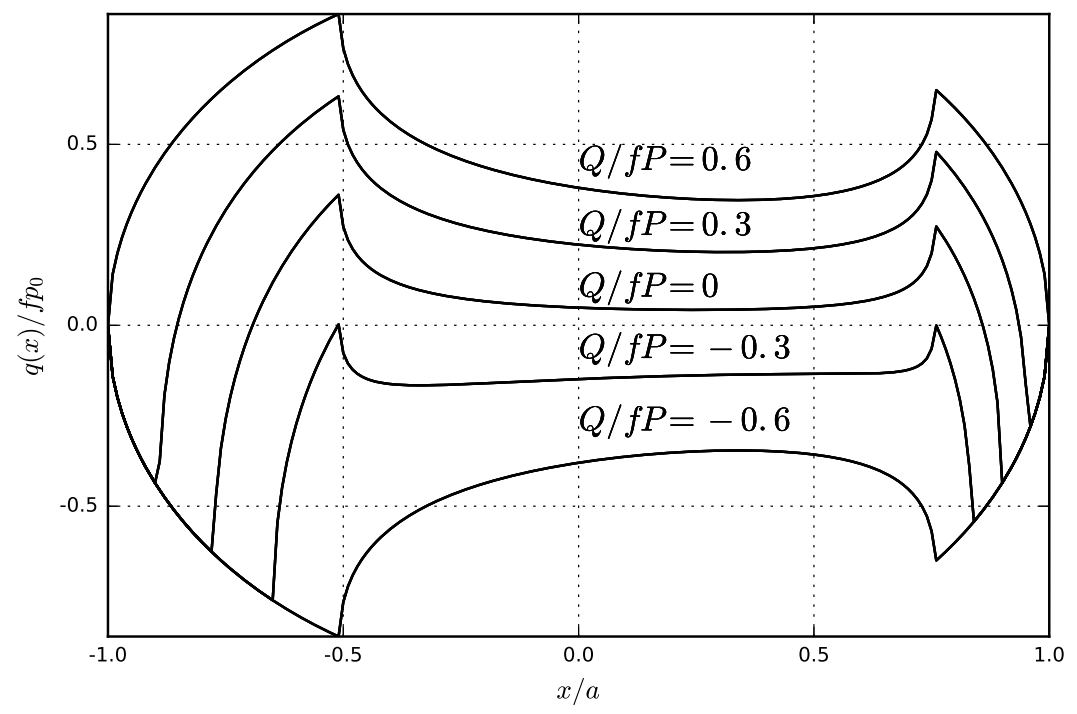

Figura 3.12: Carregamento cíclico com carga de fadiga em fase com a carga tangencial, com $Q_{\text {máx }} / f P=0.6$ e $\sigma_{B} / f p_{0}=0.5$ 


\section{Capítulo 4}

\section{O Método dos Elementos de Contorno}

\subsection{Equação Integral de Contorno}

A equação integral de contorno é obtida através da utilização do teorema de reciprocidade da teoria da elasticidade, em conjunto com uma solução conhecida como solução fundamental da equação governante para uma carga discreta num corpo infinito.

O teorema de reciprocidade pode ser enunciado da seguinte forma:

"Se dois estados de equilíbrio distintos $\left(u_{i}^{*}, \sigma_{i j}^{*}, b_{i}^{*}\right)$ e $\left(u_{i}, \sigma_{i j}, b_{i}\right)$ existir em uma região de $\Omega^{+}$na superfície limitada por $\Gamma^{+}$, o trabalho realizado pelas forças de superfície e forças de corpo do primeiro sistema sobre os deslocamentos do segundo é igual ao trabalho realizado pelas forças do segundo sistema nos deslocamentos do primeiro."

O teorema pode ser provado usando o teorema da divergência e pode ser escrito como:

$$
\int_{\Gamma} u_{i} \sigma_{i j}^{*} n_{j} d \Gamma+\int_{\Omega} u_{i} b_{i}^{*} d \Omega=\int_{\Gamma} u_{i}^{*} \sigma_{i j} n_{j} d \Gamma+\int_{\Omega} u_{i}^{*} b_{i} d \Omega
$$

onde $u_{i}, \sigma_{i j}$ e $b_{i}$, são os deslocamentos, as tensões e as forças de corpo, e $n_{j}$, são os componentes do vetor normal unitário, apontando para fora do domínio $\Omega$. O domínio $\Omega^{*}$ é denotado por um domínio infinito e $\Omega$ é um domínio finito dentro de $\Omega^{*}$ que tem um contorno $\Gamma$. As mesmas propriedades do material são assumidas por ambos os domínios. As forças de superfície $t_{i}$ no contorno $\Gamma$ são definidas por:

$$
t_{i}=\sigma_{i j} n_{j}
$$

Desta forma, a Eq. (4.1) pode ser escrita como:

$$
\int_{\Omega}\left(u_{i} b_{i}^{*}-u_{i}^{*} b_{i}\right) d \Omega=\int_{\Gamma}\left(u_{i}^{*} t_{i}-u_{i} t_{i}^{*}\right) d \Gamma
$$

Os vetores de deslocamento $u_{i}^{*}$, as forças de superfície $t_{i}^{*}$ e as força do corpo $b_{i}^{*}$ na Eq. 4.3. 
são escolhidos para ser a solução conhecida da equação de Navier devido a uma força pontual unitária aplicada ao corpo, isto é:

$$
\mu u_{i, k k}^{*}+\frac{\mu}{1-2 \nu} u_{k, k i}^{*}+\Delta\left(X-X^{\prime}\right) e_{i}=0
$$

onde $\Delta\left(X-X^{\prime}\right)$ é a função delta de Dirac, $X \epsilon \Omega^{*}$ é o ponto de carga singular e $X \epsilon$ $\Omega^{*}$ é o ponto campo. O componente do vetor unitário $e_{i}$ na Eq. (4.4) corresponde a uma força positiva unitária aplicada em $X^{\prime}$ na direção $i$. A função delta de Dirac tem a seguinte propriedade:

$$
\int_{\Omega^{*}} g(X) \Delta\left(X-X^{\prime}\right) d \Omega(X)=g\left(X^{\prime}\right)
$$

O campo de deslocamento e forças de superfície que correspondem à solução podem ser escritos como:

$$
u_{i}^{*}=U_{j}^{*} \delta_{i j}=U_{i j}\left(X^{\prime}, X\right) e_{j}
$$

e

$$
t_{i}^{*}=T_{j}^{*} \delta_{i j}=T_{i j}\left(X^{\prime}, X\right) e_{j}
$$

onde $\delta_{i j}$ é a função delta Kroneker. $U_{i j}$ e $T_{i j}$ são as soluções fundamentais dos deslocamentos e forças de superfícies, na direção $j$ no ponto $X$ devido a uma força pontual atuando na direção $i$ em $X^{\prime}$.

A componente de força de corpo $b_{i}^{*}$ (força por unidade de volume) corresponde a uma força pontual e é dada por:

$$
b_{i}^{*}=\Delta\left(X^{\prime}, X\right) e_{i}
$$

Substituindo $b_{i}^{*}$ na função de delta de Dirac, na Eq. (4.3) e especificando $X$ como a variável de integração, obtém-se a seguinte equação considerando a força unitária atuando na direção $i$ :

$$
\begin{gathered}
\int_{\Omega}\left\{u_{j}(X) \Delta_{i j}\left(X^{\prime}-X\right)-U_{i j}\left(X^{\prime}, X\right) b_{j}\left(X^{\prime}\right)\right\} d \Omega(X)= \\
\int_{\Gamma}\left\{U_{i j}\left(X^{\prime}, X\right) t_{j}(X)-T_{i j}\left(X^{\prime}, X\right) u_{j}(X)\right\} d \Gamma(X)
\end{gathered}
$$

Agora, usando as propriedades da função delta de Dirac, a Eq. (4.9) resulta em:

$$
\begin{aligned}
u_{i}\left(X^{\prime}\right)= & \int_{\Gamma} U_{i j}\left(X^{\prime}-x\right) t_{j}(x) d \Gamma(x)-\int_{\Gamma} T_{i j}\left(X^{\prime}-x\right) u_{j}(x) d \Gamma(x)+ \\
& \int_{\Omega} U_{i j}\left(X^{\prime}, X\right) b_{j}(X) d \Omega(X)
\end{aligned}
$$

onde $x^{\prime}, x \in \Gamma$ e $X^{\prime}, X \in \Omega$. Esta é a conhecida função Somigliana para deslocamentos, $u_{i}$ é uma representação contínua para os deslocamentos em qualquer ponto interior $X^{\prime}$ no domínio $\Omega$. O campo de tensão ao longo do corpo pode ser obtido através das derivadas da 
Eq. 4.10 como a seguir:

$$
\begin{aligned}
u_{i, k}\left(X^{\prime}\right)= & \int_{\Gamma} U_{i j, k}\left(X^{\prime}-x\right) t_{j}(x) d \Gamma(x)-\int_{\Gamma} T_{i j, k}\left(X^{\prime}-x\right) u_{j}(x) d \Gamma(x)+ \\
& \int_{\Omega} U_{i j, k}\left(X^{\prime}, X\right) b_{j}(X) d \Omega(X)
\end{aligned}
$$

A função Somigliana para tensões num ponto interior é obtida por substituição da Eq. 4.11) na lei de Hooke (2.12), da qual obtém-se:

$$
\begin{aligned}
\sigma_{i j}\left(\mathbf{X}^{\prime}\right)= & \int_{\Gamma} U_{i j k}\left(X^{\prime}-x\right) t_{k}(x) d \Gamma(x)-\int_{\Gamma} T_{i j k}\left(X^{\prime}-x\right) u_{k}(x) d \Gamma(x)+ \\
& \int_{\Omega} U_{i j k}\left(X^{\prime}, X\right) b_{k}(X) d \Omega(X)
\end{aligned}
$$

$U_{i j k}$ e $T_{i j k}$ são combinações lineares das derivadas das soluções fundamentais $U_{i j}$ e $T_{i j}$ e serão dadas na próxima seção.

\subsection{Solução Fundamental}

Para um problema no estado plano de deformação, as soluções fundamentais para deslocamentos $U_{i j}\left(X^{\prime}, x\right)$ e forças de superfície $T_{i j}\left(X^{\prime}, x\right)$, definidas na Eq. (4.5), são dadas por:

$$
U_{i j}\left(X^{\prime}, x\right)=\frac{1}{8 \pi G\left(1-\nu^{*}\right)}\left\{\left(3-4 \nu^{*}\right) \ln \left(\frac{1}{r}\right) \delta_{i j}+r_{, i} r_{, j}\right\}
$$

$\mathrm{e}$

$$
T_{i j}\left(X^{\prime}, x\right)=\frac{-1}{4 \pi\left(1-\nu^{*}\right) r}\left\{\left[\left(1-2 \nu^{*}\right) \delta_{i j}+2 r_{, i} r_{, j}\right] \frac{\partial r}{\partial n}-\left(1-2 \nu^{*}\right)\left(r_{, i} n_{j}-r_{, j} n_{i}\right)\right\}
$$

O campo de deformação fundamental $U_{k i j}\left(X^{\prime}, X\right)$ e o campo de tensão $T_{k i j}\left(X^{\prime}, X\right)$, como apresentado na Eq. 4.12, são dados por:

$$
U_{k i j}\left(X^{\prime}, X\right)=\frac{1}{4 \pi\left(1-\nu^{*}\right) r}\left\{\left(1-2 \nu^{*}\right)\left(r_{, j} \delta_{k i}+r_{, i} \delta_{k j}+r_{, k} \delta_{i j}\right)+2 r_{, i} r_{, j} r_{, k}\right\}
$$

e

$$
\begin{aligned}
T_{k i j}\left(X^{\prime}, X\right) & =\frac{\mu}{2 \pi\left(1-\nu^{*}\right) r^{2}}\left\{2 \frac{\partial r}{\partial n}\left[\left(1-2 \nu^{*}\right) \delta_{i j} r_{, k}+\nu^{*}\left(r_{, j} \delta_{i k}+r_{, i} \delta_{j k}\right)-4 r_{, i} r_{, j} r_{, k}\right]\right. \\
& +2 \nu^{*}\left(n_{i} r_{, j} r_{, k}+n_{j} r_{, i} r_{, k}\right)+\left(1-2 \nu^{*}\right)\left(2 n_{k} r_{, i} r_{, j}+n_{j} \delta_{i k}+n_{i} \delta_{j k}\right) \\
& \left.-\left(1-4 \nu^{*}\right) n_{k} \delta_{i j}\right\}, \quad i, j=1,2
\end{aligned}
$$


Nestas equações, $\delta_{i j}$ denota o delta de Kronecker, $r\left(X^{\prime}, X\right)$ representa a distância real entre o ponto fonte $x^{\prime}$ e o ponto campo $x$, que é dada por:

$$
r=\left|X-X^{\prime}\right| \quad \text { e } \quad r_{, i}=\frac{\partial r}{\partial x_{i}}
$$

As soluções fundamentais para o estado de tensão plana podem ser obtidas pela seguinte substituição da relação modificada de Poisson e módulo de Young:

$$
\begin{gathered}
\nu^{*}=\frac{\nu}{1+\nu} \\
E^{*}=E\left[1-\frac{\nu^{* 2}}{\left(1+\nu^{*}\right)^{2}}\right]
\end{gathered}
$$

\subsection{A equação integral de contorno}

A equação integral de contorno é obtida por um processo de limite, fazendo um ponto $X^{\prime}$ no interior do domínio $\Omega$ tender a um ponto $x^{\prime}$ no contorno $\Gamma$. Este processo pode ser demonstrado pela Figura 4.1 e a Eq. (4.9) pode ser escrita como:

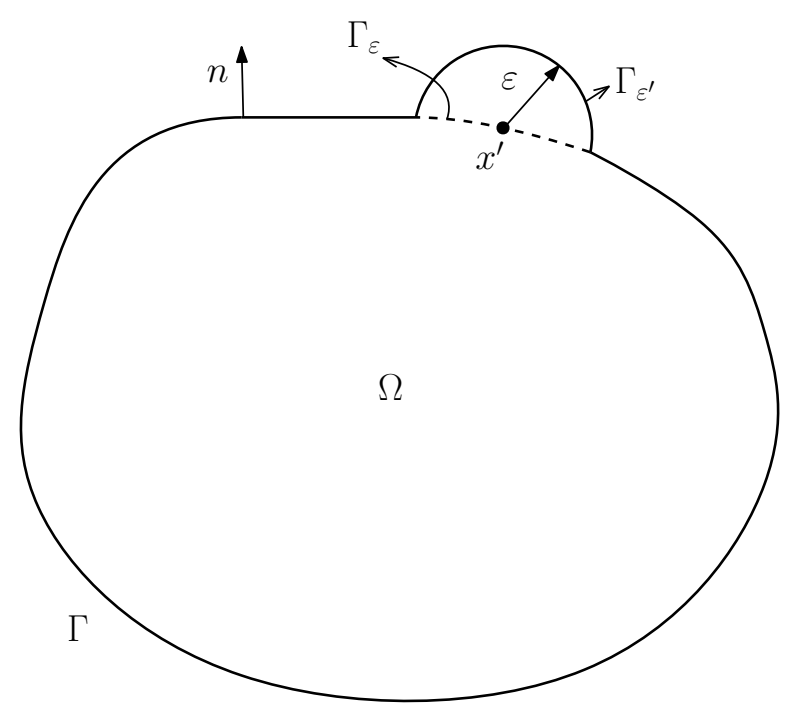

Figura 4.1: O ponto fonte $x^{\prime}$ pertence ao contorno.

$$
\begin{aligned}
u_{i}\left(X^{\prime}\right)= & \int_{\Gamma-\Gamma_{e}-\Gamma_{e}^{\prime}} U_{i j}\left(X^{\prime}, x\right) t_{j}(x) d \Gamma(x)-\int_{\Gamma-\Gamma_{e}-\Gamma_{e}^{\prime}} T_{i j}\left(X^{\prime}, x\right) u_{j}(x) d \Gamma(x)+ \\
& \int_{\Gamma-\Gamma_{e}-\Gamma_{e}^{\prime}} U_{i j}\left(X^{\prime}, X\right) b_{j}(X) d \Omega(X)
\end{aligned}
$$

onde o contorno total é definido como:

$$
\Gamma^{\prime}=\left(\Gamma-\Gamma_{\varepsilon}^{\prime}\right)+\Gamma_{\varepsilon}^{\prime}
$$


$\Gamma_{\varepsilon}^{\prime}$ representa o contorno de um semicírculo de raio $\varepsilon, \Gamma_{\varepsilon}^{\prime}$ tende a $\Gamma_{\varepsilon}$ quando $\varepsilon \rightarrow 0$. Tomando o limite de $\varepsilon \rightarrow 0$, a formulação direta de elementos contornos é obtida como:

$$
\begin{aligned}
C_{i j}\left(x^{\prime}\right) u_{j}\left(x^{\prime}\right)= & \int_{\Gamma} U_{i j}\left(x^{\prime}, x\right) t_{j}(x) d \Gamma(x)-\int_{\Gamma} T_{i j}\left(x^{\prime}, x\right) u_{j}(x) d \Gamma(x)+ \\
& \int_{\Omega} U_{i j}\left(x^{\prime}, X\right) b_{j}(X) d \Omega(X) d \Omega(x)
\end{aligned}
$$

onde

$$
C_{i j}\left(x^{\prime}\right)=\delta_{i j}+\lim _{\varepsilon \rightarrow 0}\left\{\int_{\Gamma_{\varepsilon}} T_{i j}\left(x^{\prime}, x\right) u_{j}(x)\right\}
$$

A Equação 4.22 representa a formulação direta do método de elementos de contorno o qual relaciona deslocamentos e forças de superfície no contorno. Esta equação integral de contorno para um ponto geral sobre o contorno na ausência de forças do corpo $b_{j}$ pode ser escrita como:

$$
C_{i j}\left(x^{\prime}\right) u_{j}\left(x^{\prime}\right)+\int_{\Gamma} T_{i j}\left(x^{\prime}, x\right) u_{j}(x) d \Gamma(x)=\int_{\Gamma} U_{i j}\left(x^{\prime}, x\right) t_{j}(x) d \Gamma(x)
$$

onde $C_{i j}\left(X^{\prime}\right)=\delta_{i j}$ quando o ponto $x^{\prime}$ está dentro do domínio $\Omega$. A avaliação de $C_{i j}\left(x^{\prime}\right)$ é mais complicada quando $x^{\prime}$ está no contorno $\Gamma$, mas de um modo geral, tem-se:

$$
C_{i j}=\left\{\begin{array}{lll}
\delta_{i j}, & \text { se } & \mathbf{X}^{\prime} \in \text { ao domínio } \\
\frac{\theta_{i n t}}{2 \pi} \delta_{i j}, & \text { se } & \mathbf{X}^{\prime} \in \text { ao contorno } \\
0, & \text { se } & \mathbf{X}^{\prime} \notin \text { ao domínio ou ao contorno }
\end{array}\right.
$$

onde $\theta_{\text {int }}$ é o ângulo interno do contorno $\Gamma$ no ponto $\mathbf{X}^{\prime}$ (veja Figura 4.2).

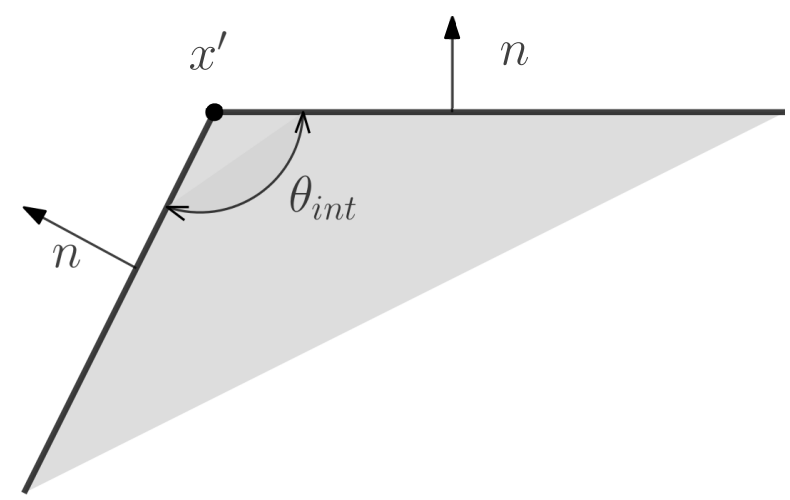

Figura 4.2: Ângulo interno no contorno do componente.

Quando o ponto fonte encontra-se em ponto suave do contorno, isto é, não é um canto, tem-se:

$$
C_{i j}=\frac{1}{2} \delta_{i j}
$$


Baseado na formulação apresentada, obtém-se a equação:

$$
C_{i j}\left(x^{\prime}\right) u_{j}\left(x^{\prime}\right)+\int_{\Gamma} T_{i j}\left(x^{\prime}, x\right) u_{j}(x) d \Gamma(x)=\int_{\Gamma} U_{i j}\left(x^{\prime}, x\right) t_{j}(x) d \Gamma(x)
$$

Dividindo o contorno $\Gamma$ em $N e$ elementos de contorno, a Equação 4.27), de outra forma, pode ser escrita como:

$$
C_{i j} u_{j}(d)+\sum_{j=1}^{N e} \int_{\Gamma_{j}} T_{i k}^{*} u_{i} d \Gamma_{j}=\sum_{j=1}^{N e} \int_{\Gamma_{j}} U_{i k}^{*} t_{j} d \Gamma_{j}
$$

Essa equação é aplicada em cada um dos nós do elemento de tal forma que a equação integral de contorno é transformada em um sistema linear de equações algébricas:

$$
\mathbf{H u}=\mathbf{G t}
$$

onde os tensores de segunda ordem $\mathbf{H}$ e $\mathbf{G}$ contém as integrais das soluções fundamentais de forças de superfície $T_{i j}$ e de deslocamentos $U_{i j}$, e os vetores $\mathbf{t}$ e $\mathbf{u}$ contém todas as forças de superfícies e deslocamentos conhecidos ou não. Através de algumas manipulações algébricas podemos isolar as incógnitas em um vetor $\mathbf{x}$ de forma que o sistema (4.29) possa ser representado por:

$$
\mathbf{A x}=\mathbf{b}
$$

onde uma solução única pode ser obtida.

\subsection{Elementos de contorno quadráticos contínuos}

Na discretização utilizando elementos de contorno quadráticos contínuos, a geometria é aproximada por uma função quadrática ao longo de cada elemento, sendo necessários três pontos nodais por elemento conforme mostrado na Figura (4.3).

Assim, os deslocamento e as forças de superfícies são aproximados da seguinte forma:

$$
\mathbf{u}=\left\{\begin{array}{l}
u_{1} \\
u_{2} \\
u_{3}
\end{array}\right\}=\left[\begin{array}{cccccc}
N^{(1)} & 0 & N^{(2)} & 0 & N^{(3)} & 0 \\
0 & N^{(1)} & 0 & N^{(2)} & 0 & N^{(3)}
\end{array}\right]\left\{\begin{array}{c}
u_{1}^{(1)} \\
u_{2}^{(1)} \\
u_{1}^{(2)} \\
u_{2}^{(2)} \\
u_{1}^{(3)} \\
u_{2}^{(3)}
\end{array}\right\}=\mathbf{N u}^{(n)}
$$




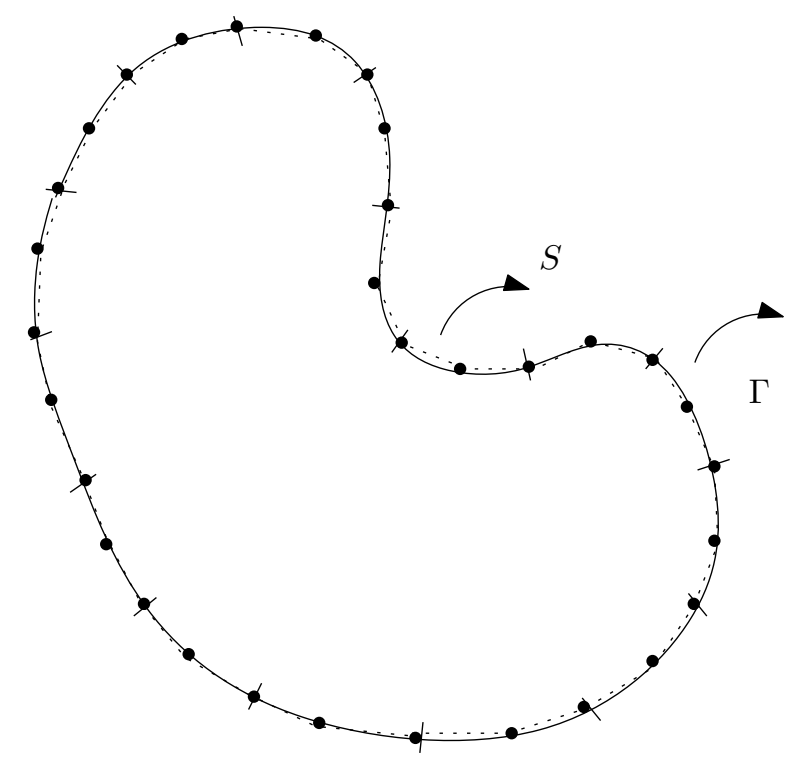

Figura 4.3: Elementos quadráticos contínuos.

$\mathbf{t}=\left\{\begin{array}{c}t_{1} \\ t_{2} \\ t_{3}\end{array}\right\}=\left[\begin{array}{cccccc}N^{(1)} & 0 & N^{(2)} & 0 & N^{(3)} & 0 \\ 0 & N^{(1)} & 0 & N^{(2)} & 0 & N^{(3)}\end{array}\right]\left\{\begin{array}{c}t_{1}^{(1)} \\ t_{2}^{(1)} \\ t_{1}^{(2)} \\ t_{2}^{(2)} \\ t_{1}^{(3)} \\ t_{2}^{(3)}\end{array}\right\}=\mathbf{N t}^{(n)}$

onde $u_{i}^{(n)}$ e $t_{i}^{(n)}$ são os valores nodais de deslocamentos e forças de superfícies, respectivamente, e $N^{(i)}$ são as funções de forma quadráticas definidas por:

$$
\begin{aligned}
& N^{(1)}=\frac{1}{2} \xi(\xi-1) \\
& N^{(2)}=1-\xi^{2} \\
& N^{(3)}=\frac{1}{2} \xi(\xi+1)
\end{aligned}
$$

onde $\xi$ representa uma coordenada local do elemento, ilustrada na Figura 4.4

Da mesma forma que os deslocamentos e forças de superfície, a geometria do problema também é aproximada por elementos de contorno quadráticos contínuos: 


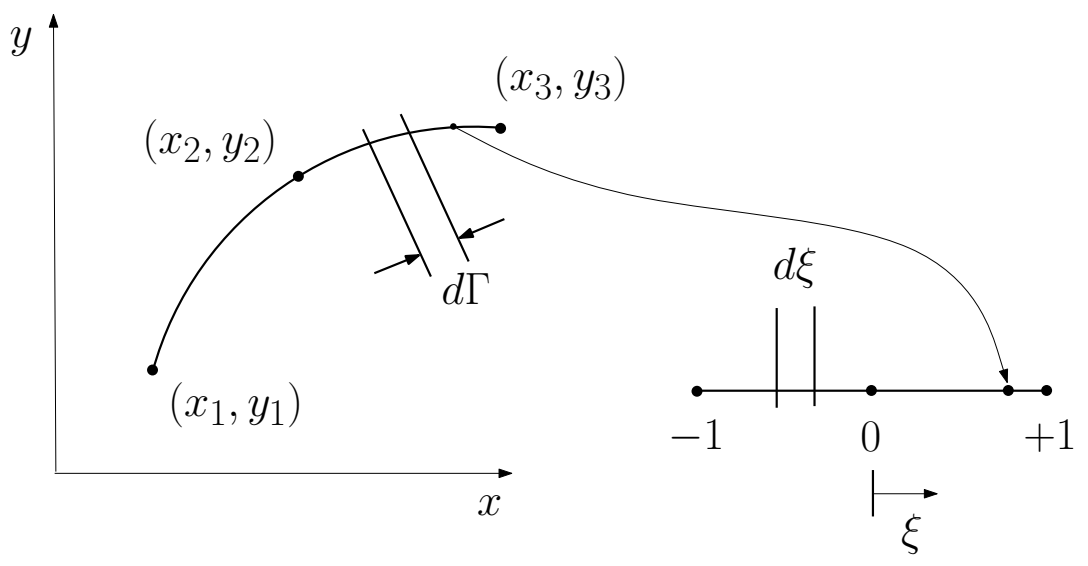

Figura 4.4: Coordenada local $\xi$ para elementos quadráticos contínuos.

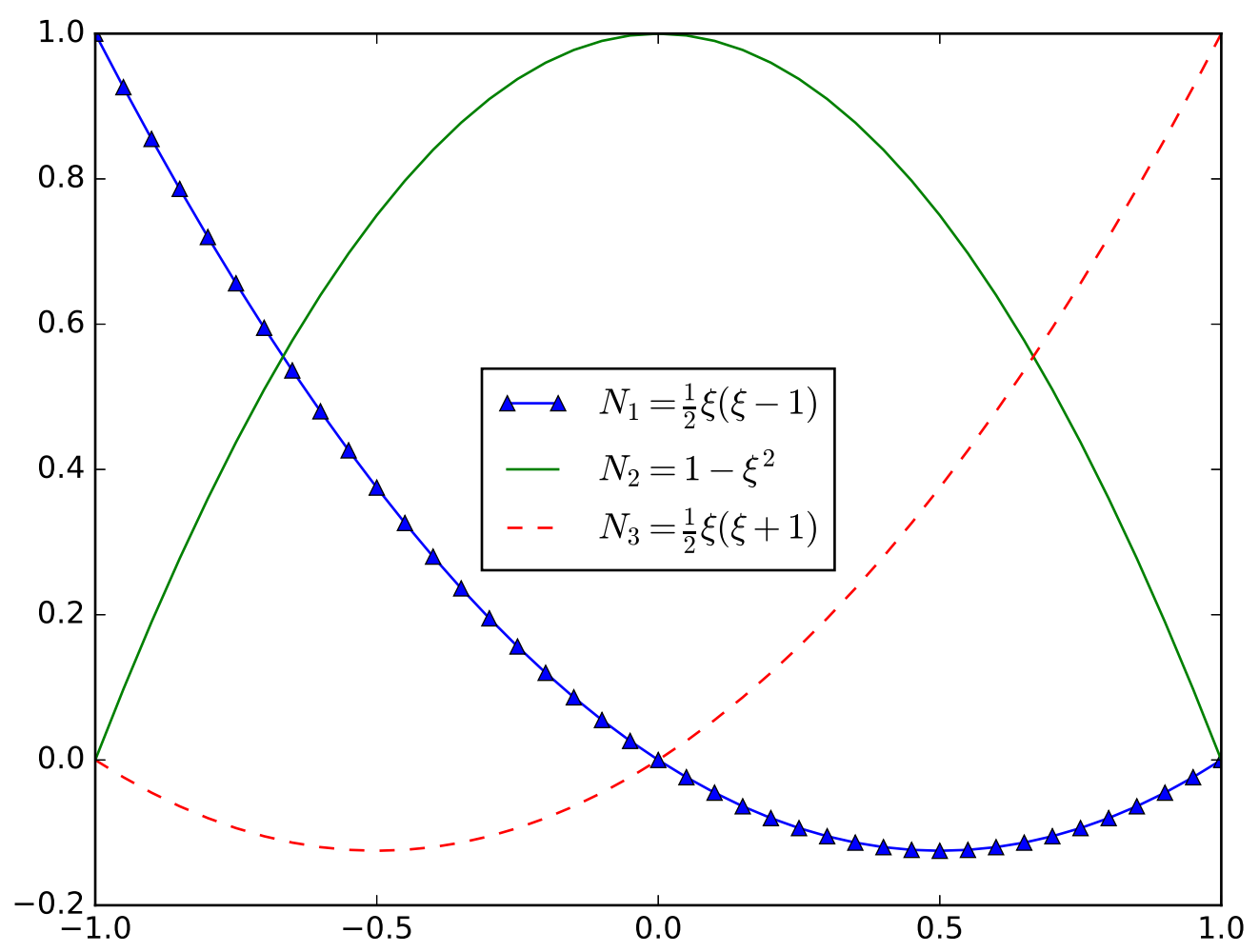

Figura 4.5: Funções de forma de elementos quadráticos contínuos. 


$$
\left\{\begin{array}{l}
x_{1} \\
x_{2} \\
x_{3}
\end{array}\right\}=\left[\begin{array}{cccccc}
N_{1} & 0 & N_{2} & 0 & N_{3} & 0 \\
0 & N_{1} & 0 & N_{2} & 0 & N_{3}
\end{array}\right]\left\{\begin{array}{l}
x_{1}^{1} \\
x_{2}^{1} \\
x_{1}^{2} \\
x_{2}^{2} \\
x_{1}^{3} \\
x_{2}^{3}
\end{array}\right\}
$$

Considere que o domínio tenha sido dividido em $\mathrm{Ne}$ elementos de contorno. Substituindo as Eq. 4.31, 4.32) e 4.36 na Eq. 4.28, tem-se:

$$
c^{l} u^{l}+\sum_{j=1}^{N e}\left\{\int_{\Gamma_{j}} \mathbf{T} \mathbf{N} d \Gamma\right\} u^{j}=\sum_{j=1}^{N e}\left\{\int_{\Gamma_{j}} \mathbf{U} \mathbf{N} d \Gamma\right\} t^{j}
$$

Chamando

$$
\int_{\Gamma_{j}} \mathbf{U N} d \Gamma=\mathbf{G}
$$

$\mathrm{e}$

$$
\int_{\Gamma_{j}} \mathbf{T N} d \Gamma=\mathbf{H}
$$

tem-se

$$
\sum_{j=1}^{N} \mathbf{H}^{l j} \mathbf{u}^{j}=\sum_{j=1}^{N} \mathbf{G}^{l j} \mathbf{t}^{j}
$$

ou, na forma matricial

$$
\mathbf{H u}=\mathbf{G t}
$$

\subsubsection{Integração das matrizes $\mathrm{H}$ e $\mathrm{G}$ quando o ponto fonte não pertence ao elemento}

A integração dos termos das matrizes $\mathbf{H}$ e $\mathbf{G}$ quando o ponto fonte não pertence aos elementos é uma integração regular que pode ser realizada usando, por exemplo, quadratura de Gauss. Esta integração é descrita a seguir: 


$$
\begin{aligned}
\mathbf{H}^{(j)} & =\int_{\Gamma_{j}} \mathbf{T}_{l k} \mathbf{N}^{(j)} d \Gamma=\int_{-1}^{1} \mathbf{T}_{l k} \mathbf{N}^{(j)}|J| d \xi \\
\mathbf{G}^{(j)} & =\int_{\Gamma_{j}} \mathbf{U}_{l k} \mathbf{N}^{(j)} d \Gamma=\int_{-1}^{1} \mathbf{U}_{l k} \mathbf{N}^{(j)}|J| d \xi
\end{aligned}
$$

onde $|J|$ representa o módulo do jacobiano da transformação $\left(\mathbf{X}_{1}, \mathbf{X}_{2}\right) \rightarrow \xi$ :

$$
|J|=\frac{d \Gamma}{d \xi}=\left\{\left(\frac{d x_{1}}{d \xi}\right)^{2}+\left(\frac{d x_{2}}{d \xi}\right)^{2}\right\}^{1 / 2}
$$

onde $d x_{1} / d \xi$ e $d x_{2} / d \xi$ são obtidos derivando-se as equações 4.32 em relação a $\xi$.

Integrais singulares da ordem $O(\ln r)$ podem ser avaliadas eficientemente pela quadratura de Gauss com uma transformação de variáveis cúbicas que cancela exatamente a singularidade logarítmica. Uma outra possibilidade é o uso da quadratura logarítmica de Gauss. De acordo com este método, os termos incluindo singularidades logarítmicas podem ser integrados por:

$$
I=\int_{0}^{1} \ln \left(\frac{1}{\xi}\right) f(\xi) d \xi \cong \sum_{i=1}^{N} w_{i} f(\xi),
$$

onde $N$ é o número de pontos de Gauss logarítmico.

Neste trabalho, os termos não singulares das matrizes H e G são integrados utilizando-se quadratura de Gauss padrão com 10 pontos de integração. Os termos singulares de $\mathrm{G}$ são do tipo $\ln (r)$ sendo integrados usando quadratura logarítmica de Gauss com 10 pontos de integração. Já os termos singulares de $\mathbf{H}$ são do tipo $1 / r$ e precisam ser calculados no sentido do valor principal de Cauchy. Uma maneira bastante simples de se tratar esta singularidade é através de considerações de corpos rígidos. Assumindo que um corpo rígido tenha todos os seus pontos do contorno deslocados de um valor unitário e que não existam forças de corpo $\left(b_{i}=0\right)$ na direção de um dos eixos de coordenadas, as forças de superfície em qualquer ponto do contorno deste corpo devem ser zero. Desta forma, a Equação (4.41) torna-se:

$$
\mathbf{H v}^{q}=0
$$

onde $\mathbf{v}^{q}$ é um vetor que para todos os nós tem deslocamentos unitários ao longo da direção $q$ e zero na outra direção. Para satisfazer a Eq. (4.46) tem-se:

$$
H_{i i}=-\sum_{j=1}^{N e} H_{i j} \quad j \neq i
$$

sendo $j$ par ou ímpar. 
O termo da diagonal da matriz $\mathbf{H}$ é igual ao negativo da soma de todos os outros termos fora da diagonal correspondentes ao grau de liberdade em consideração.

\subsection{Tensões no contorno}

Para se calcular o tensor de tensões em um dado nó do contorno, considere um nó em que as direções dos vetores tangente e normal ao contorno não coincidam com as direções dos eixos geométricos (Fig. 4.6). Neste nó é criado um novo sistema de referência $x_{1}^{\prime} x_{2}^{\prime}$ possuindo direções que coincidam com os vetores tangente e normal ao contorno neste nó. Escrevendo os deslocamentos e as forças de superfícies neste sistema local, tem-se:

$$
\begin{aligned}
u_{i}^{\prime} & =l_{i j} u_{j} \\
t_{i}^{\prime} & =l_{i j} t_{j}
\end{aligned}
$$

onde $l_{i j}$ são os cossenos diretores.

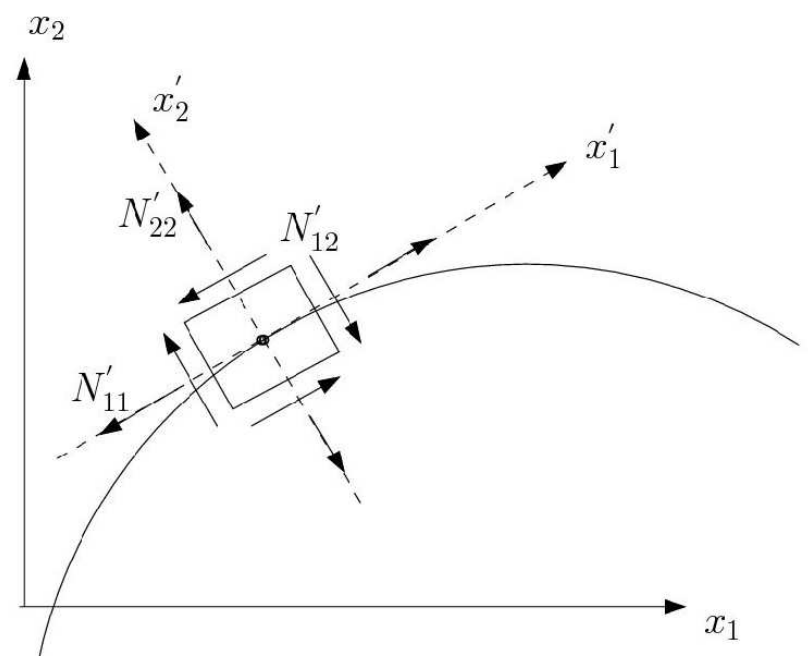

Figura 4.6: Tensões no contorno.

No sistema local tem-se a seguinte relação:

$$
\begin{aligned}
& \sigma_{22}^{\prime}=t_{2}^{\prime} \\
& \sigma_{12}^{\prime}=t_{1}^{\prime}
\end{aligned}
$$

A deformação $\varepsilon_{11}^{\prime}$ pode ser calculada, sabendo que: 


$$
\begin{aligned}
\varepsilon_{11}^{\prime} & =\frac{1}{2}\left(u_{1,1}^{\prime}+u_{1,1}^{\prime}\right)=u_{1,1}^{\prime} \\
u_{1,1}^{\prime} & =\frac{d u_{1}^{\prime}}{d x_{1}^{\prime}}=\frac{d u_{1}^{\prime}}{d \xi} \frac{d \xi}{d x_{1}^{\prime}}
\end{aligned}
$$

Usando geometria diferencial na Eq. (4.50), pode-se notar que a direção local $x_{1}^{\prime}$ é tangente ao comprimento infinitesimal de arco $d s$ dado por

$$
\begin{aligned}
d s=\sqrt{d{x_{1}^{\prime}}^{2}+d x_{2}^{\prime 2}} & =\sqrt{\left(\frac{d x_{1}^{\prime}}{d \xi}\right)^{2}+\left(\frac{d x_{2}^{\prime}}{d \xi}\right)^{2}} d \xi \\
\frac{d s}{d \xi} & =J
\end{aligned}
$$

Um pequeno movimento ao longo de $s$ corresponde a um pequeno movimento em $x_{1}^{\prime}$. Isto permite com que $x_{1}^{\prime}$ na Eq. (4.50) seja substituído pela Eq. (4.51), ou seja:

$$
\begin{aligned}
\varepsilon_{11}^{\prime} & =\frac{d u_{1}^{\prime}}{d \xi} \frac{d \xi}{d s} \\
\varepsilon_{11}^{\prime} & =\frac{d u_{1}^{\prime}}{d \xi} J^{-1}
\end{aligned}
$$

sendo

$$
\begin{aligned}
u_{1} & =\sum_{i=1}^{3} N^{(i)} u_{1}^{(i)} \\
\frac{d u_{1}}{d \xi} & =\sum_{n=1}^{3} \frac{d N^{(i)}}{d \xi} u_{1}^{(i)}
\end{aligned}
$$

onde $N^{(i)}$ são as funções de forma. Pode-se então obter a deformação

$$
\varepsilon_{11}^{\prime}=\sum_{n=1}^{3} \frac{d N^{(i)}}{d \xi} u_{1}^{(i)} J^{-1}
$$

Na relação tensão deformação dada por:

$$
\sigma_{i j}^{\prime}=\lambda \delta_{i j} \varepsilon_{k k}^{\prime}+G \varepsilon_{i j}^{\prime}
$$


tem-se três equações incógnitas $\sigma_{11}^{\prime}, \varepsilon_{22}^{\prime}, \varepsilon_{12}^{\prime}$, que agora podem então ser calculadas.

Por último, as tensões tem que ser escritas no referencial global $x_{1} x_{2}$, ou seja

$$
\left\{\begin{array}{l}
\sigma_{11} \\
\sigma_{22} \\
\sigma_{12}
\end{array}\right\}=\mathcal{R}^{-1}\left\{\begin{array}{l}
\sigma_{11}^{\prime} \\
\sigma_{22}^{\prime} \\
\sigma_{12}^{\prime}
\end{array}\right\}
$$

onde $\mathcal{R}$ é a matriz de transformação de coordenadas. 


\section{Capítulo 5}

\section{Modelagem Numérica}

\subsection{Modelo Discreto}

A formulação de contato a ser usada deriva da definição padrão de interação entre sólidos elastoplásticos (KIKUCHI; ODEN, 1988). Os dois corpos em contato são limitados por seus respectivos contornos que possuem duas regiões: a região de possível contato $\Gamma_{c}$ e a região livre $\Gamma_{n c}$ como na Fig. 5.1.

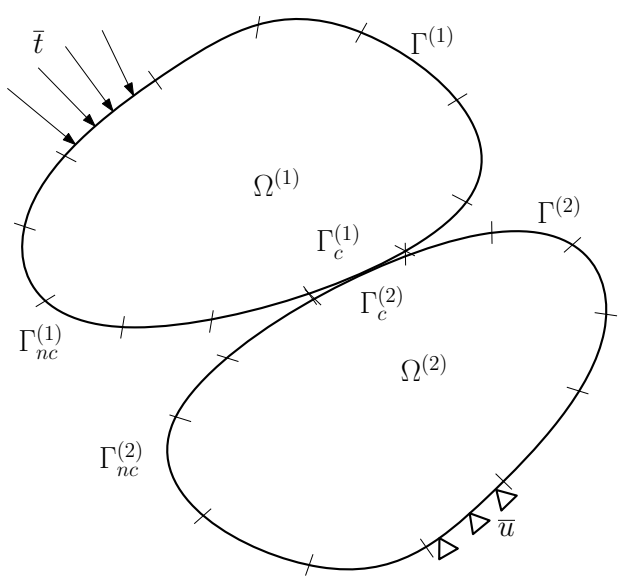

Figura 5.1: Dois corpos em contato.

Dentro da região de possível contato, qualquer modo de contato pode estar presente dependendo do tipo de carregamento. O método dos elementos de contorno é então aplicado para a determinação dos modos e de um valor quantitativo das variáveis de contato. Os comportamento elástico dos dois corpos, $\gamma=1,2$, ainda é regido pelas teoria elasticidade e uma equação de contorno pode ser deduzida para cada um deles. Em função de uma carga externa as forças de superfície e deslocamentos dos corpos são descritas da forma: 


$$
\begin{gathered}
C_{i j}^{\gamma} u_{j}^{\gamma}+\int_{\Gamma_{n c}^{\gamma}} T_{i j}^{\gamma} u_{j}^{\gamma} d \Gamma^{\gamma}+\int_{\Gamma_{c}^{\gamma}} T_{i j}^{\gamma} u_{j}^{\gamma} d \Gamma^{\gamma}= \\
\int_{\Gamma_{n c}^{\gamma}} U_{i j}^{\gamma} t_{j}^{\gamma} d \Gamma^{\gamma}+\int_{\Gamma_{c}^{\gamma}} U_{i j}^{\gamma} t_{j}^{\gamma} d \Gamma^{\gamma} \quad \forall, \gamma \in \Gamma .
\end{gathered}
$$

A Equação (5.1) pode ser levada ao domínio discreto da mesma forma que a Eq. (4.27):

$$
c_{i j}^{\gamma} u_{j}^{\gamma}+\sum_{n=1}^{N} H_{i j}^{n^{\gamma}} u_{j}^{n^{\gamma}}=\sum_{n=1}^{N} G_{i j}^{n^{\gamma}} t_{j}^{n^{\gamma}}
$$

onde $n$ é o numero de nós em $\gamma=1,2$. Essas equações são representadas matricialmente por:

$$
\mathbf{H}^{\gamma} \mathbf{u}^{\gamma}=\mathbf{G}^{\gamma} \mathbf{t}^{\gamma}
$$

Os vetores $\mathbf{u}^{\gamma}$ e $\mathbf{t}^{\gamma}$ representam, os valores de deslocamento e forças de superfície dos corpos que poderiam ser facilmente descobertos em problemas de multi-regiões. No entanto, problemas de contato possuem uma não-linearidade geométrica, resultante do desconhecimento e da extensão da zona de contato. O tamanho da área de contato se torna parte do problema, juntamente com as forças de superfície e deslocamentos em toda região de possível contato $\Gamma_{c}$.

Posteriormente à aplicação das condições de contorno do problema, o sistema fica desbalanceado, com mais variáveis do que equações. Geralmente, em problemas de MEC, existe um tipo de condição de contorno conhecida e a geração de um vetor de solução misto, o que não acontece nesta formulação. A outra região $\Gamma_{n c}$ se comporta de forma semelhante às matrizes do método de contorno, fazendo a troca das matrizes de influência de cada corpo, formando $\mathbf{A}_{n c}^{\gamma}$, que não mudam durante o processo de solução (ABASCAL, 1995) e relaciona todos os valores nodais externos a região de provável contato, $\mathbf{x}_{n c}^{\gamma}$.

O conjunto de variáveis de contato, $\mathbf{u}_{c}^{\gamma}$ e $\mathbf{t}_{c}^{\gamma}$, se relacionam com suas respectivos conjuntos de matrizes de influência $\mathbf{H}_{c}^{\gamma}$ e $\mathbf{G}_{c}^{\gamma}$. $\mathrm{O}$ sistema desbalanceado é representado por:

$$
\left[\begin{array}{cccccc}
\mathbf{A}_{n c}^{1} & 0 & \mathbf{H}_{c}^{1} & 0 & -\mathbf{G}_{c}^{1} & 0 \\
0 & \mathbf{A}_{n c}^{2} & 0 & \mathbf{H}_{c}^{2} & 0 & -\mathbf{G}_{c}^{2}
\end{array}\right]\left\{\begin{array}{c}
\mathbf{x}_{n c}^{1} \\
\mathbf{x}_{n c}^{2} \\
\mathbf{u}_{c}^{1} \\
\mathbf{u}_{c}^{2} \\
\mathbf{t}_{c}^{1} \\
\mathbf{t}_{c}^{2}
\end{array}\right\}=\left\{\begin{array}{l}
\mathbf{b}^{1} \\
\mathbf{b}^{2}
\end{array}\right\}
$$

onde os vetores $\mathbf{b}^{\gamma}$ são resultado da aplicação das condições de contorno. Para que o sistema possua uma solução, é necessário alocar valores extras que relacionem as variáveis de contato 
de cada corpo. A tabela 3.1 apresenta uma série de equações que relacionam forças de superfície e deslocamentos de pares de nós que podem ser representadas de forma matricial e completar o sistema, caracterizando o método de restrições diretas. Elas variam para cada modo de contato que os pares estão: deslizamento, separação e adesão. Com cada par tendo a liberdade de estar em modos de contatos diferentes, pois esta é uma formulação nó-a-nó:

\section{Deslizamento:}

$$
\mathbf{c}_{u}=\left[\begin{array}{llll}
0 & 0 & 0 & 0 \\
0 & 0 & 0 & 0 \\
1 & 0 & 1 & 0 \\
0 & 0 & 0 & 0
\end{array}\right]\left\{\begin{array}{c}
u_{t}^{a} \\
u_{n}^{a} \\
u_{t}^{b} \\
u_{n}^{b}
\end{array}\right\} \quad \mathbf{c}_{t}=\left[\begin{array}{cccc}
1 & 0 & -1 & 0 \\
\pm f & 1 & 0 & 0 \\
0 & 0 & 0 & 0 \\
0 & 0 & \pm f & 1
\end{array}\right]\left\{\begin{array}{c}
t_{t}^{a} \\
t_{n}^{a} \\
t_{t}^{b} \\
t_{n}^{b}
\end{array}\right\}
$$

Adesão:

$$
\mathbf{c}_{u}=\left[\begin{array}{cccc}
0 & 0 & 0 & 0 \\
0 & 0 & 0 & 0 \\
1 & 0 & 1 & 0 \\
0 & 1 & 0 & 1
\end{array}\right]\left\{\begin{array}{c}
u_{t}^{a} \\
u_{n}^{a} \\
u_{t}^{b} \\
u_{n}^{b}
\end{array}\right\} \quad \mathbf{c}_{t}=\left[\begin{array}{cccc}
1 & 0 & -1 & 0 \\
0 & 1 & 0 & -1 \\
0 & 0 & 0 & 0 \\
0 & 0 & 0 & 0
\end{array}\right]\left\{\begin{array}{c}
t_{t}^{a} \\
t_{n}^{a} \\
t_{t}^{b} \\
t_{n}^{b}
\end{array}\right\}
$$

\section{Separação:}

$$
\mathbf{c}_{u}=\left[\begin{array}{llll}
0 & 0 & 0 & 0 \\
0 & 0 & 0 & 0 \\
0 & 0 & 0 & 0 \\
0 & 0 & 0 & 0
\end{array}\right]\left\{\begin{array}{c}
u_{t}^{a} \\
u_{n}^{a} \\
u_{t}^{b} \\
u_{n}^{b}
\end{array}\right\} \quad \mathbf{c}_{t}=\left[\begin{array}{llll}
1 & 0 & 0 & 0 \\
0 & 1 & 0 & 0 \\
0 & 0 & 1 & 0 \\
0 & 0 & 0 & 1
\end{array}\right]\left\{\begin{array}{c}
t_{t}^{a} \\
t_{n}^{a} \\
t_{t}^{b} \\
t_{n}^{b}
\end{array}\right\}
$$

Depois que o modo de contato de cada par é avaliado, forma-se um conjunto de restrições para deslocamento e tração, $\mathbf{C}_{u}^{\gamma}$ e $\mathbf{C}_{t}^{\gamma}$. Além do modo de contato, o gap entre os pontos é medido $\left(\mathbf{v}^{\gamma}\right)$ e colocado no grau de liberdade correspondente ao par de nós avaliado. A Equação (5.4) é redefinida de forma que:

$$
\left[\begin{array}{cccccc}
\mathbf{A}_{n c}^{1} & 0 & \mathbf{H}_{c}^{1} & 0 & -\mathbf{G}_{c}^{1} & 0 \\
0 & \mathbf{A}_{n c}^{2} & 0 & \mathbf{H}_{c}^{2} & 0 & -\mathbf{G}_{c}^{2} \\
0 & 0 & \mathbf{C}_{u}^{1} & \mathbf{C}_{u}^{2} & \mathbf{C}_{t}^{1} & \mathbf{C}_{t}^{2}
\end{array}\right]\left\{\begin{array}{c}
\mathbf{x}_{n c}^{1} \\
\mathbf{x}_{n c}^{2} \\
\mathbf{u}_{c}^{1} \\
\mathbf{u}_{c}^{2} \\
\mathbf{t}_{c}^{1} \\
\mathbf{t}_{c}^{2}
\end{array}\right\}=\left\{\begin{array}{c}
\mathbf{b}^{1} \\
\mathbf{b}^{2} \\
\mathbf{v}^{1,2}
\end{array}\right\}
$$

Portanto, a Eq. 5.5) é um sistema não-linear completo e matricialmente representado por,

$$
A x=b,
$$


Uma vantagem dessa formulação é sua simples implementação computacional, e outra, é o fato de que para uma mesma configuração, a variação das condições de contorno não muda todo sistema, mas apenas a parte de aplicação das restrições. Isso é de grande ajuda em problemas de contato com fricção, onde as condições de contorno são aplicadas gradualmente. É necessário ressaltar que nesses casos, a região de provável contato deve ser escolhida cautelosamente e ter o menor tamanho possível, pois o seu aumento resulta em um maior número de termos checados a cada aplicação das condições de contorno, levando a um tempo de processamento computacional maior.

Por outro lado, o acoplamento de malhas nó-a-nó está limitado à problemas com pequenas deformações e pouco deslizamento. Quando o deslocamento tangencial do nó é grande, ele começa a se distanciar do par de contato original e a aplicação das restrições de contato se torna inadequada para a situação. Essa desvantagem não é preocupante para problemas de fretting, onde os deslocamentos pequenos fazem parte do fenômeno. O fato da geração de malha ter que ser conforme é mais importante, porque se perde muito tempo preparando a malha em alguns problemas em comparação com outros métodos de acoplamento.

\subsection{Solução do Sistema Não-Linear}

A solução para sistemas não-lineares como os da Eq. (5.6) foi primeiramente proposto por Pang (1990), e recentemente implementada com sucesso no método dos elementos de contorno (RODRÍGUEZ-TEMBLEQUE; ABASCAL, 2010). É uma extensão do método clássico de newton (HOFFMAN; FRANKEL, 2001), que tem como ideia principal utilizar o valor de uma função aplicada em um ponto relacionado com o valor da derivada do mesmo ponto, para achar a raiz , $x^{*}$, de uma função não-linear arbitrária, $\mathcal{F}(x)$ :

$$
\mathcal{F}\left(x_{k}\right)+\left(x^{*}-x_{k}\right) \mathcal{F}^{\prime}\left(x_{k}\right)=0
$$

O valor de $x^{*}$ é achado iterativamente, onde o valor $x_{k}$ é achado a partir de um incremento ao resultado obtido no passo anterior:

$$
x_{k+1}=x_{k}+\frac{\mathcal{F}\left(x_{k}\right)}{\mathcal{F}^{\prime}\left(x_{k}\right)}=x_{k}+\delta_{k}
$$

o processo é repetido até que um dos critérios de parada sejam satisfeitos, sendo eles:

$$
\begin{array}{r}
\left|\mathcal{F}\left(x_{k+1}\right)\right|<\varepsilon_{1} \\
\left|x_{k+1}-x_{k}\right|<\varepsilon_{2}
\end{array}
$$

no primeiro caso, $x_{k+1}=x^{*}$ porque a função atingiu um valor bem próximo de zero, $\varepsilon_{1}$. No 
segundo caso, os resultados achados pela Eq. (5.8) são bem próximos um do outro, podendo ser considerados iguais, e o valor não está evoluindo com os incrementos.

Essa é uma das formas mais comuns de encontrar raízes de funções não-lineares por convergir rapidamente e ser de fácil implementação. Ele requer um chute inicial, $x_{0}$, e a derivada da função. Se a mesma não for diferenciável ou achar a derivada for um trabalho de certa complexidade é conveniente usar o método das secantes.

Para sistemas multidimensionais, o mesmo princípio é aplicado:

$$
\mathbf{x}_{k+1}=\mathbf{x}_{k}-\mathbf{J}^{-1} \mathbf{R}
$$

onde $\mathbf{J}$ é a matriz jacobiana, que relaciona as derivadas parciais das funções não-lineares, e $\mathbf{R}$ é a função resíduo onde os valores do vetor $\mathbf{x}_{\mathbf{k}}$ são aplicados no sistema. O produto da matriz jacobiana com a função residual dá o incremento interativo para o método.

No caso deste trabalho, assumiu-se que $\mathbf{J}=\mathbf{A}$, pois isso forçará o vetor residual calculado no passo $k, \mathbf{R}=\mathbf{A} \mathbf{x}_{k}-\mathbf{b}$, a zero. O processo da Eq. (5.11) é repetido até que o resíduo alcance um valor bem próximo de zero, calculado da forma:

$$
\varepsilon=\sqrt{\left(\mathbf{x}_{k+1}-\mathbf{x}_{k}\right)^{T}\left(\mathbf{x}_{k+1}-\mathbf{x}_{k}\right)}
$$

O algoritmo 1 apresenta o processo interativo usado para resolver o sistema não-linear deste trabalho:

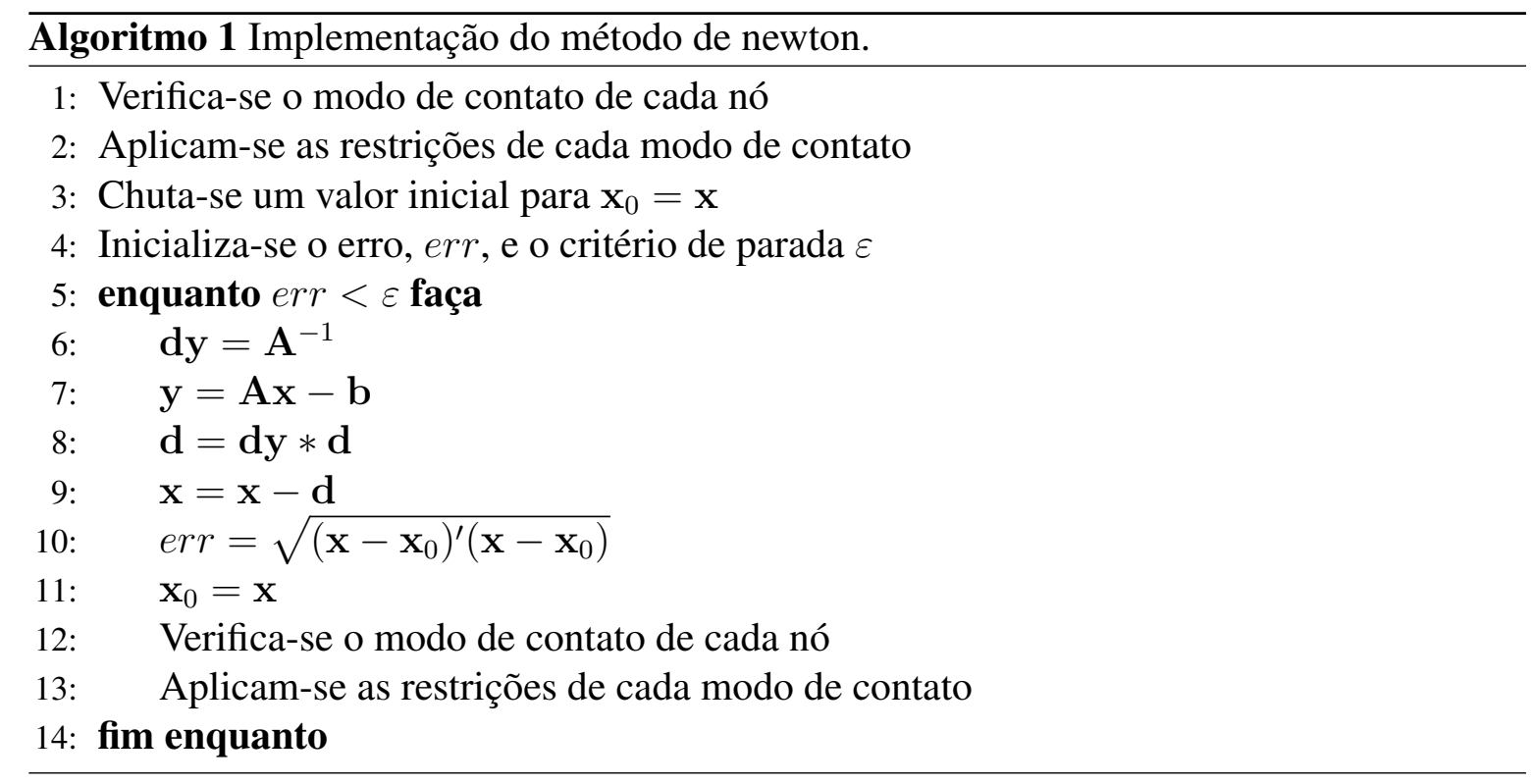




\subsection{Modelagem Numérica}

\subsubsection{Aplicação Incremental de Carga}

Nos problemas de contato, a solução final é obtida somente quando a carga externa máxima ou contato total da região de contato é atingida. Entretanto, como a região de contato é uma função da força aplicada e do coeficiente de atrito, a solução deve ser obtida com auxílio de uma solução numérica iterativa. Ainda mais se o contato for entre contornos não conformes, a solução aproximada é alcançada com aplicação gradual de carga em várias etapas. É necessário considerar também que nos problemas de contato, as equações de equilíbrio e compatibilidade ao longo da região de contato devem ser satisfeitas.

Sabe-se que existem vários métodos para a aplicação de carga nos problemas de contato. A aplicação instantânea de uma carga externa em uma única vez é aceitável se houver contato nó a nó na região de adesão. Nesse caso, o processo iterativo de solução do sistema é utilizado até que a região de escorregamento e adesão sejam conhecidos.

Outra abordagem, mais recomendada, é a aplicação incremental de carga. Nesse caso, a carga total será aplicada gradualmente, em vários incrementos. A vantagem dessa abordagem é um resultado mais aproximado e também sua aplicação, uma vez que ela serve tanto para modo de contato nó a nó quanto para contato de uma superfície com um nó. Por ser um processo iterativo, a história das tensões de contato, as quais tem importância em casos específicos de contato como fretting, devem ser registradas.

$\mathrm{Na}$ abordagem incremental, as condições de contorno, geometria deformada dos corpos e estado de contato são atualizados em cada iteração. O número de incrementos é predefinido pelo usuário e a soma dos incrementos é igual à carga total externa, ou seja:

$$
P_{\text {max }}=\sum_{m=1}^{M} \Delta P^{m}
$$

onde $\Delta P$ é a carga aplicada em cada incremento, $P_{\max }$ é carga externa total aplicada e $M$ é número de incrementos. A força total aplicada é calculado pela Equação (5.14).

$$
P_{j}^{m}=P_{j}^{m-1}+\Delta P_{j}^{m}
$$

onde $P_{j}^{m}$ é a força externa total até o incremento $m$. Na aplicação de cada incremento de carga $(\Delta P)$ haverá uma resposta do sistema que se encontra inicialmente em equilíbrio. A resposta do sistema resulta em pequenas variações nas forças de superfícies e nos deslocamentos no contorno do sistema até obter um novo equilíbrio. As variações de deslocamento e forças de superfície são definidas como:

$$
u_{j}^{m}=u_{j}^{m-1}+\Delta u_{j}^{m}
$$




$$
t_{j}^{m}=t_{j}^{m-1}+\Delta t_{j}^{m}
$$

onde $\Delta u_{j}^{m}$ e $\Delta t_{j}^{m}$ são variações incrementais de deslocamento e força de superfície devido a carga incremental $\Delta P_{j}^{m}$. Rescrevendo a equação integral de contorno, tem-se:

$$
C_{i j}\left(u_{j}^{m-1}+\Delta u_{j}^{m}\right)+\int_{\Gamma} T_{i j}\left(u_{j}^{m-1}+\Delta u_{j}^{m}\right) d \Gamma=\int_{\Gamma} U_{i j}\left(t_{j}^{m-1}+\Delta t_{j}^{m}\right) d \Gamma
$$

A integral do contorno para cada incremento é obtida através da equação abaixo:

$$
C_{i j} \Delta u_{j}^{m}+\int_{\Gamma} T_{i j} \Delta u_{j}^{m} d \Gamma=\int_{\Gamma} U_{i j} \Delta t_{j}^{m} d \Gamma
$$

Os nós do contorno discretizado devem ser organizados na região de contato e formar pares de nós, criando a superfície de contato. Todos os pares de nós devem ser resolvidos como um sistema de contato independente, satisfazendo forças de superfície incremental $\Delta \mathbf{t}$ e deslocamentos incrementais $\Delta \mathbf{u}$. Além disso este procedimento deve ser aplicado tanto para a equação de equilíbrio quanto para a equação de compatibilidade. A partir disso, percebe-se que para cada corpo haverá um sistema de equações, mostrado anteriormente na Eq. (5.3). Reformulando para o caso incremental, tem-se:

$$
\mathbf{H}^{1} \Delta \mathbf{u}^{1}=\mathbf{G}^{1} \Delta \mathbf{t}^{1} \quad \text { e } \quad \mathbf{H}^{2} \Delta \mathbf{u}^{2}=\mathbf{G}^{2} \Delta \mathbf{t}^{2}
$$

onde os vetores $\Delta \mathbf{u}$ e $\Delta \mathbf{t}$ contém, respectivamente, os valores de deslocamentos e forças de superfície para cada incremento. Para obter a solução do problema, as condições de contorno fora da região de contato e restrições de contato dentro da região de contato deverão ser aplicadas.

\subsubsection{Decisão do Modo de Contato}

Como já mencionado anteriormente, o modo de contato é verificado a cada passo de incremento de carga para decidir quais nós estão em contato e quais não. Considerando o par de contato $a$ e $b$, com forças de superfície e deslocamentos conhecidos no passo $m-1$, se no passo $m$ nenhum contato é detectado, a relação a seguir é verdadeira:

$$
\begin{gathered}
\left(\Delta u_{n}^{a}+\Delta u_{n}^{b}\right)^{m}<g_{0}^{m-1} \\
t_{n}^{m-1}+\Delta t_{n}^{m} \geq 0 .
\end{gathered}
$$


Se o oposto acontece,

$$
\begin{gathered}
\left(\Delta u_{n}^{a}+\Delta u_{n}^{b}\right)^{m} \geq g_{0}^{m-1} \\
t_{n}^{m-1}+\Delta t_{n}^{m}<0
\end{gathered}
$$

os nós $a$ e $b$ não estão em contato. A função $g_{0}$ representa o gap entre os nós enquanto $u_{n} \mathrm{e}$ $t_{n}$ são os deslocamentos normais e as forças de superfícies normais, respectivamente.

Acontecendo o contato, uma segunda verificação é feita relativa ao movimento tangencial dos nós de contato. A avaliação dos pares, para o modo de adesão é dada por,

$$
\left|t_{t}^{m}\right|=\left|t_{t}^{m-1}+\Delta t_{t}^{m}\right| \leq \mu\left|t_{n}^{m-1}+\Delta t_{n}^{m}\right|=\mu\left|t_{n}^{m}\right|
$$

Se esta condição é valida, o par está em estado de adesão. Opostamente:

$$
\left|t_{t}^{m-1}+\Delta t_{t}^{m}\right| \geq \mu\left|t_{n}^{m-1}+\Delta t_{n}^{m}\right|
$$

a condição de deslizamento é alcançada. A lei de atrito de Coulomb, define dois coeficientes de fricção, um estático e um dinâmico. No entanto, em problemas em que existe deslizamento e aderência simultaneamente, $f$ pode ser aproximado por um valor médio (NOWELL; HILLS, 1987). O algoritmo 2 engloba as Eq. (5.17), (5.18), (5.19) e a lógica de decisão dos modos de contato.

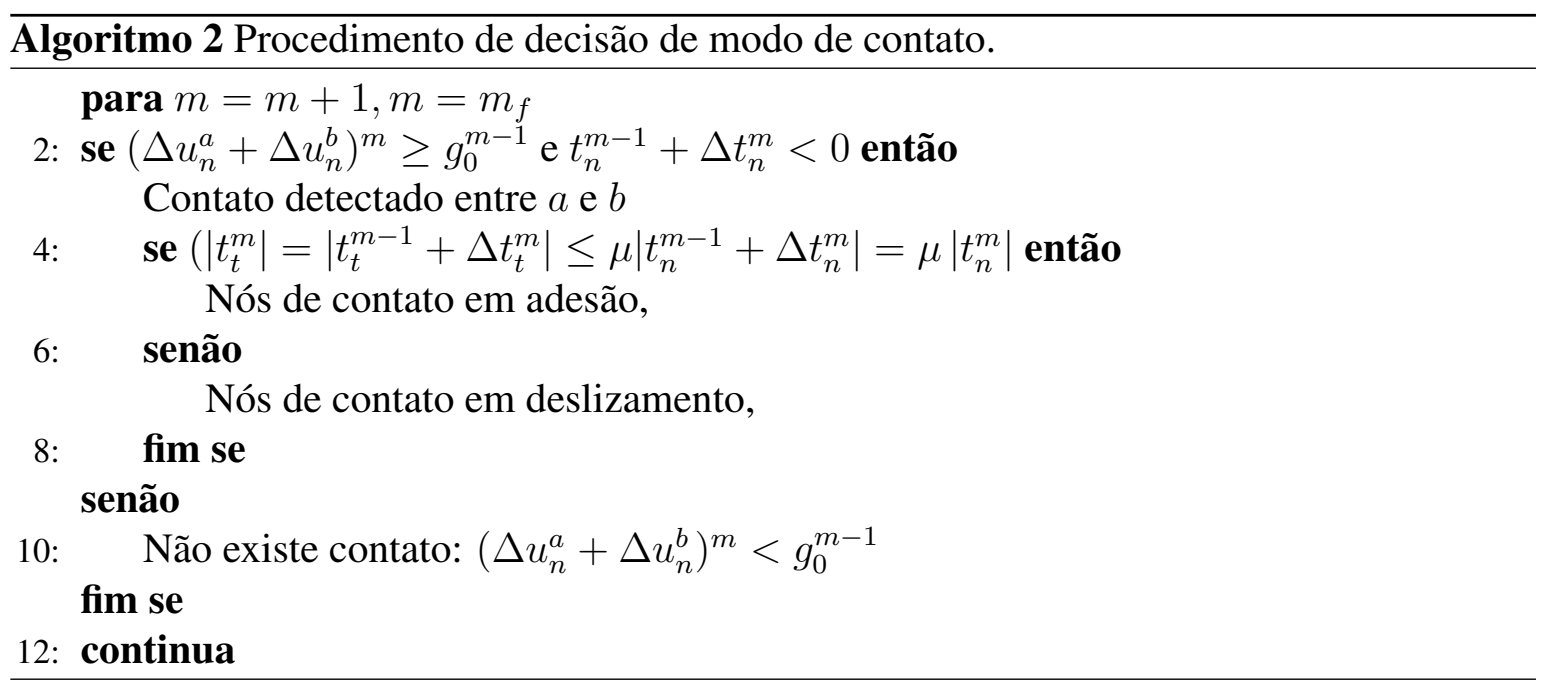




\section{Capítulo 6}

\section{Resultados}

Este capítulo contém os exemplos usados para a validação do código de elementos de contorno para problemas de contato com atrito. Todos os exemplos foram rodados em um computador de sistema operacional Windows 10-64 bits, com processador Intel Core i7-2600 que possui 4 núcleos de processamento com frequência de $3,40 \mathrm{GHz}$ e $8 \mathrm{~GB}$ de memória RAM.

O código foi desenvolvido na linguagem de programação MATLAB e os resultados trabalhados no software Paraview (HENDERSON; AHRENS, 2004). Todos os exemplos foram resolvidos com elementos de contorno quadráticos contínuos.

\subsection{Indentador do Tipo Plano}

O primeiro exemplo é um dos problemas clássicos com solução analítica deduzida por Hertz. Um perfurador cilíndrico com o perfil plano é pressionado contra um semi-espaço elástico por uma força normal $P$. Considerando que o perfurador é rígido, e o contato completo, a solução analítica do problema é dada por:

$$
p(x)=-\frac{P}{\pi \sqrt{a^{2}-x^{2}}}
$$

Esse tipo de distribuição da pressão de contato é singular nas pontas, com a solução analítica tendendo à infinito quando $|x|=a$.

\subsubsection{Considerações Iniciais}

Durante a construção da malha, teve-se o cuidado de colocar as interfaces de contato com o mesmo número de nós. Na Figura 6.1. é observado o acúmulo de elementos na região de contato, as dimensões dos corpos e os locais de aplicação das condições de contorno.

O material escolhido para compor o indentador foi o diamante com módulo de elasti- 
cidade $E_{1}=1000 \mathrm{GPa}$ e coeficiente de Poisson $v_{1}=0,1$. O outro corpo é constituído alumínio com módulo de elasticidade $E_{2}=69 \mathrm{GPa}$ e coeficiente de Poisson $v_{2}=0,33$.

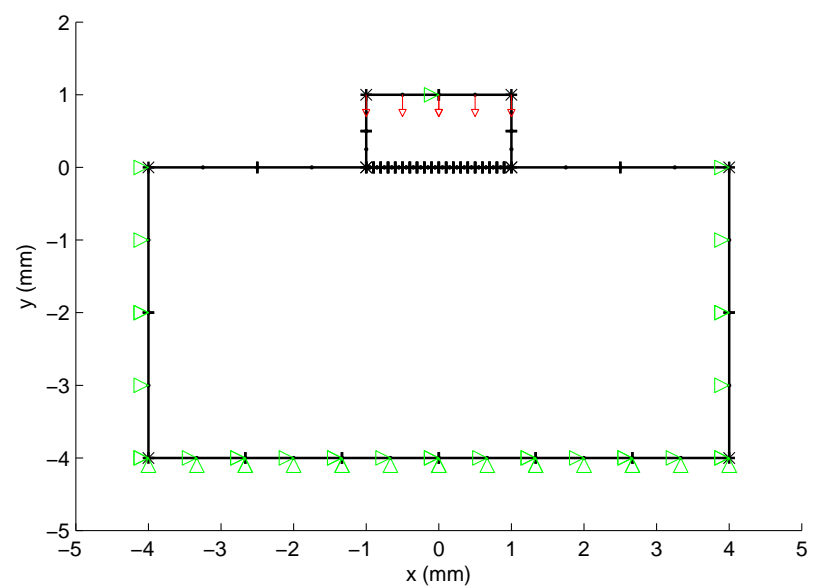

Figura 6.1: Malha do problema com 20 elementos de contato (240 Graus de liberdade).

\subsubsection{Carga Normal}

Como o problema tem coeficiente de atrito nulo $(f=0)$, ele pode ser feito em apenas um passo e a carga normal aplicada foi de $20 \mathrm{~N}$. Os resultados obtidos com 10 elementos de contato foram comparados com a solução analítica e são mostrados na Fig. 6.2.

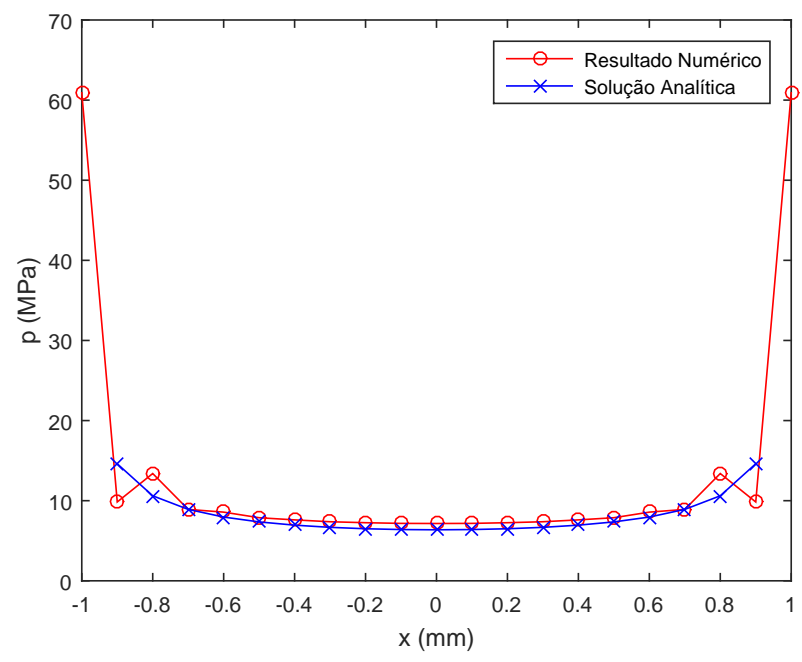

Figura 6.2: Comparação do resultado numérico com o resultado analítico da pressão de contato (10 elementos).

Na Figura 6.2 pode ser observado que mesmo com uma malha pobre o resultado numérico tem o mesmo comportamento que o resultado analítico. Conforme o resultado numérico se aproxima dos pontos de descontinuidade geométrica ele apresenta oscilações e um crescimento exacerbado no final da mesma forma que o resultado analítico tende ao infinito nessas áreas. 
O refinamento da malha gera uma menor região de oscilação que nunca chega a desaparecer, pois o comportamento é inerente à aplicação das restrições nó-a-nó (Fig. 6.3). As forças de superfície nos pontos de descontinuidade geométrica tem as direções de trações extremamente voláteis e o uso de elementos de contorno quadráticos descontínuos seria mais apropriado neste caso, resultando em um aumento dos graus de liberdade do problema.

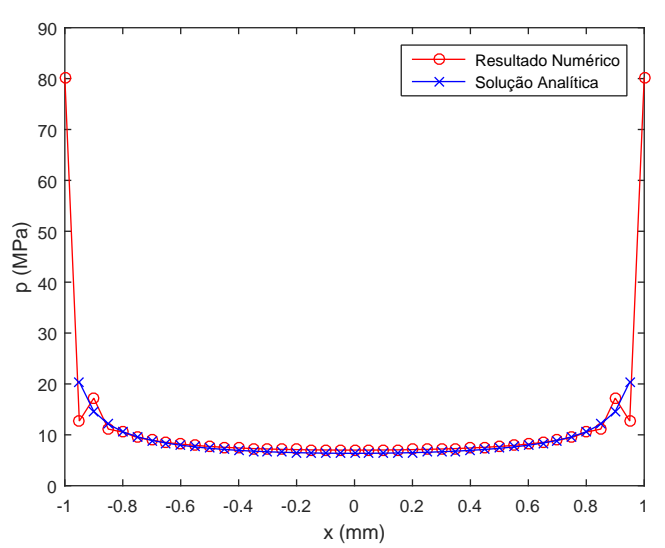

20 elementos.

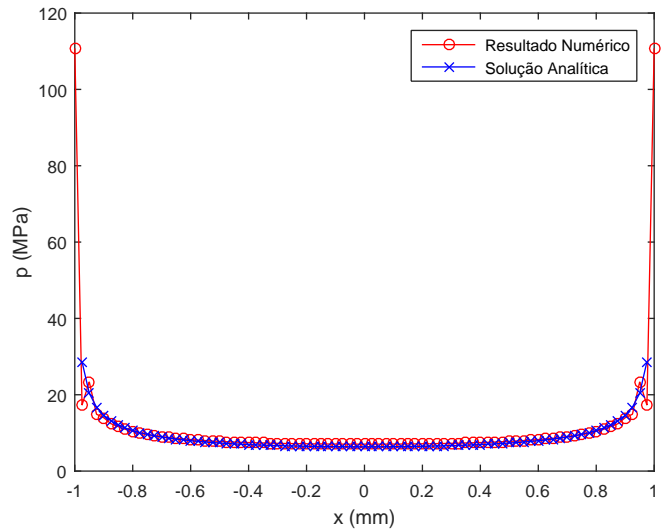

(a) 40 elementos.

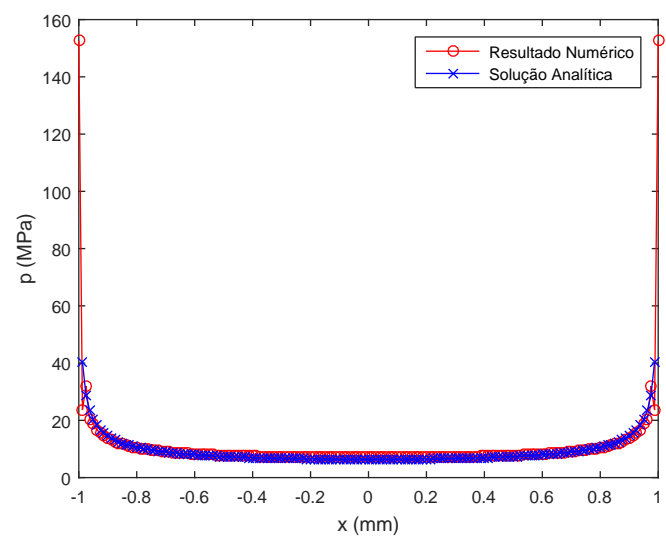

(b) 80 elementos.

Figura 6.3: Pressão de Contato para diferentes malhas.

No entanto, o aumento do número de elementos de contato não aumentou a precisão dos resultados numéricos no ponto $(x, y)=(0,0)$, que foi escolhido porque é o único que se mantém fixo durante qualquer refinamento da zona de contato. Na Figura 6.4, estão dispostos os valores do erro absoluto no ponto escolhido para diferentes refinamentos da região de contato.

Por fim, a Figura 6.5 contém a distribuição das tensões equivalentes de von Mises do segundo corpo. Os valores do penetrador de diamante são bem superiores aos do corpo de alumínio devido à grande diferença entre módulos de elasticidade, então a peça foi removida para que as tensões do corpo inferior fossem observadas mais facilmente. Foram usados 400 pontos internos. 


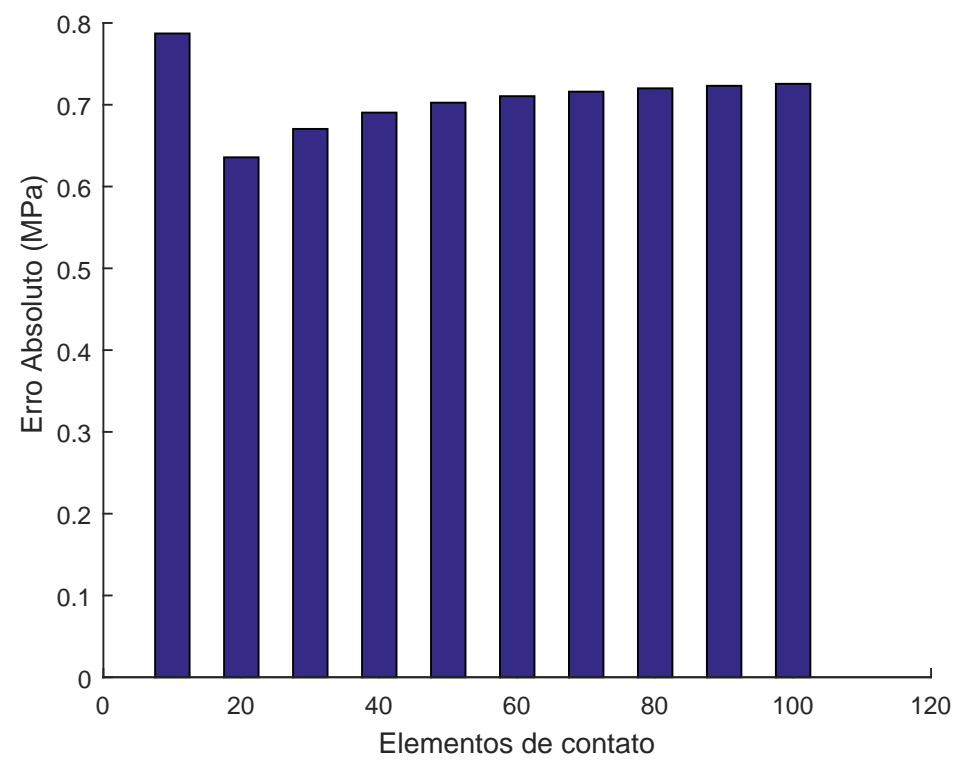

Figura 6.4: Valores da pressão de contato no ponto $(x, y)=(0,0)$.

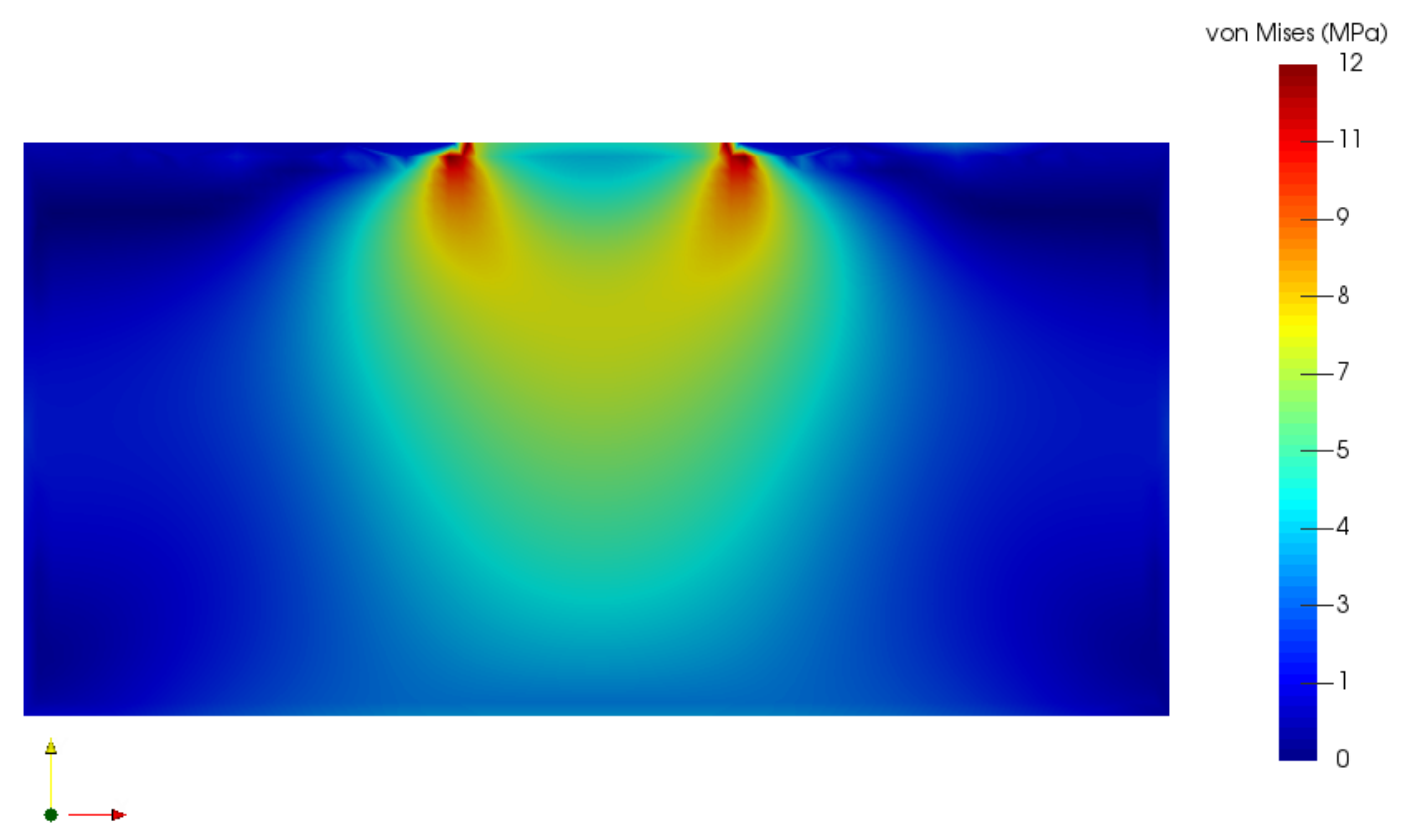

Figura 6.5: Distribuição das tensões de von Mises. 


\subsection{Problema de Cattaneo-Mindlin}

O exemplo a seguir apresenta duas sapatas de perfil circular em contato devido à uma carga normal aplicada e posteriormente, uma carga tangencial cíclica incapaz de causar deslizamento total entre os corpos (Figura 6.7), como em um problema de fretting.

As soluções analíticas do problema foram deduzidas no Capítulo 2, e os resultados obtidos pela simulação em cada fase de carregamento foram comparados com seus respectivos valores analíticos.

\subsubsection{Considerações Iniciais}

A presença de atrito no problema traz a necessidade de uma aplicação incremental das cargas no sistema para que se chegue à uma reposta sem oscilações. A aplicação das cargas tem cinco fases distintas onde os resultados numéricos foram avaliados, eles são apresentados na Fig. 6.6 .

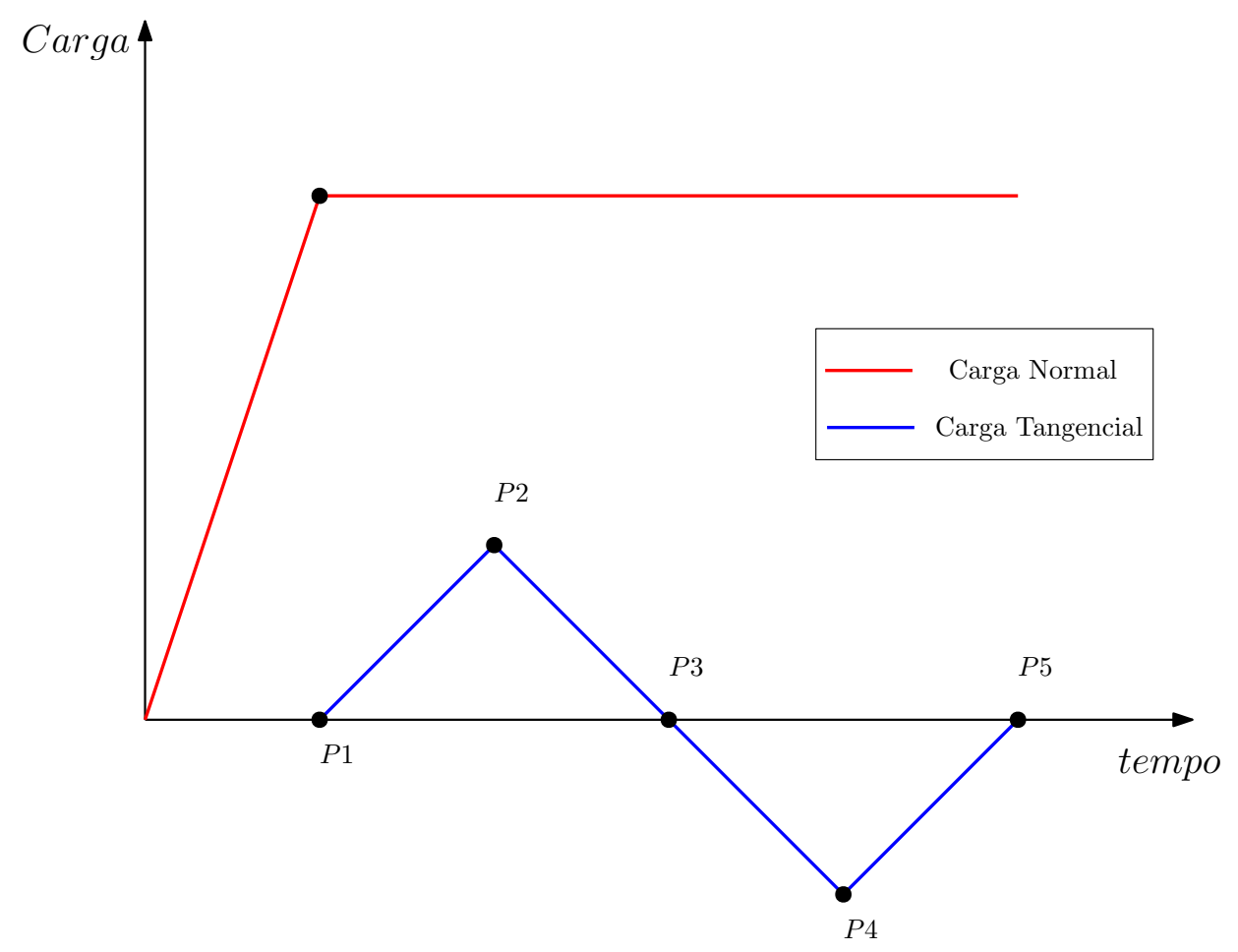

Figura 6.6: Esquema de carregamento incremental para o problema de Cattaneo-Mindlin

O ponto $P 1$ é quando carga normal é completamente aplicada, $P 2$ é o momento de aplicação da carga tangencial máxima, $P 3$ quando é feito o descarregamento e por fim, $P 4$ e $P 5$, a aplicação do valor mínimo da carga tangencial e seu descarregamento. Cada fase tem 50 passos de incremento de carga.

As propriedades geométricas e materiais do problema são dadas pela Tabela 6.1 e pela Fig. 6.7 
Tabela 6.1: Propriedades materiais e geométricas.

\begin{tabular}{ccc}
\hline Propriedade & Símbolo & Valor \\
Raio & $R$ & $70 \mathrm{~mm}$ \\
Comprimento & $w$ & $6,5 \mathrm{~mm}$ \\
Altura & $h$ & $6,5 \mathrm{~mm}$ \\
Módulo de elasticidade & $E$ & $73,4 \mathrm{GPa}$ \\
Razão de Poisson & $\nu$ & 0,33 \\
Carga Normal & $P$ & $100 \mathrm{~N} / \mathrm{mm}$ \\
Carga Horizontal & $Q$ & $15 \mathrm{~N} / \mathrm{mm}$ \\
\hline
\end{tabular}

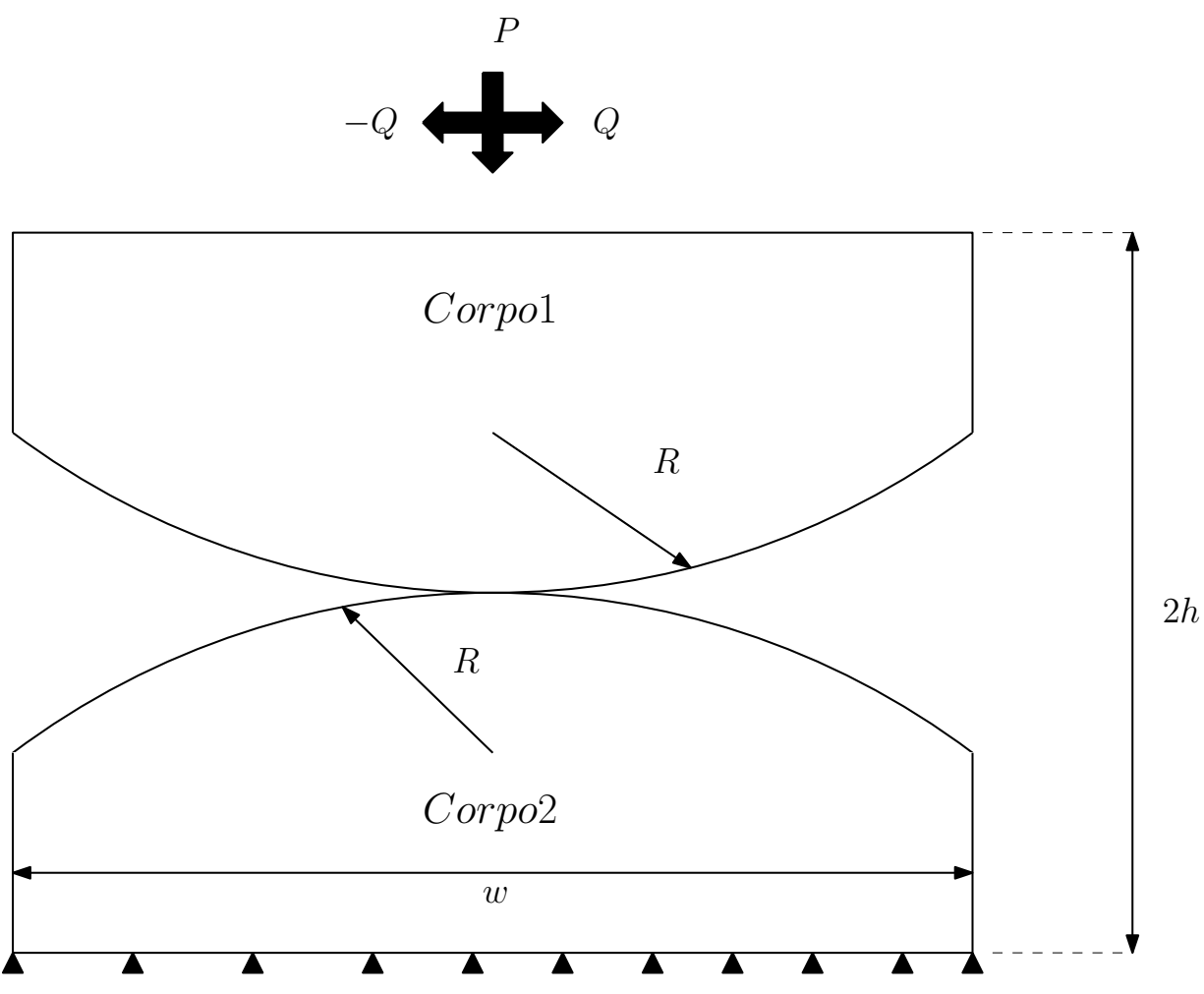

Figura 6.7: Geometria do problema. 
O mapa de cor com as tensões equivalentes de von Mises foi pintado para cada fase da simulação com a malha apresentada na Fig. 6.8. Ela possui 60 elementos de contato em cada interface de contato com cada corpo é composto por 162 elementos de contorno (324 nós, 648 graus de liberdade) e 584 pontos internos para colorir os domínios.

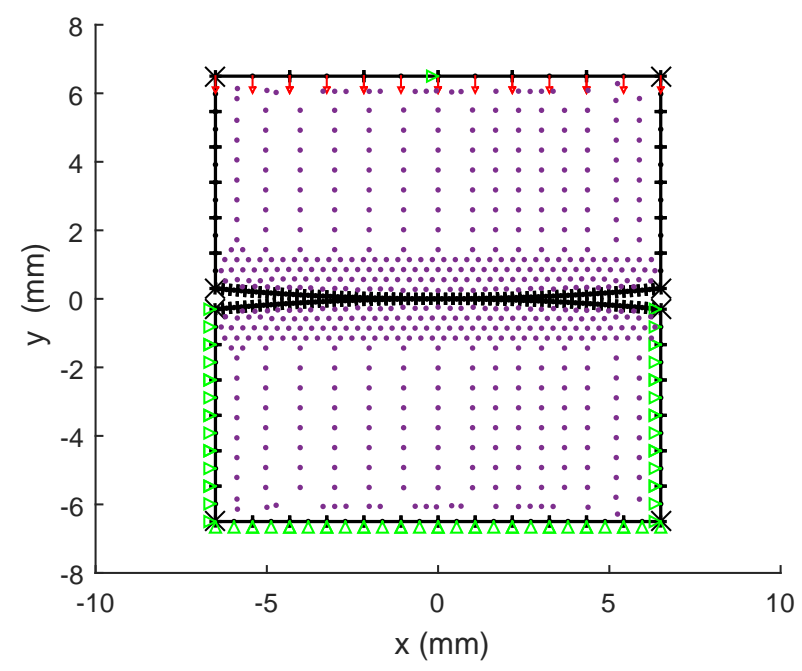

Figura 6.8: Malha com 60 elementos de contato e 584 pontos internos em cada corpo.

\subsubsection{Carga Normal}

A primeira etapa do problema é a gradual aplicação da carga normal que determina a área de contato entre os corpos e pela falta de deslizamento total, se manterá constante. A semi-largura é medida pelas coordenadas dos nós que tem pressão de contato diferente de zero e seu erro relativo ao valor analítico, dado pela Eq. (3.19), é medido por:

$$
\text { erro\% }=\frac{\left|a_{\text {analitica }}-a_{\text {numérica }}\right|}{a_{\text {analitica }}} \cdot 100
$$

$\mathrm{O}$ erro percentual da área de contato calculado pela Eq. (6.2) foi tirado para múltiplas configurações de malha, tendo em foco o aumento de elementos na interface de contato entre os corpos. As medidas estão apresentadas no gráfico de barras da Fig. 6.9, e é notória a redução do erro percentual até o refinamento da malha para 60 elementos de contato, após isso, os valores tem comportamento oscilatório com picos cada vez menores à medida que a interface é discretizada com mais elementos.

Isso acontece porque o contato entre corpos possui rápidas variações nos seus resultados para forças superficiais, caracterizando um problema de alto gradiente. Portanto, eles dependem do posicionamento dos nós, que mudam a cada refinamento, consequência do tipo de gerador de malha usado que usa o número de nós de contato como referência para dividir o segmento geométrico uniformemente (ALBUQUERQUE, 2001). Esse fato mostra que um gerador de malha adaptativo que crie mais elementos nas regiões de rápida variação dos 
resultados levaria à erro bem menor com poucos elementos de contato.

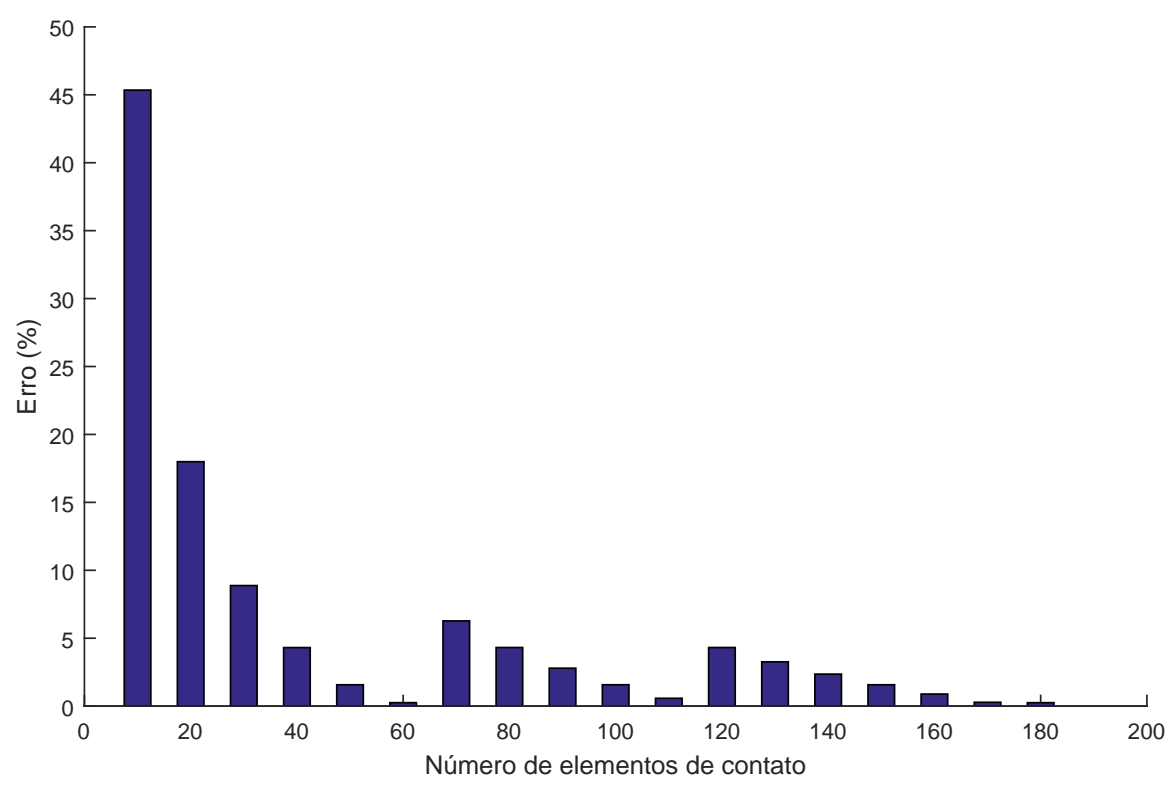

Figura 6.9: Erro percentual da semi-largura de contato em função do número de elementos de contato.

As respostas numéricas e analíticas das tensões ao longo da superfície do primeiro corpo são mostradas na Fig. 6.12(a). Elas foram obtidas com 120 elementos de contato e apresentam boa concordância entre si. É importante ressaltar o cancelamento das tensões de cisalhamento resultante da semelhança elástica entre os corpos.

Finalmente, pode-se observar na Fig. 6.13 (a) o mapa de cor com as tensões de von Mises dos corpos em contato elástico por uma carga normal e fica evidente a concentração dos valores mais altos das tensões nas regiões mais próximas da interface entre os corpos.

\subsubsection{Carga Tangencial Monotônica}

A segunda etapa do problema é aplicar uma carga tangencial positiva que se relaciona com a carga normal por $Q / f P=0,5$. A carga tangencial não é capaz de causar deslizamento total entre os corpos, portanto existirá uma zona de adesão, calculada analiticamente pela Eq. (3.25). O valor obtido pelo algoritmo de elementos de contorno será comparado com o resultado analítico de forma que:

$$
\text { erro\% }=\frac{\left|c_{\text {analítica }}-c_{\text {numérica }}\right|}{c_{\text {analitica }}} \cdot 100
$$

Como feito anteriormente, foi feito um gráfico de barras do erro em função do número de elementos de contato, apresentado pela Fig. 6.12(b). Com a malha mais grosseria, os nós se acumulam na região de adesão e mantém a medida da zona de adesão constante. Quando o número de nós se eleva, o erro de $c$ apresenta oscilações como o erro da área de contato. 


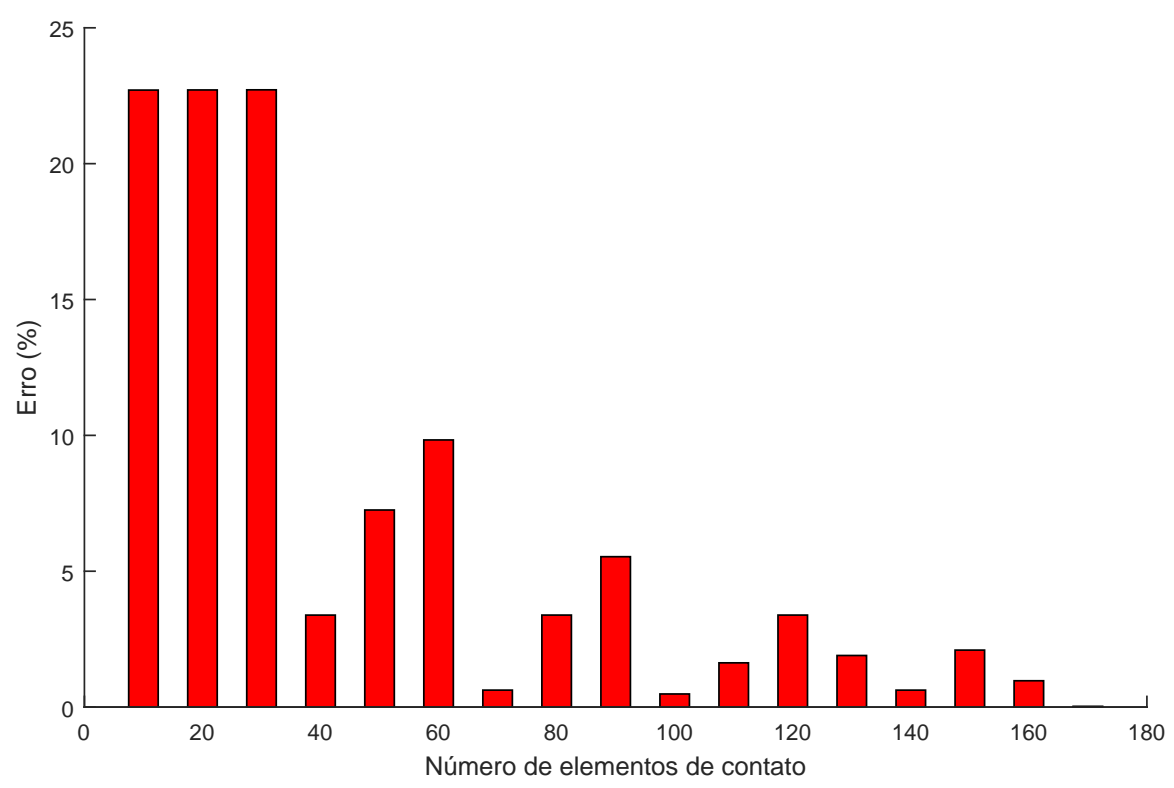

Figura 6.10: Erro percentual da zona de adesão em função do número de elementos de contato.

As tensões na região de contato para a segunda fase de aplicação de carga são mostradas pela Fig. 6.12(c). As tensões normais não apresentam variações em relação a primeira fase porque a carga normal é mantida em seu valor máximo. Fica exposto a queda repentina das tensões de cisalhamento quando as mesmas passam da zona de deslizamento para a zona de adesão. Os resultados obtidos pelo algoritmo também se conciliam com as respostas analíticas.

A carga tangencial foi aplicada na direção $+x$, então as tensões cisalhantes apontam para a direção oposta do movimento. Isso pode ser visto no mapa de cor da fase 2, Fig. 6.13(b), onde o corpo onde a força foi aplicada apresentam variação do campo de tensões para a direção $-x$.

\subsubsection{Carga Tangencial Oscilatória}

A variação no sentindo da aplicação da carga tangencial causa um momento em que toda zona de contato fica em adesão e as regiões distantes ao centro iniciam o deslizamento da direção contrária. A nova região de adesão é calculada pela Eq. 3.28. E como feito nas fases anteriores, a convergência da malha foi checada medindo a diferença entre as respostas numéricas e analíticas à medida que a malha foi sendo refinada.

A Figura 6.11 ilustra o comportamento dos resultados numéricos em $P 3$, que é oscilatório como nos erros expostos anteriormente mas, convergem para os valores analíticos.

Na distribuição de tensões da Fig. 6.12(c), a região de deslizamento reverso e a dependência do histórico de carregamentos está evidente pelo número de picos existentes na solução 


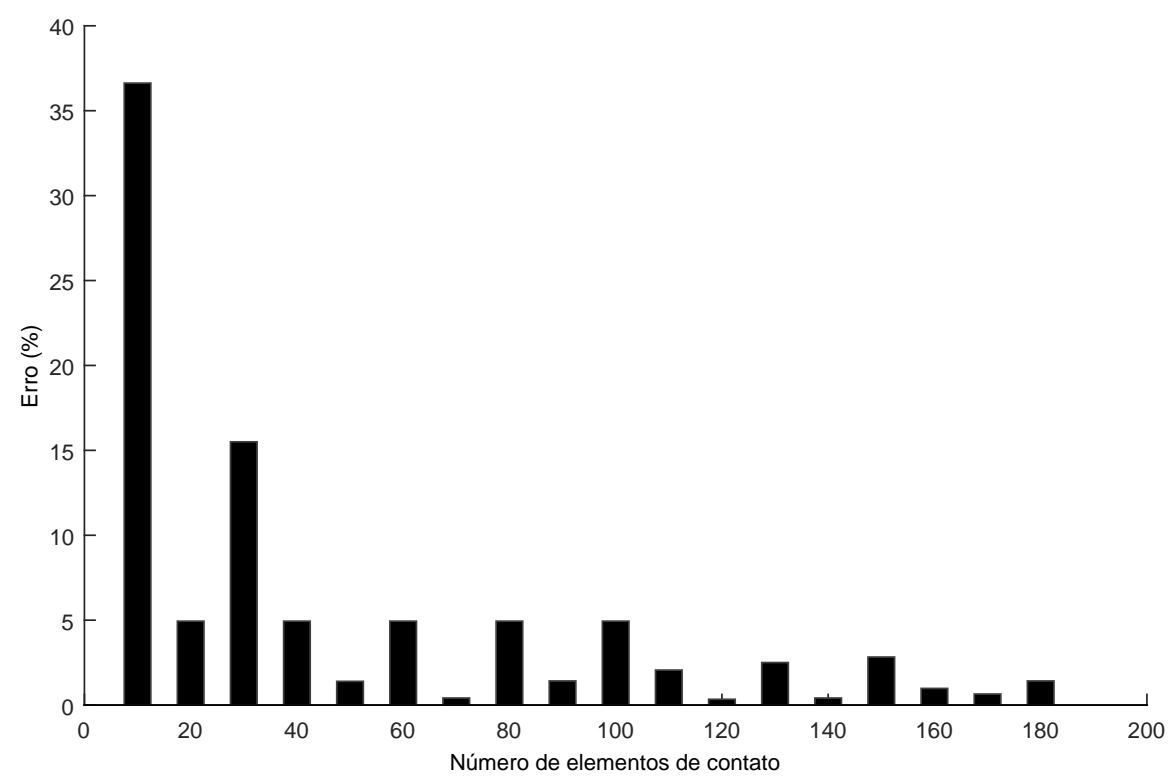

Figura 6.11: Erro percentual da zona de adesão $\left(c^{\prime}\right)$ em função do número de elementos de contato.

analítica corroborada pelos resultados numéricos. O mapa de cor na Fig. 6.13(c) apresenta um comportamento semelhante ao mapa de cor de $P 1$ onde só existe a influência da carga normal.

Nas fases restantes $P 4$ e $P 5$ o comportamento das tensões na região de contato e do mapa de cor de von Mises mudam em relação à direção da carga tangencial. As tensões cisalhantes em $P 4$ terão o mesmo módulo que em $P 2$ e as tensões de von Mises se deslocam para $+x$ porque é a direção contrária a aplicação da carga. Isto é ilustrado pelas Fig. 6.12.(d) e 6.13(d).

Já as tensões cisalhantes em $P 5$ tem o mesmo valor em módulo que em P3 mas o descarregamento foi feito da carga mínima, então os deslizamentos reversos serão positivos. Por fim o mapa de cor tem o mesmo comportamento que em $P 1$ e $P 3$. Os comportamentos são vistos nas Fig. 6.12(e) e 6.13(e). 


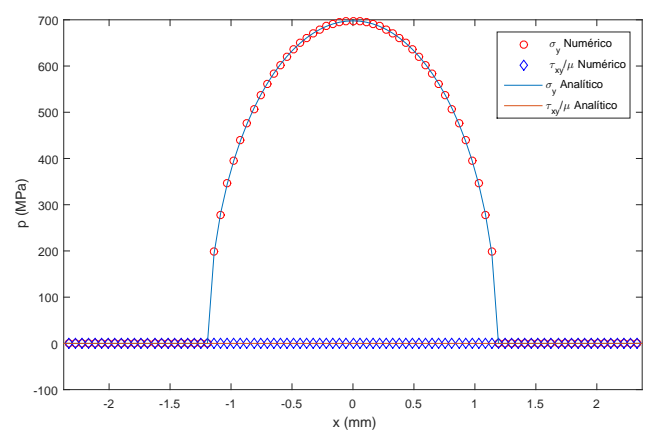

(a) Tensões normais e tangenciais na fase 1.

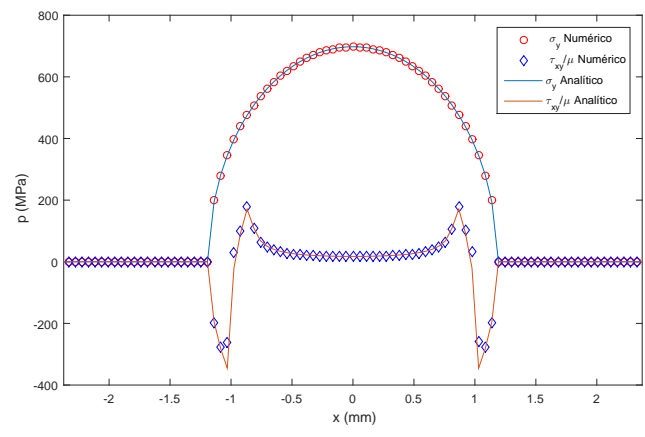

(c) Tensões normais e tangenciais na fase 3.

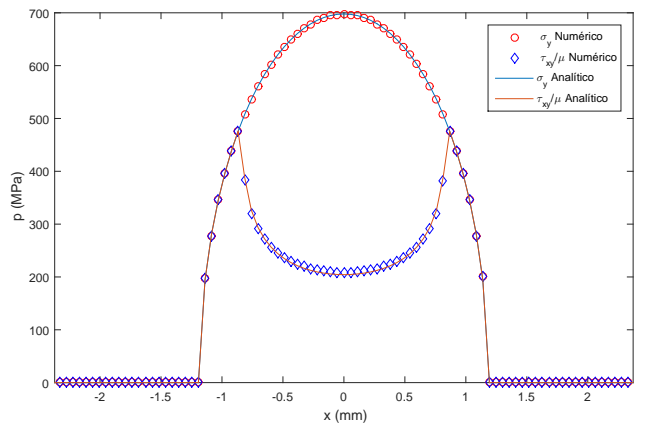

(b) Tensões normais e tangenciais na fase 2.

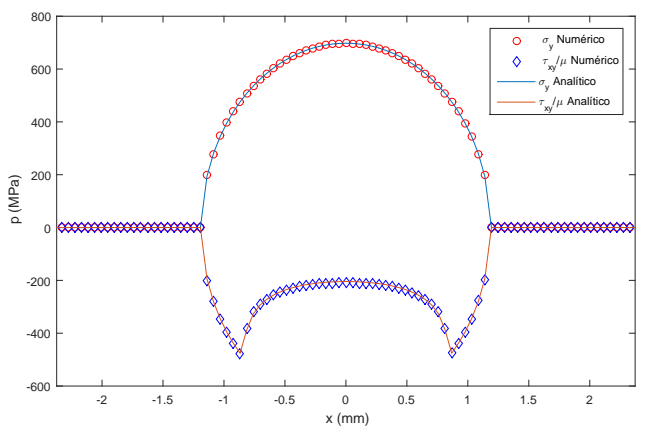

(d) Tensões normais e tangenciais na fase 4 .

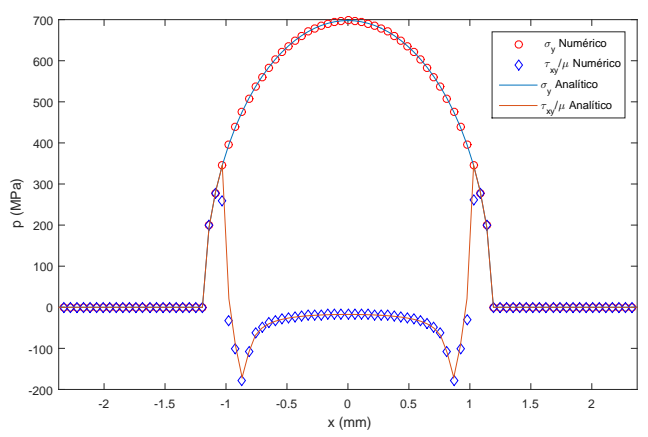

(e) Tensões normais e tangenciais na fase 5 .

Figura 6.12: Tensões na zona de contato. 

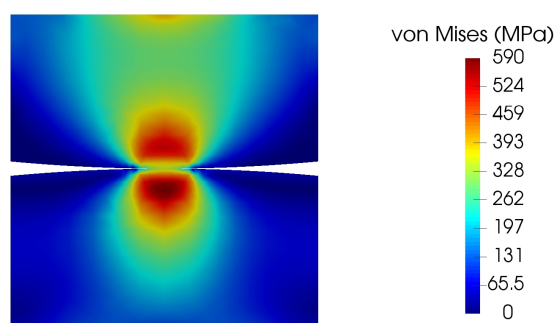

(a) Tensões equivalentes na fase 1 .

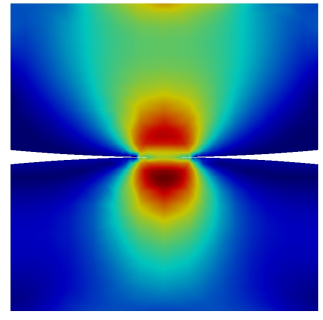

von Mises (MPa)

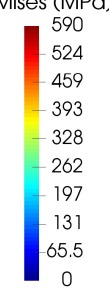

(c) Tensões equivalentes na fase 3 .

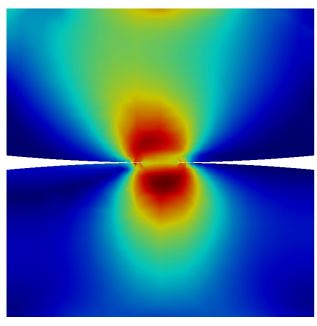

von Mises (MPa)

590
-524
-459
-393
-328
-262
197
131
65.5
0

(b) Tensões equivalentes na fase 2 .
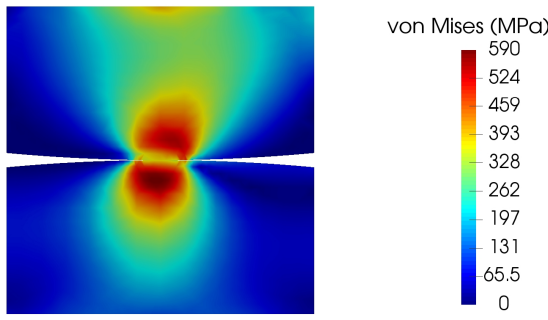

(d) Tensões equivalentes na fase 4.

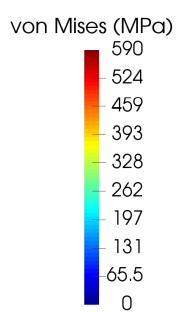

(e) Tensões equivalentes na fase 5 .

Figura 6.13: Tensões na zona de contato. 


\subsubsection{Convergência do Método de Newton}

O Método de Newton se mostrou satisfatório durante todos os passos de aplicação de carga, resolvendo rapidamente cada passo em poucas iterações. Até em momentos que a malha se tornava extremamente refinada, o método conseguiu solucionar o problema rapidamente e o que se tornava demorado era a checagem dos modos de contato. O critério de convergência escolhido neste trabalho é que o valor do resíduo deve ser menor que $\varepsilon=10^{-10}$.

A Figura 6.14 mostra o número de iterações necessárias em cada passo para a convergência do método. O maior valor é encontrado na primeira aplicação de carga que é bem superior aos passos restantes. As variações de carga ocorrem a cada cinquenta incrementos, onde são observados picos no número de iterações que são superiores à maioria dos passos mas nunca na escala do primeiro incremento.

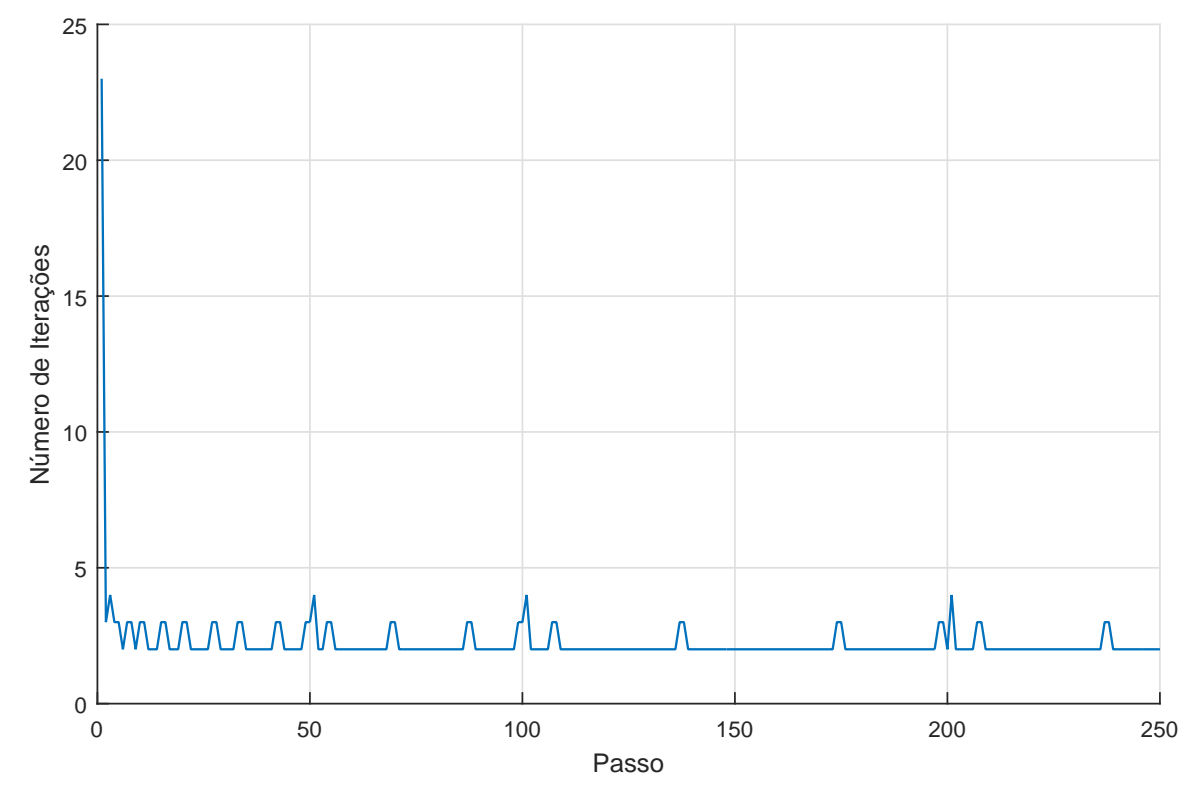

Figura 6.14: Número de iterações para cada passo de aplicação de carga.

Para avaliar o comportamento do resíduo durante a solução do sistema não-linear, o problema foi resolvido com apenas cinco passos. Cada um deles apresenta a aplicação das cargas normais e tangenciais em sua plenitude, o que resulta em uma precisão menor nos valores das tensões superficiais, mas como elas não são o foco da análise, os valores do resíduos foram medidos em cada iteração. A Figura 6.15 apresenta os valores obtidos.

O primeiro passo, o da carga normal, continua precisando de um número de iterações superiores aos passos de cargas tangenciais. Isto pode ser atribuído à evolução do tamanho da área de contato durante a aplicação da força normal que sempre parte de um ponto para um valor real. 


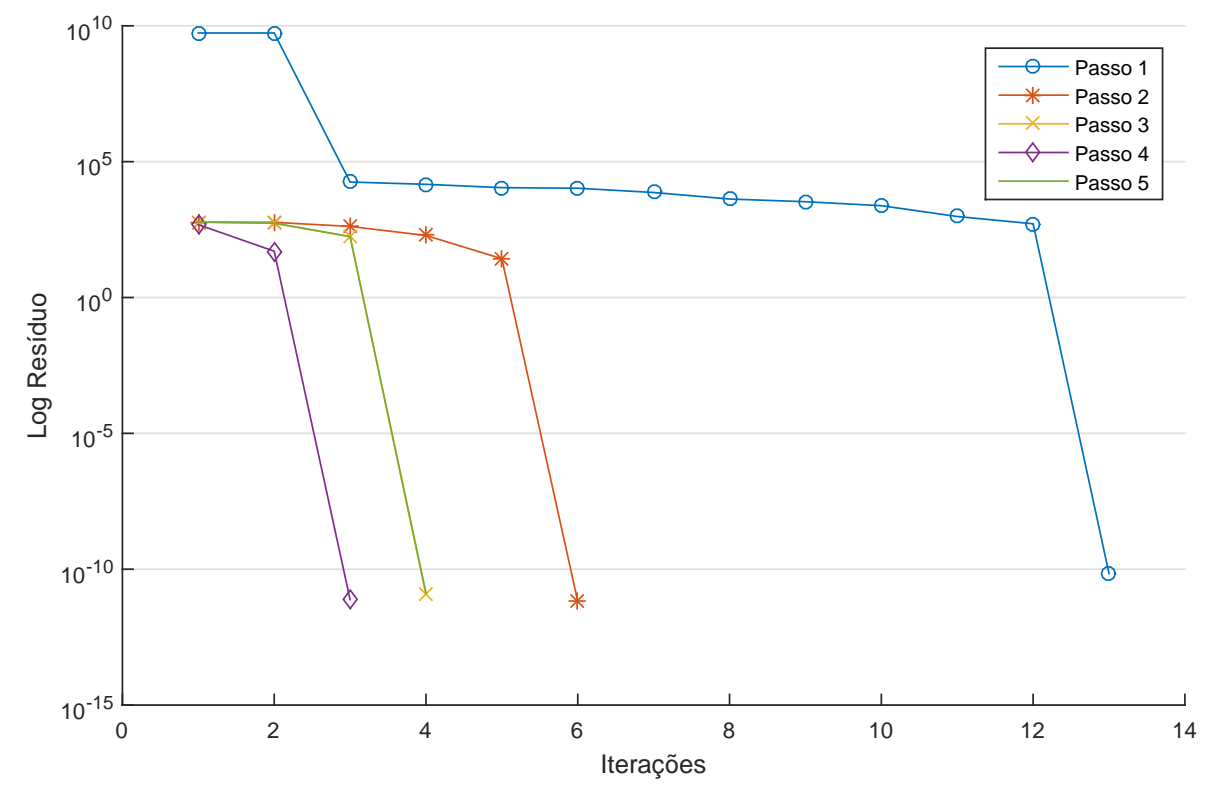

Figura 6.15: Resíduo em cada iteração para diferentes passos.

\subsection{Carga Remota}

Por fim, foi escolhido um problema semelhante as configurações experimentais feitas para análise de fadiga por fretting onde um corpo de prova é colocado sob cargas cíclicas de contato e de fadiga para determinação de parâmetros que ajudem na compreensão do fenômeno.

\subsubsection{Considerações iniciais}

As propriedades materiais do problema de Cattaneo-Mindlin foram mantidas, bem como o número de passos incrementais e as cargas aplicadas ao sistema. O grande diferencial deste exemplo são as condições de contorno e que os corpos possuem perfis de contato diferentes, nele uma sapata é pressionada contra uma superfície plana.

As condições de contorno durante estão dispostas na Fig. 6.16. Em (a) acontece a aplicação da carga normal no plano de dimensões $26 \mathrm{~mm}$ x $13 \mathrm{~mm}$. Em (b), é aplicada a carga tangencial na sapata e a carga de fadiga $\sigma_{B}=75 \mathrm{~N} / \mathrm{mm}$ no corpo inferior. No entanto, quando com essas condições de contorno, o corpo plano se distancia da sapata em função do efeito de Poisson. Isto diminuiria a pressão normal de contato que tem que se manter constante durante o ciclo. Por essa razão, foi calculado o deslocamento do corpo plano cara a mesma carga e o valor foi usado como condição de contorno em y para a sapata. E por fim, em (c) as cargas são aplicadas na direção contrária e também levam em conta o efeito de Poisson.

Essas condições de contorno foram aplicadas em cinco fases de modo semelhante ao problema anterior, sempre tendo o cuidado de manter a carga de fadiga em fase com a carga 


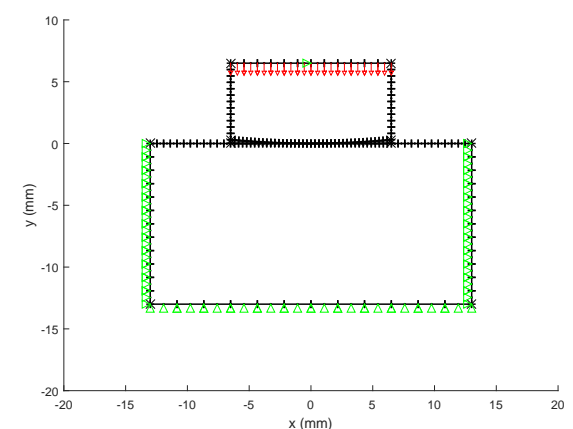

(a) Aplicação da carga normal no plano.

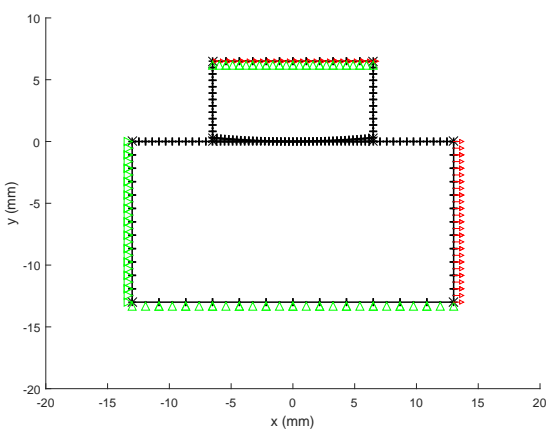

(b) Aplicação de $Q$ e $\sigma_{B}$ na direção $+x$.

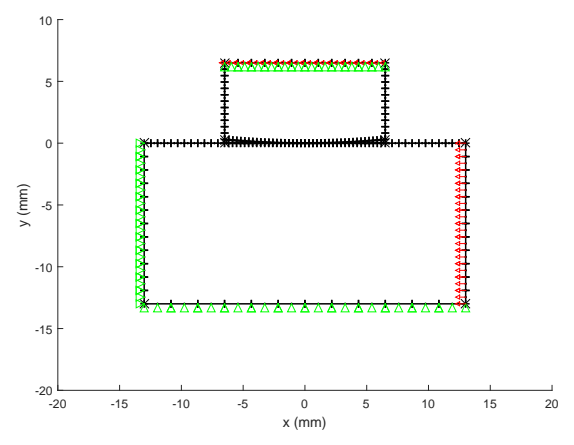

(c) Aplicação de $Q$ e $\sigma_{B}$ na direção $-x$.

Figura 6.16: Condições de contorno do problema.

tangencial para que as tensões possam ser avaliadas pelas soluções analíticas.

\subsubsection{Análise das Tensões}

As tensões de cada fase do problemas são apresentadas pela Fig. 6.17. O resultado numérico da carga normal de contato apresentou boa concordância com a resposta analítica e pôde ser refinado com um número elevado de elementos. Já as fases onde a carga tangencial está em fase com a carga de fadiga, o deslocamento tangencial do corpo de interface plana impossibilitou simulações com um número alto de elementos na região de contato.

Isto se dá pelo método de aplicação das restrições usado no trabalho. Quando existe um grande número na região de provável contato e os mesmos deslocam tangencialmente eles se afastam do par inicial e começam a interferir nos nós vizinhos. O fenômeno é agravado nas fases $P 3$ e $P 4$, onde os nós estão sendo aproximados pela compressão do corpo plano.

Fora isso, é notório que mesmo com esse método de aplicação de restrição, os valores numéricos acompanham o comportamento previsto na teoria de fretting e deslocam a zona de adesão com uma precisão aceitável. 


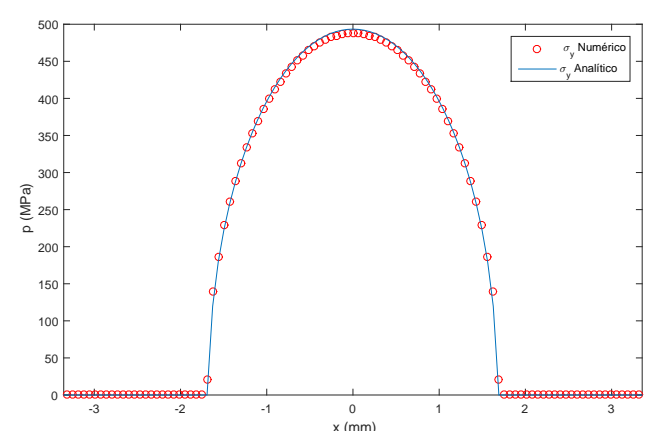

(a) P1 - 100 elementos.

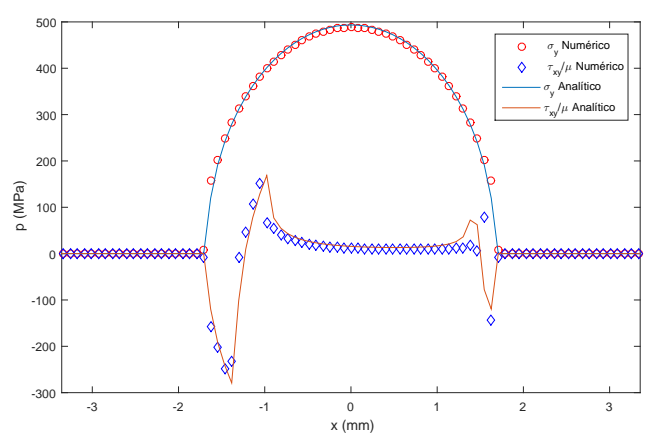

(c) P3 - 80 elementos.

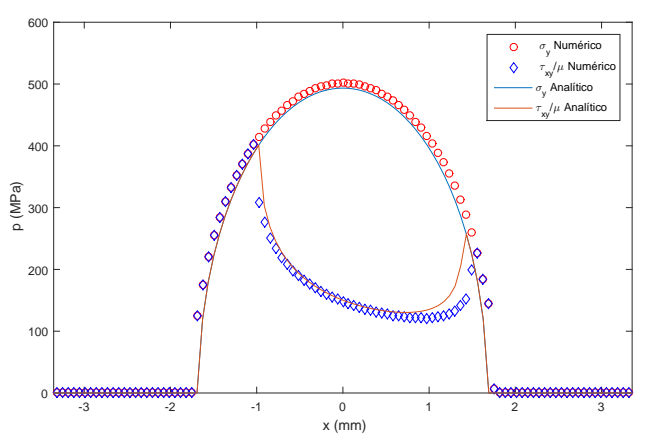

(b) $P 2$ - 80 elementos.

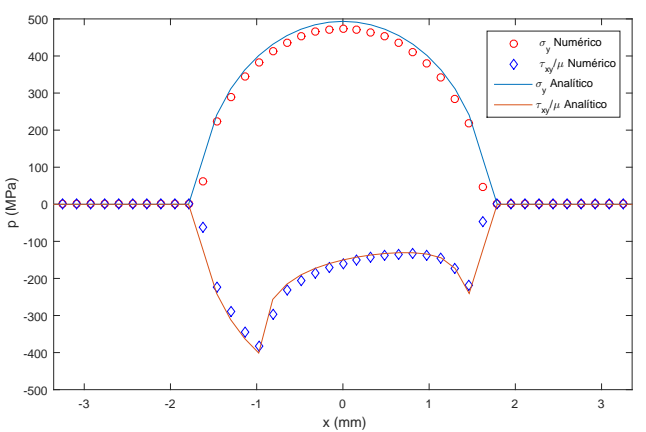

(d) P4 - 40 elementos.

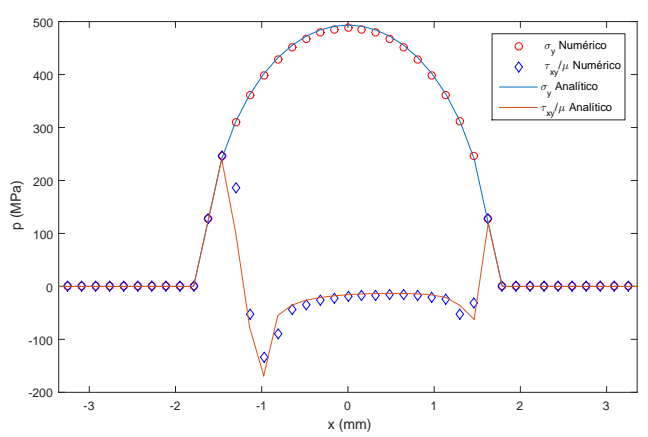

(e) P5 - 40 elementos.

Figura 6.17: Tensões na zona de contato. 


\section{Capítulo 7}

\section{Considerações Finais}

\subsection{Conclusões}

Este trabalho apresenta uma formulação baseada no método de elementos de contorno para a solução problemas de contato com atrito foi capaz de avaliar problemas com modos de contato mistos, de condições de contorno diversas e contato entre corpos constituídos de materiais diferentes.

Para isso, cada corpo foi modelado separadamente e as condições de contato foram aplicadas usando as matrizes de restrição, formando um sistema não-linear de equações que foi solucionado pelo método de Newton.

O código foi testado para três problemas de características distintas. O primeiro, o problema de indentação por um cilindro rígido de perfil plano, que testa a capacidade do código de trabalhar com materiais de características elásticas diferentes por apresentar um indentador de diamante em contato com um corpo de alumínio e também por ter uma solução analítica singular nas extremidades do contato. Os resultados numéricos obtidos acompanharam o comportamento da solução analítica e sua precisão não aumentou mesmo com o refinamento da malha, podendo ser explicado pelo fato que a resposta analítica é idealizada para um corpo rígido aplicado a um deformável, enquanto na simulação apesar de seu alto módulo de elasticidade, o corpo de diamante sofreu deformações.

O segundo problema foi o de duas sapatas de perfil circular e com características elásticas similares, chamado de Cattaneo-Mindlin. Neste exemplo, uma carga normal era aplicada e em seguida, uma carga tangencial oscilatória que são características de um problema de fretting. Em todos os passos as respostas numéricas apresentaram boa concordância com as soluções analíticas, conseguindo detectar bem os picos e as variações das tensões de cisalhamento durante o carregamento e descarregamento. Vale ressaltar que o refinamento da malha por segmentos de mesmo tamanho fez com que o valor do erro caia de forma alternante.

O terceiro e último problema é de uma sapata de perfil circular com um corpo plano em contato. A carga tangencial aplicada na sapata continua oscilatória mas houve aumento da 
zona de adesão por causa da carga de fadiga aplicada ao corpo plano em fase com a carga tangencial. Os resultados são satisfatórios, no entanto, em alguns momentos a possibilidade de refinamento da malha é atrapalhado pelo tipo de aplicação das restrições, no caso deste trabalho foi feito com a técnica de nó-a-nó. Quando o corpo sofre compressão pela carga remota, os nós ficam muito próximos um do outro e a avaliação dos pares de contato sofre interferência. A precisão dos resultados é afetada porque uma das condições de contorno, o deslocamento vertical, é calculado previamente sendo que o valor pode interferir na pressão normal, por oferecer deslocamentos em casas decimais um pouco acima ou um pouco abaixo do ideal.

O método de Newton convergiu rapidamente na maioria dos passos de carga incremental, sendo que o momento que ele precisa de mais iterações para obter solução do sistema é no primeiro passo. Isso acontece porque inicialmente, os corpos são colocados com apenas um ponto de conexão um com o outro e no momento que a carga é aplicada ocorre a evolução rápida da área de contato para múltiplos pontos da interface de contato.

\subsection{Trabalho Futuro}

Uma primeira sugestão seria a evolução do tipo de aplicação das restrições, onde existem uma série de técnicas de acoplamentos de malha como nó-segmento e método mortar. Emprego de diferentes modelos constitutivos que levem em consideração as tensões e deformações plásticas dos corpos, e também avaliem as tensões em problemas termoelásticos e termoviscoelásticos. Existe também a possibilidade de eliminar o processo de geração de malha, com a implementação de MEC isogeométrico. Pode-se também, estender a formulações para problemas tridimensionais e de grande escala usando métodos rápidos.

Outras sugestões são, a avaliação de contatos singulares com elementos descontínuos, o uso de técnicas de refinamento de malha $h$ e $p$ adaptativo e por fim a consideração da área de contato não uniforme devido ao desgaste.

\subsection{Publicações}

Este trabalho deu origem à três publicações listadas abaixo:

1. SHATERZADEH-YAZDI, M. H. ; SOLLERO, P. ; CAVALCANTE, B. ; ALBUQUERQUE, E. L. ; DOCA, T. Analysis of Cattaneo-Mindlin problems using the Boundary Element Method. International Symposium of Fretting Fatigue, 2016, Brasília. Proceedings of the ISFF8, 2016.

2. CAVALCANTE, B. ; SHATERZADEH-YAZDI, M. H. ; SOLLERO, P. ; ALBUQUERQUE, E. L. ; DOCA, T. Fretting problem analisys with the boundary element 
method. XXXVII Iberian Latin American Congress on Computational Methods in Engineering, 2016, Brasília. XXXVII Iberian Latin American Congress on Computational Methods in Engineering, 2016.

3. CAVAlCANTE, B. ; AlBUQUERQUE, E. L. ; DOCA, T; SOlleRO, P. ; SHATERZADEH-YAZDI, M. H. Analysis of Cattaneo-Mindlin problem using the Boundary Element Method, Tribology International, 2016, In Press. 


\section{Referências Bibliográficas}

ABASCAL, R. 2D transient dynamic friction contact problems. I. Numerical analysis. Eng. Anal. Bound. Elem., Elsevier, v. 16, n. 3, p. 227-233, 1995.

ABASCAL, R.; GONZÁLEZ, J. Using the boundary element method to solve rolling contact problems. Eng. Anal. Bound. Elem., v. 21, n. 4, p. 385-392, 1998.

ABASCAL, R.; RODRÍGUEZ-TEMBLEQUE, L. Steady-state 3D rolling-contact using boundary elements. Commun. Numer. Methods Eng., John Wiley \& Sons, Ltd., v. 23, n. 10, p. $905-920$, dec 2006.

ALART, P.; CURNIER, A. A mixed formulation for frictional contact problems prone to Newton like solution methods. Comput. Methods Appl. Mech. Eng., v. 92, n. 3, p. 353-375, 1991.

ALBUQUERQUE, E.-L. Análise de problemas dinâmicos em materiais anisotrópicos usando o Método dos Elementos de Contorno. 146 p. Tese (Doutorado) - Universidade Estadual de Campinas, 2001.

ALIABADI, M. The Boundary Element Method, Applications in Solids and Structures. [S.1.]: John Wiley \& Sons, 2002. 598 p.

AMONTONS, G. De la résistance causée dans les machines, tant par les frottemens des parties qui les composent, que par la roideur des Cordes qu'on y employe, et la manière de calculer l'un et l'autre. Mém. Math. Phys. Hist. Acad. R. Sci, p. 206-227, 1699.

ANDERSSON, T. The boundary element method applied to two-dimensional contact problems with friction. Springer, p. 239-258, 1981.

ARAÚJO, J.; NOWELL, D. Analysis of pad size effects in fretting fatigue using short crack arrest methodologies. Int. J. Fatigue, v. 21, n. 9, p. 947-956, 1999.

AZEVEDO, C. et al. Fretting fatigue in overhead conductors: Rig design and failure analysis of a grosbeak aluminium cable steel reinforced conductor. Eng. Fail. Anal., v. 16, n. 1, p. 136-151, 2009.

BANERJEE, P.-K. The Boundary Element Methods in Engineering. 2nd. ed. [S.1.]: McGrall Hill, 1994.

BREBBIA, C.-A.; DOMINGUEZ, J. Boundary Elements: An Introductory Course. [S.1.]: WIT Press, 1996. 328 p.

CATTANEO, C. Sul contatto di due corpi elastici: distribuzione locale degli sforzi. Rend. Accad. Naz. Lincei, v. 27, n. 6, p. 342-348, 1938. 
CHRISTENSEN, P.; KLARBRING, A. Formulation and comparison of algorithms for frictional contact problems. Int. J. . . , v. 173, n. November 1996, p. 145-173, 1998.

COULOMB, C. Théorie des machines simples, en ayant regard au frottement de leurs parties et à la roideur des cordages. Mém. Math. Phys. Hist. Acad. R. Sci, p. 161--331, 1779.

EDEN, E.-M.; ROSE, W.-N.; CUNNINGHAM, F.-L. The endurance of metals: experiments on rotating beams at university college, london. Proc. Inst. Mech. Eng., v. 4, p. 839-974, 1911.

FADEL, A. et al. Effect of high mean tensile stress on the fretting fatigue life of an Ibis steel reinforced aluminium conductor. International Journal of Fatigue, v. 42, p. 24-34, 2012.

GOLDEN, P. Development of a dovetail fretting fatigue fixture for turbine engine materials. Int. J. Fatigue, v. 31, n. 4, p. 620-628, apr 2009.

GONZÁLEZ, J. A.; ABASCAL, R. An algorithm to solve coupled 2D rolling contact problems. Int. J. Numer. Meth. Eng., v. 49, n. February, p. 1143-1167, 2000.

HARISH, G.; FARRIS, T. Shell modeling of fretting in riveted lap joints. AIAA journal, v. 36, n. 6, p. 1087-1093, 1998.

HENDERSON, A.; AHRENS, J. The Paraview guide : a parallel visualization application. New York: Kitware, Inc., 2004. ISBN 1-930934-14-9. Disponível em: <http://opac.inria.fr/ record=b1117983>

HERTZ, H. Über die berührung fester elastischer körper. J. für die reine und Angew. Math., v. 171 , p. $156-171,1881$.

HILLS, D.; NOWELL, D.; SACKFIELD, A. Mechanics of Elastic Contacts. [S.1.]: Butterworth-Heinemann, 1993. 349-391 p.

HILLS, D.-A.; NOWELL, D. Mechanics of Fretting Fatique. Dordrecht: Springer Netherlands, 1994. v. 30. 1-250 p. (Solid Mechanics and Its Applications, v. 30).

HOFFMAN, J.-D.; FRANKEL, S. Numerical Methods for Engineers and Scientists, Second Edition. second. [S.1.]: CRC Press, 2001. 840 p.

HOJJATI-TALEMI, R. et al. Numerical estimation of fretting fatigue lifetime using damage and fracture mechanics. Tribology Letters, v. 52, n. 1, p. 11-25, 2013.

HUTCHINGS, I. M. Leonardo da Vincis studies of friction. Wear, v. 360, p. 51-66, 2016.

JOHNSON, K. L. Contact Mechanics. Cambridge: Cambridge University Press, 1987. $452 \mathrm{p}$.

JUOKSUKANGAS, J.; LEHTOVAARA, A.; MÄNTYLÄ, A. Experimental and numerical investigation of fretting fatigue behavior in bolted joints. Tribology International, v. 103, p. 440-448, 2016.

KANE, J. H. Boundary element analysis in engineering continuum mechanics. [S.1.]: Englewood Cliffs, NJ Prentice Hall, 1994.

KARAMI, G. A boundary element method for two-dimensional contact problems. [S.1.]: Springer, 1987. v. 51. 
KESAVAN, D. et al. High temperature fretting wear prediction of exhaust valve material. Tribology International, v. 100, p. 280-286, 2016.

KIKUCHI, N.; ODEN, J. Contact problems in elasticity: a study of variational inequalities and finite element methods. [S.1.]: SIAM J Appl Math, 1988.

KONYUKHOV, A.; IZI, R. Introduction to Computational Contact Mechanics: A Geometrical Approach. [S.1.]: Wiley, 2015. 304 p.

MAN, K.-W. Contact mechanics using boundary elements. [S.1.]: Computational Mechanics Publications, 1994. $182 \mathrm{p}$.

MCDEVITT, T. W.; LAURSEN, T. A. A mortar-finite element formulation for frictional contact problems. Int. J. Numer. Methods Eng., v. 48, n. 10, p. 1525-1547, 2000.

MCDOWELL, J.-R. Fretting Corrosion Tendencies of Several Combinations of Materials. In: Symp. Frett. Corros. 100 Barr Harbor Drive, PO Box C700, West Conshohocken, PA 19428-2959: ASTM International, 1952. p. 24-16.

METALS, A. Properties and Selection of Metals. [S.1.]: Handbook, 1961.

MINDLIN, R. D. Compliance of elastic bodies in contact. Journal of applied mechanics, v. 16, p. 159-268, 1949.

MISES, R. v. Mechanik der festen körper im plastisch- deformablen zustand. Nachrichten von der Gesellschaft der Wissenschaften zu Göttingen, Mathematisch-Physikalische Klasse, v. 1913, p. 582-592, 1913.

MUSKHELISHVILI, N. I. Some Basic Problems of the Mathematical Theory of Elasticity. Gröningen: Noordhoff, 1953. 704 p.

NOWELL, D.; HILLS, D.-A. Mechanics of fretting fatigue tests. Int. J. Mech. Sci., v. 29, n. 5, p. 355-365, 1987.

PANAGIOTOPOULOS, I. P. A nonlinear programming approach to the unilateral contact-, and friction-boundary value problem in the theory of elasticity. Ingenieur-Archiv, Springer, v. 44, n. 6, p. 421-432, 1975.

PANG, J.-S. Newton's Method for 5-Differentiable equations. Math. Oper. Res., v. 15, n. 1, 1990.

PARIS, F.; BLAZQUEZ, A.; CANAS, J. Contact problems with nonconforming discretizations using boundary element method. Computers \& structures, Elsevier, v. 57, n. 5, p. 829-839, 1995.

PARIS, F.; GARRIDO, J. An incremental procedure for friction contact problems with the boundary element method. Engineering analysis with boundary elements, Elsevier, v. 6, n. 4, p. 202-213, 1989.

POPOV, V. L. Contact mechanics and friction. Contact Mech. Frict., Springer Berlin Heidelberg, p. 55-70, 2010.

RODRÍGUEZ-TEMBLEQUE, L.; ABASCAL, R. A FEM-BEM fast methodology for 3D frictional contact problems. Comput. Struct., v. 88, n. 15-16, p. 924-937, 2010. 
RODRÍGUEZ-TEMBLEQUE, L.; ABASCAL, R.; ALIABADI, M.-H. A boundary element formulation for wear modeling on $3 \mathrm{~d}$ contact and rolling-contact problems. Int. J. Solids Struct., v. 47, n. 18-19, p. 2600-2612, sep 2010.

RODRÍGUEZ-TEMBLEQUE, L.; ABASCAL, R.; ALIABADI, M.-H. A boundary elements formulation for 3d fretting-wear problems. Eng. Anal. Bound. Elem., v. 35, n. 7, p. 935-943, jul 2011.

ROYHMAN, D. et al. Fretting-corrosion behavior in hip implant modular junctions: The influence of friction energy and $\mathrm{pH}$ variation. Journal of the Mechanical Behavior of Biomedical Materials, v. 62, p. 570-587, 2016.

RUIZ, C.; BODDINGTON, P.-H.-B.; CHEN, K.-C. An investigation of fatigue and fretting in a dovetail joint. Exp. Mech., v. 24, n. 3, p. 208-217, 1984.

RUIZ, C.; CHEN, K. Life assessment of dovetail joints between blades and discs in aeroengines. Mechanical Engineering Publications,, v. 15, p. 187-194, 1986.

RUIZ, C.; NOWELL, D. Designing against fretting fatigue in aeroengines. Eur. Struct. Integr. Soc., v. 26, n. C, p. 73-95, 2000.

SHATERZADEH-YAZDI, M.-H. Análise de contato entre dois corpos elásticos usando o Método dos Elementos de Contorno. 124 p. Dissertação (Mestre) - Universidade Estadual de Campinas, 2015.

SIGNORINI, A. Sopra alcune questioni di elastostatica. Atti della Societa Italiana per il Progresso delle Scienze, 1933.

STRÖMBERG, N. A Newton method for three-dimensional fretting problems. Int. J. Solids Struct., v. 36, n. 14, p. 2075-2090, 1999.

SZOLWINSKI, M.-P.; FARRIS, T.-N. Mechanics of fretting fatigue crack formation. Wear, v. 98, p. 93-107, 1996.

TIMOSHENKO, S.-P.; GERE, J.-M. Theory of Elastic Stability. [S.1.]: Courier Corporation, 2012. 560 p.

TOMLISON, G.-A. The Rusting of Steel Surfaces in Contact . Proc. R. Soc. London. Ser. A, Contain. Pap. a Math. Phys. Character., v. 115, n. 771, p. 472-483, 1927.

WARLOW-DAVIES, E.-J. Fretting corrosion and fatigue strength: brief results of preliminary experiments. Proc. Inst. Mech. Eng., v. 146, p. 32-38, 1941.

WRIGGERS, P. Computational contact mechanics. [S.1.: s.n.], 2006. 1-518 p.

WROBEL, L.-C. The Boundary Element Method, Applications in Thermo-Fluids and Acoustics. [S.1.]: John Wiley \& Sons, 2002. 468 p. 